Portland State University

PDXScholar

Spring 1-1-2012

\title{
Gendering Gardasil: Framing Gender and Sexuality in Media Representations of the HPV Vaccine
}

Maura Kathleen Pisciotta

Portland State University

Follow this and additional works at: https://pdxscholar.library.pdx.edu/open_access_etds

Part of the Advertising and Promotion Management Commons, Pharmaceutical Preparations Commons, and the Virus Diseases Commons

Let us know how access to this document benefits you.

\section{Recommended Citation}

Pisciotta, Maura Kathleen, "Gendering Gardasil: Framing Gender and Sexuality in Media Representations of the HPV Vaccine" (2012). Dissertations and Theses. Paper 807.

https://doi.org/10.15760/etd.807

This Thesis is brought to you for free and open access. It has been accepted for inclusion in Dissertations and Theses by an authorized administrator of PDXScholar. Please contact us if we can make this document more accessible: pdxscholar@pdx.edu. 
Gendering Gardasil: Framing Gender and Sexuality in Media Representations of the HPV Vaccine

by

Maura Kathleen Pisciotta

A thesis submitted in partial fulfillment of the requirements for the degree of

\author{
Master of Science \\ in \\ Sociology
}

Thesis Committee:

Maura Kelly, Chair

Matthew Carlson

Margaret Everett

Portland State University

(C)2012 


\begin{abstract}
In an age of biomedicine, technologies, drugs, and treatments are expanding in new and diverse ways. Especially relevant to biomedicalization and this research is how such information is conveyed to the public through the media. Medical information is omnipresent in the media through direct-to-consumer (DTC) advertising and regular coverage of health topics in the news. The accessibility and proliferation of medical information provides an important opportunity to examine the ways in which these topics are framed in the media. This research specifically examines the framing of the HPV vaccine, Gardasil in the mass media.

In this study, I explore how Gardasil was framed, how gender and sexuality were utilized within such frames, and what groups influenced these frames. I employ frame analysis to examine the presentation of Gardasil in the mass media. Due to the vaccine's intricate connection to gender and sexuality, I examine how these dimensions are utilized and reproduced in such frames. Gardasil was originally approved only for women, making gender a salient aspect of the vaccine. The current body of research examining Gardasil in the media presents data from the time the vaccine was only available to women. Now that the HPV vaccine is approved for men, this research seeks to contribute to a more comprehensive understanding of how Gardasil was framed in the media now that it is available to men and women. And given that Gardasil prevents a sexually transmitted infection (STI) in men and women, it is uniquely tied to issues of sexuality.
\end{abstract}


To analyze Gardasil in the media, I examine newspaper articles, magazine articles, and media representations from stakeholder groups, including DTC advertising, official statements, and group websites. Analysis of key sources indicates that Merck dominated the framing of the vaccine in DTC advertisements and the news media, illustrating the power of the pharmaceutical industry. Findings indicate that the initial marketing of Gardasil constructed the vaccine as uniquely tied to femininity and later, women's empowerment. However, once the drug was approved for men, messages were reframed to appeal to a wider audience. Overall, the media continued to frame the vaccine specifically for women, further constructing HPV as a "woman's disease." The dominant focus on women concomitantly silenced the sexual health of men and sexual minorities. In conclusion, the marketing, discourse, and structural elements of Gardasil make it less accessible to those most in need, therefore contributing to the ongoing problem of cervical cancer and HPV. 


\section{ACKNOWLEDGMENTS}

There are many people for whom I owe great thanks. First, thank you to my committee, especially Dr. Maura Kelly. Maura has been a wonderful mentor with unwavering support. To "the gals"- thank you for reading draft after draft and watching presentation after presentation. I am appreciative of your time, support, and constructive criticism. The following people have been influential in this process: Jacqui Frost, Jen Rainer, Jena Zarza, Patrick Smith, Tori Crain, Sarah Arpin, Andrea Bertotti Metoyer, Skye Miner, Vikas Gumbhir, Corrine Buchanan, Hilary Harrison, Nicole Froland and Paulette Soltani. And to my family, Cailene and Steven, and my loving parents, Sally O’Neill and Steve Pisciotta. 


\section{TABLE OF CONTENTS}

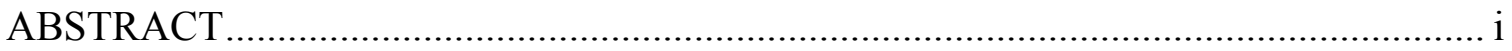

ACKNOWLEDGMENTS .................................................................................ii

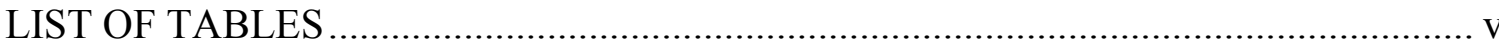

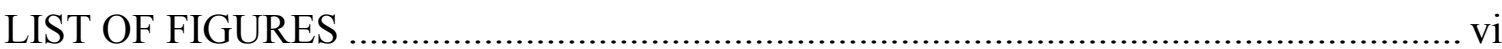

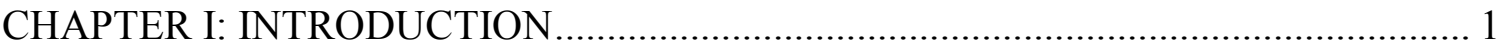

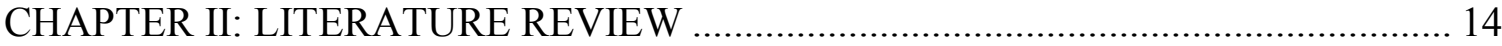

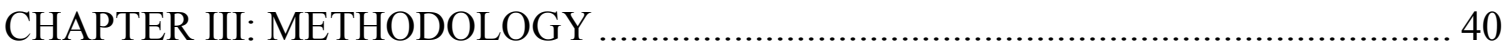

CHAPTER IV: KEY STAKEHOLDER FINDINGS ………………………………..... 51

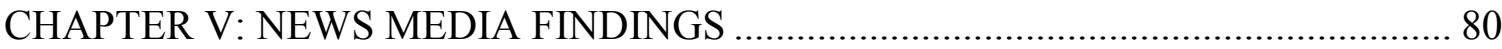

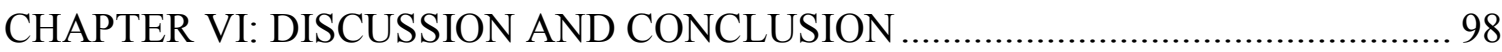

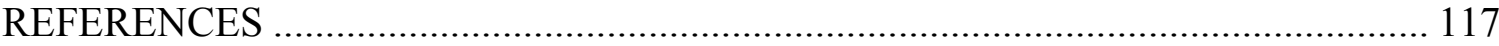

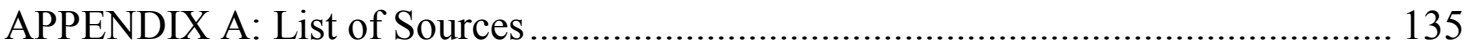

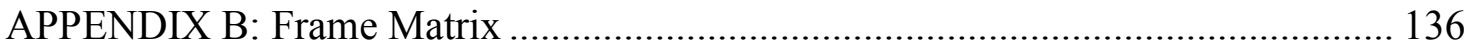

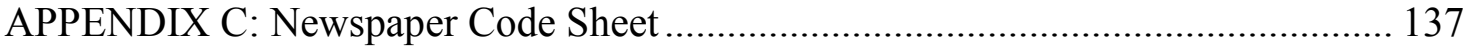

APPENDIX D: Magazine Code Sheet...................................................................... 139

APPENDIX E: Conceptual Map of Frames and Their Sources .................................. 141 


\section{LIST OF TABLES}

Table \#1: Magazine by Circulation Rate, Gender, and Median Age............43 


\section{LIST OF FIGURES}

Figure \#1: Newspaper Articles, by Year................................. 42

Figure \#2: Magazine Articles, by Year and Audience.........................44

Figure \#3: DTC Print Advertisement: Proactive Cervical Cancer Prevention.....55

Figure \#4: DTC Print Advertisement: The Focus on Cervical Cancer..............57

Figure \#5: DTC Print Advertisements: "I Chose" Campaign....................59

Figure \#6: DTC Commercial Advertisement: Choose to Get Vaccinated.........60

Figure \#7: DTC Print Advertisement: Mother "Chose" to Vaccinate Daughter...63

Figure \#8: DTC Commercial Advertisement: Mother-Daughter Dyads...........64

Figure \#9: DTC Print Advertisement: "Protect Your Child” Campaign............65

Figure \#10: Gardasil Website Homepage..................................67 


\section{CHAPTER I: INTRODUCTION}

\section{Vaccines in a Biomedical Age}

The promotion of pharmaceutical products in the media has significantly transformed and expanded within the current biomedical age. The deregulation of marketing pharmaceutical products has facilitated a surge in direct-of-consumer (DTC) advertising in the media. In fact, individuals spend more time viewing DTC advertisements than they spend with their doctor (Brownfield et al. 2004). Concurrently, the public regularly seeks out medical information in the media, taking an active role in their own health experiences (Brodie et al. 2003). It is these two elements that make the media an interesting area to explore the presentation of pharmaceutical innovation.

Vaccines are a unique form of medical technology, emphasizing containment as the way to maintain good health. Vaccines are arguably one of the greatest medical advancements in recent history; widespread vaccination has led to a drastic decrease in contagious diseases and in turn, morbidity and mortality rates. However, in light of recent events, vaccines have become a controversial topic. The perceived link between vaccines and autism caused a firestorm after an article published in The Lancet described the dangers of vaccines (Colgrove 2006). While the relationship between the MMR vaccine and autism has since been debunked, a recent poll found that only 52\% of Americans believe that vaccines don't cause autism, suggesting that half the population is still uncertain about their safety (Gardner 2011). Additionally, legislative efforts to increase vaccination rates are often viewed as "big government" intrusion and an attack on individual rights. Mamo, Nelson, and Clark best encapsulate the social dimensions of 
vaccines when they state that they are sites of "cultural, social and political contestation" (2010:124).

This research explores the coverage, promotion, and portrayal of the first HPV vaccine, Gardasil, in the media. Specifically, I describe how Gardasil was framed, what groups framed the vaccine, and how the promotion of the vaccine utilized cultural messages of gender and sexuality. The Gardasil vaccine was branded an important part of women's sexual health maintenance and drew concern over the implications of preventing a sexually transmitted infection (STI). I turn to the media to examine how it was presented to the public and its intersections with gender and sexuality. The media is useful to study this topic as it "is imbricated with popular and visual cultural materials, representations, and media coverage of things medical" (Clarke 2010:105).

At its most basic level, gender is intricately connected to technologies, discourses, and institutions (Balsamo 1996; de Lauretis 1997). Research examining gender within the context of medical products, technologies, or treatments further illustrates this relationship (e.g. Kempner 2006; Loe 2001, 2004; Oudshoorn 2003; Riska 2010; Rosenfeld and Faircloth 2006). Medical innovations can both reinforce and reproduce gender. Because gender is intertwined with sexuality, the gendered discourses can concomitantly reproduce or convey cultural messages of sexuality. Within the realm of medicine, reproductive health practices or technologies often perpetuate heteronormativity, or the belief that heterosexuality is the primary, normal, and expected sexual orientation (Jackson 2006; Kitzinger 2005). In turn, it ignores health problems that 
uniquely affect sexual minorities. Heteronormativity is regularly, though often implicitly, reproduced within the dominant discourse.

The Gardasil vaccine is uniquely contested, in part due to its relationship to gender and sexuality. For instance, the vaccine is intended to prevent a STI; through this alone, Gardasil is intertwined with issues of sexuality. Additionally, while HPV is a gender-neutral infection, the HPV vaccine was initially only approved for women. The exclusive focus on women and their bodies constructed Gardasil as a gendered vaccine (Casper and Carenter 2008) and HPV as a woman's infection (Habel et al. 2009; Hilton et al. 2010). Lastly, while HPV disproportionately affects men who have sex with men and women who have sex with women, as opposed to heterosexual sexual partners, the promotion of the vaccine has focused almost exclusively on heterosexuals (Epstein 2010). These elements offer an interesting analysis to explore how Gardasil, a vaccine intertwined with contentious gendered and sexualized topics, was presented to the public.

For this research, I utilize biomedicalization theory to account for the multidimensional ways in which Gardasil emerged and operated in the media (Clarke et al. 2003). Examining Gardasil within the biomedicalization framework contributes to the growing body of research that explores the new ways that medicine operates in our modern age. In order to assess the coverage of Gardasil in the media, I employ frame analysis. This tool both describes how a topic is framed and what groups framed it (Entman 1993; Gamson and Lasch 1983; Gamson and Modigliani 1989). Applying frame analysis to the presentation of pharmaceuticals in the media is a nuanced approach to studying this topic. Given that "things medical" are omnipresent in the media, frame 
analysis is useful to understand these messages and explore their implications.

Additionally, this research seeks to contribute to a more comprehensive understanding of the gendered discourse surrounding the H PV vaccine. Since there is a dearth of research examining the utilization and reproduction of gender in media messages after Gardasil became available to men, the current study seeks to fill this gap by examining the gendered discourse both before and after the vaccine was approved for men. Like other pharmaceutical products (migraine medication, erectile dysfunction medication), gender is intricately involved in the social meaning of Gardasil. Indeed, the way in which it is portrayed can affect how individuals interact with and understand the vaccine. In sum, I conceptualize Gardasil as a biomedical innovation that extended beyond HPV prevention; Gardasil reproduced messages of gender and sexuality and in turn, became a new way to "do gender."

\section{The Making of an Influential Vaccine}

This section examines the vaccine's evolution, from development to its controversial implementation. I elucidate the key topics and events that emerged in media coverage of the vaccine. Additionally, I identify stakeholders that publicly supported or endorsed the vaccine. This discussion places Gardasil within the context of public discourse and critical assessment, illustrating the multidimensional nature of the Gardasil debate.

I first describe HPV and its presence in the United States and abroad. Next, I explain the Gardasil vaccine, detailing its approval and initial gender-specific nature. I briefly describe the campaigns that publicized the link between HPV and cervical cancer. 
Meanwhile, a firestorm of controversy ensued as organizations asserted a link between Gardasil and premature sexual activity. In light of this, I explore the moral, political, and religious undertones of the vaccine's implementation and the uproar over legislation mandating the vaccine. Finally, I describe the inclusion of men in Gardasil's target population, an event which occurred three years following the FDA's approval of Gardasil in women.

\section{Human Papillomavirus and the Creation of Gardasil}

HPV is the most common STI within the United States (Center for Disease Control 2012). ${ }^{1}$ Currently, 20 million men and women in the United States have HPV and another 6.5 million will be infected each year. In fact, at least $50 \%$ of sexually active people have had HPV at some point in their lives. HPV is a largely invisible infection as it is most often undetectable, asymptomatic, and typically clears on its own. In rare cases, HPV can lead to genital warts and cancer. While there are over 100 types of HPV, very few are associated with cancer. This includes cancer of the cervix, vagina, vulva, anus, penis, head, throat, neck, along with genital warts and recurrent respiratory papillomatosis. While men and women have similar rates of HPV, their HPV-related outcomes vary; cervical cancer is more common than other any other HPV-associated cancers. There are 11,000 cases of cervical cancer each year that result in 4,000 deaths annually. Despite many cancers being linked with HPV, cervical cancer is the most common and has received the greatest amount of attention. Other HPV related cancers

\footnotetext{
${ }^{1}$ The following facts about HPV are from the CDC Fact Sheet
} 
are equally problematic; however, these cancers do not occur at the same rate as cervical cancer.

HPV and HPV-related cancers adversely affect certain demographics within the U.S. and abroad. HPV is an epidemic within the Global South as the majority of cervical cancer cases occur in developing nations (Parkin and Bray 2006). Additionally, HPV is linked to poverty and low socioeconomic index (Kahn, Lan, and Kahn 2007) making low-income populations within the U.S. adversely affected. Additionally, sexual minorities are also differentially affected (CDC 2012). Since certain populations within the U.S. and abroad are more susceptible to infection, the vaccine is an important tool in decreasing HPV and HPV-related cancer worldwide. The success of the vaccine in combating these issues on an international scale is yet to be known.

Merck \& Co. Inc. (Merck), one of the largest pharmaceutical companies in the world, was the first to produce, market, and gain approval for an HPV vaccine. ${ }^{2}$ This vaccine is a preventative technology that seeks to inhibit HPV and in turn, the cancers that it causes. Studies examining the efficacy of Gardasil in males and females were launched in 1997 (Food and Drug Administration 2006). While these studies were ongoing, Merck brought forth initial findings to the FDA in May of 2006 to seek approval for Gardasil in women. Gardasil was given priority in the FDA because of its "potential to meet an un-met medical need" (FDA 2006:11). While this meeting was specifically for approving Gardasil for women, questions about vaccinating men did emerge. In response, Merck pointed to the lack of data examining Gardasil's safety and efficacy in men though

\footnotetext{
${ }^{2}$ Ceravix, another HPV vaccine produced by GlaxoSmithKlein, is also FDA approved. This HPV vaccine has not rendered the same attention or controversy as Gardasil. When I state "HPV vaccine" I am specifically referring to Gardasil.
} 
a Merck researcher later stated, "efficacy of Gardasil in men is highly likely to be significant" (FDA 2006:166). According to the FDA transcripts it was the high rates of cervical cancer worldwide, the positive results of the vaccine in women, and the insufficient data for men that expedited the approval specifically for women. While the reasons to vaccinate only women are not the focus of this research, it is important to consider the social, political, cultural and economic reasons that influence the construction of pharmaceutical innovation. Oudshoorn (2003) points out that the production of science and technology is not neutral but rather often guided by cultural beliefs about gender, among other things.

Immediately following FDA approval in June of 2006, the Advisory Committee on Immunization Practices recommended Gardasil for routine vaccination for girls ages nine through twelve. In the meantime, studies examining the vaccine's efficacy in men continued. It was not until October of 2009, three years after FDA approval of women, that the FDA approved Gardasil for males between ages nine and twenty-six.

Gardasil specifically targets four main types of HPV that are associated with cancer (types 16 and 18) and genital warts (types 6 and 11). Gardasil is a three-dose vaccine distributed over a six month period. Shots occur two months and six months following the first dose and cost about $\$ 390$ for the three-shot series. Currently, the vaccine is available for men and women between the ages nine and twenty-six. Merck and the Advisory Committee on Immunization Practices encourages vaccination between the ages of nine and twelve as Gardasil is most effective prior to sexual activity. 
However, Merck suggests that vaccination can still be beneficial to those already exposed to HPV, though the vaccine may not grant full inoculation (Hildesheim et al. 2007).

\section{Gardasil Marketing Campaign}

Merck developed numerous DTC advertising campaigns both before and after Gardasil was approved by the FDA. Prior to approval, Merck produced the "Make the Connection," "Tell Someone," and "Make the Commitment" campaigns which sought to bolster the connection between HPV and cervical cancer. Overall, these campaigns focused on connecting HPV specifically to cervical cancer in order to gain public acceptance of the new "cancer vaccine."

More recent campaigns include "One Less," "I chose," and a revamped "One Less" campaign which I call, "Protect your child." The "One Less" and "I chose" campaigns include televised commercial advertisements and print advertisements in magazines. Commercial advertisements showcase ethnically diverse girls engaging in activities such as soccer, skateboarding, and surfing. These advertisements focus exclusively on girls and women. However, the most recent print advertisements in the "Protect Your Child" campaign emerged in 2010 and are the first to include males. These print advertisements are intended for mothers as they are only found in adult women's magazines. I address the DTC advertising campaigns in-depth in chapter five.

\section{A Firestorm Over Girls}

While many groups heralded the vaccine a "significant advance in the protection of women's health" (Vesely 2006), other organizations were quick to voice their criticisms. Prominent conservative organizations such as the Family Research Council 
and Focus on the Family connected Gardasil to premature sexual activity and promiscuity. Similarly, many asserted that Gardasil gives girls the "green light" to sexual activity. David Dunn, a director at the Oklahoma Family Policy stated, "If we're not careful, young women will interpret this wonderful medical news as their own invincible protection against all STDs and as a green light for more sexual activity" (Woosley 2006). These organizations later modified their stance by focusing their critique on the dangers of mandating Gardasil through legislature (though they maintained abstinence as the primary answer to HPV prevention).

To abate such controversy, research suggests that Merck framed Gardasil as cervical cancer prevention instead of $H P V$ prevention. This move allowed the promotion of the vaccine to focus on preventing cancer instead of HPV. Mamo et al. discusses the focus on cancer as positioning "Gardasil as an intervention into cervical cancer rather than protection from the consequences of unprotected sexual behaviors" (2010:129). Similarly, Epstein and Huff (2010) found that Merck purposefully avoided HPV in their marketing as a way to evade controversy over preventing a sexually transmitted infection. ${ }^{3}$ When HPV-related cancers are discussed, there is a significant focus on cervical cancer instead of other HPV-related cancers. This is illustrated by a Merck researcher stating, "cervical cancer is the most important disease caused by HPV infection" (FDA 2006:19). These examples illustrate a purposive strategy to focus on cervical cancer and divert attention away from HPV as a way to make the vaccine more marketable to the general public. This topic will be further explored in chapters four and six.

${ }^{3}$ Merck sought the advice of the Office of Women's Health within the FDA. 


\section{Legislation and Gardasil}

Public health experts look to herd immunization, or the vaccination of the majority of the population, as the primary method to eradicate diseases. To achieve herd immunization, legislation is enacted that requires vaccination as a requirement of school attendance. However, these mandates have become especially contentious in light of fears over vaccines and discontent over government intrusion on individual health matters. Mandatory vaccination for attendance in schools (e.g. mumps and measles vaccine) has elicited a debate over parental rights and fear of "big government" (Colgrove 2006). In the case of Gardasil, many proponents sought legislation to increase vaccination rates. However, Gardasil's perceived link to sexual activity constituted these measures highly controversial.

Between 2006 and 2007, twenty-four state legislatures discussed compulsory vaccinations for girls (Krishnan 2008). Advocates like Juan Carlos Felix of the National Cervical Cancer Coalition stated, "I would like to see it that if you don't have your HPV vaccine, you can't start high school" (Omaha World Herald). Other public health representatives echoed a similar sentiment in the news media. In 2006, Michigan emerged as the first state to pass legislation mandating Gardasil through the efforts of state legislator, Beverly Hammerstrom. Following suit, Texas Governor Rick Perry bypassed the legislature with an executive order mandating the vaccine for all sixth-grade girls in early 2007. While mandating vaccines is a common type of public health legislation, executive orders are not a routine way to enact them. Soon after, information surfaced that Merck donated to Perry's political campaign and Women in Government 
(WIG), a group Hammerstrom belonged to (Colgrove 2010). Given the public outcry associated with mandating Gardasil and the economic and political links between Merck and politicians, these legislative efforts were largely unsuccessful. In fact, three months following Perry's executive order, the bill was overturned and Merck suspended all attempts at mandating Gardasil at the state level. These debates over legislation expose the political, economic, social, and religious interplay around Gardasil.

Now Enter Men

In mid-2008, newspapers began covering the topic of vaccinating men with Gardasil. Advocates looked to men's vaccination as a major opportunity to decrease HPV and HPV-related diseases. As stated in the media, the benefits of vaccinating men include protecting them and their partners from HPV. With the CDC's introduction of the page "HPV and Men- Fact Sheet," more attention was allocated to the presence of HPV in men. After findings from a Merck-funded study established that Gardasil prevents HPV infections in males (Giuliano et al. 2011), Merck moved forward to gain FDA approval for use of Gardasil in males. Dr. Maura Gillison, a prominent HPV researcher, advocated for vaccinating males as a way to prevent HPV-associated cancers in men. She stated, "When you look at the cancers associated with HPV in men—including penile cancer, anal squamous cell carcinoma, oral cancers-it's very close to the number of cases of cervical cancer that occur in the U.S. in women every year" (Masters 2007). Also, there is greater incidence of oral cancers in males (Gillison et al. 2012), making their vaccination an important preventative tool. The FDA approved Gardasil for use in males in late 2009. 
Vaccinating men with Gardasil is a new way to decrease the prevalence of HPV and HPV-related cancers in men and women. However, vaccinating males has not garnered the same attention as media coverage of women's vaccination. Furthermore, the Advisory Council on Immunization Practices did not recommend routine vaccination in males until October 2011, two years following their approval. This is compared to women, who were recommended immediately following FDA approval. Given that only $1.4 \%$ of men have been vaccinated, compared to $32 \%$ in women, vaccinating men with Gardasil has been largely unsuccessful (National Cancer Institute 2011).

\section{Research Questions}

This research examines how Gardasil was framed in the media and how gender and sexuality were utilized in these frames. Additionally, I locate the groups that produced these frames to illustrate the power that exists within framing, an idea that will be explored in the next chapter. Lastly, I analyze Gardasil within the biomedicalization framework as it best accounts for the ways in which medicine and the media interact within our modern age. The following questions structure this research:

1. What key stakeholder organizations sought control in media coverage of Gardasil?

2. How did stakeholders frame the vaccine?

3. What are the dominant frames in media coverage of Gardasil?

4. What changes in frames occur once Gardasil became available to men?

5. How are gender and sexuality utilized in media frames of Gardasil? 
6. What is the role of biomedicalization in the media coverage of Gardasil?

\section{Organization of Thesis}

This thesis is divided into six chapters. The current chapter has introduced the vaccine and provided a brief historical account of Gardasil within the public discourse. In the second chapter, I situate this research within the theoretical framework of biomedicalization which provides a blueprint for this research. In this section, I outline the literature on health, gender, and sexuality and discuss the mass media's portrayal of these topics. I also detail frame analysis, as it informs my methodological framework that I later explain in chapter three.

Chapters four and five detail the findings of this research. Chapter four presents the stakeholder groups that framed the vaccine and their dominant frames. This includes DTC advertising, stakeholder websites, and official statements from these groups. The fifth chapter presents the dominant frames in the news media, including newspapers and magazines. In the final chapter, I situate my findings into a larger body of theoretical and empirical literature. I discuss the implications of these findings, my methodological and theoretical limitations, and future research to explore. 


\section{CHAPTER II: LITERATURE REVIEW}

This research contributes to a more comprehensive understanding of the gendered and sexualized discourse in the mass media surrounding the HPV vaccine both before and after the FDA approved Gardasil for men. Given the expansive influence of medical advancements and their presence in the media, I explore such topics in this section. The current body of research that specifically explores Gardasil accounts for its coverage in the media only when it was approved for women. Now that Gardasil is also available for men, my research seeks to examine how the gendered and sexualized discourse surrounding the vaccine changed over time. Like other medical technologies, Gardasil extends beyond just preventing a disease; it offers insight into the political and cultural landscape as well as sex, gender, and health in America.

The current chapter offers a comprehensive review of the literature that better situates this research. The three major areas of focus in this chapter are: (1) biomedicalization and its intersection with gender and sexuality, (2) frame analysis and an examination of media portrayal of health and medicine, and (3) empirical research analyzing Gardasil in the media. Together, the theoretical and empirical literature provides a framework for this research and underscores the unanswered questions that this particular study seeks to address. 


\section{The Expansion of Medicine}

In this section I present the theoretical framework of this research, biomedicalization (Clarke et al. 2003). Before an in-depth exploration into the processes of biomedicalization, I must first expound the historical context from which it arrived. Therefore, I briefly describe medicalization (Conrad 1992; Zola 1972) and the larger societal shift to biomedicalization (Clarke et al. 2003). Next, I outline biomedicalization's five interactive processes, explaining the two primary processes that frame this research. Lastly, I discuss the intersection of gender, sexuality, health, and medicine.

Overall, this discussion underscores the influence of the media as a site of medical knowledge production and distribution. Additionally, since this research speaks to the intricate connections with gender and sexuality, I suggest that it is important to conceptualize these concepts within health and a medical perspective.

\section{Medicalization to Biomedicalization}

Medicine is constantly evolving, expanding its influence to operate culturally, politically, economically, and socially. Much of its evolution during the $20^{\text {th }}$ century is captured in the medicalization thesis (Conrad 1992; Zola 1972). Medicalization is the process of "... defining a problem in medical terms, using medical language to describe a problem, adopting a medical framework to understand a problem, or using medical intervention to 'treat' it." (Conrad 1992:211). This principally includes how normal life processes are defined as medical problems and are treated as such (Conrad and Schneider 1980). Medicalization lays the groundwork for understanding medicine's social control, 
though it does not fully capture the new ways that medicine operates within the modern age.

Recent shifts, like the rise in biotechnology and technoscientific innovations, have facilitated significant changes in medicine. Where medicalization explained "clinical gaze" via medical agents, biomedicalization describes the "molecular gaze" facilitated by new changes in technoscience. Clarke et al. describe such changes in biomedicalization which is the "second transformation of American medicine" (2003:161). ${ }^{4}$ Biomedicalization is the "increasingly complex, multisited, multidirectional process of medicalization that today is being both extended and reconstituted through the emergent social forms and practices of a highly and increasingly technoscientific biomedicine" (Clarke et al. 2003:162).While medicalization details medical definitions and control, biomedicalization accounts for the new ways that surveillance facilitates the transformations of bodies and identities. ${ }^{5}$ Biomedicalization is being transformed "from the inside out," influencing health, illness, medicine, healing, and "life itself" (Clarke et al. 2003; Rose 2007). Thus, biomedicalization best accounts for the recent technological, economic, and cultural changes of health and medicine and the diverse, nuanced, and pervasive ways in which medicine currently operates. For this research, I conceptualize biomedicalization as a discourse that enforces health through risk and surveillance.

Biomedicalization is continually constructed through five interactive processes. These include the (1) the privatization of the medical industry, (2) a focus on health through risk and surveillance, (3) the technoscientization of biomedicine, (4) the

\footnotetext{
${ }^{4}$ Medicalization (Zola 1972; Conrad 1992) being the first.

${ }^{5}$ Such as through technoscience or the privatization of medical and pharmaceutical industry.
} 
transformation and proliferation of medical knowledge production and consumption and (5) the transformation of bodies, identities, and subjectivities (Clarke et al. 2003). Within the confines of this research, I seek to address the second and fourth processes: the focus on health through risk and surveillance and the transformation and proliferation of medical knowledge production and consumption. Specifically, I explore how gender is tied to the discourse on health and risk. Lastly, I highlight how gender and sexuality are co-constructed through these two processes.

The Focus on Health Though Risk and Surveillance. This process details two interactive elements: the commitment to maintain and/or achieve health and increased risk and self-surveillance. Crawford (1985) illustrates that health is a moral accomplishment. In this way, health is revered as an ideal that one must maintain or achieve. However, health is constantly vulnerable to various risks and dangers that are enforced by risk discourse. In turn, it encourages individuals to maintain health (and avoid risk) through treatments, drugs, or technologies. Biomedicalization illustrates that risk is no longer entrenched within the doctor's office; risk is constant, often overemphasized (Clarke et al. 2003), and is constituted through discourse, knowledge, and institutions (Lupton 1999).

A major facet in biomedicalization is how individuals enact their own surveillance. Foucault's (1988) notion of "technologies of the self" best explains this phenomenon. Foucault defines technologies of the self as "individuals to affect by their own means or with the help of others a certain number of operations on their bodies and souls, thoughts, conduct, and way of being, so as to transform themselves in order to 
attain a certain state of happiness, purity, wisdom, perfection or immortality" (Foucault 1988:18). This describes how individuals enact surveillance on themselves to maintain or achieve the moral obligation of health. This concept illustrates a larger shift in social control from medical professionals to the individual. Indeed, individuals are encouraged to "know your body" (Balsamo 1996:5).

\section{The Transformation and Proliferation of Medical Knowledge Production and} Consumption. Medical knowledge and information continues to expand to new outlets, especially within the media. Pharmaceutical companies utilize the media as the primary avenue to advertise. The rise in DTC advertising has constituted prescription drug advertisements a ubiquitous part of our health experience and a major source of health information (Brownfield et al. 2004). ${ }^{6}$ The dominant discourse is rich with information about health, medicine, and even our own bodies. Clarke (2010) discusses how the popular and visual contribute to biomedicalization. She states,

My argument is that in deeply significant but largely ignored ways, contemporary American biomedicalization itself is imbricated with popular and visual cultural materials, representations, and media coverage of things medical... In turn, such images and objects themselves have become constitutive of medical knowledge and practices. (p. 105)

The proliferation of medical knowledge allows individuals to experience health and the body in new ways (Crawford 1985). Such changes facilitate a new cultural responsibility to search and access one's own health information by visiting websites, the news media, and/or looking to other social groups for information (Clarke et al. 2003). Given the expansion of medical discourse and its role in promoting pharmaceutical products, the media provides an interesting site to examine representations of Gardasil.

${ }^{6}$ I discuss DTC advertising more in-depth later in this chapter. 
Gender, Sexuality, and Health.

Feminists in the late 1970's-1980's critiqued medicine as an institution of social control, revealing numerous examples of the medicalization of women and their bodies (and later the medicalization of men) and underscored the intersection of gender, health, and medicine. It is important to study women and men, femininity and masculinity, as these categories continually construct each other. In fact, the intersection of biomedicalization and gender illustrate that gender is constituted relationally (Riska 2010). The current research explores both femininity and masculinity within the context of medical discourse surrounding the Gardasil vaccine. The following examines how gender is interconnected with health and medicine.

Femininity and Health. Historically, women and their bodies have been perceived as significantly different and inferior to men and their bodies (Weitz 2010). Aristotle and Darwin wrote about the frailties and inadequacies of women and used their reproductive processes as justification. In fact, it is women's reproductive processes that have been historically subject to medical intervention, such as contraception and pregnancy (Oudshoorn 2003). These ideas sustained part of the dominant ideology well into the $19^{\text {th }}$ and $20^{\text {th }}$ century as feminists exposed the over-medicalization of women with examples such as menstruation, pregnancy, childbirth, fertility, menopause, and breastfeeding (Reissman 1983; Riska 2003; Wertz and Wertz 1989). ${ }^{7}$ Indeed, Conrad states, "it is abundantly clear that women's natural life processes (especially concerning reproduction)

\footnotetext{
${ }^{7}$ Reissman (2003) points out that some women actually fought for medicalization in hopes of benefiting from it, such as with childbirth and abortion. She argues that to only speak of the medicalization of women in passive terms reinforces women as passive subjectivities.
} 
are much more likely to be medicalized than men's" (1992:222). ${ }^{8}$ However, medicalization research has limited its focus on women. As we move into a more biomedical age, gender continues to be a salient dimension of medicine. Additionally, research has greatly expanded its focus to study men, their health, and their body which is explored in the following section.

Connell's (1987) concept of emphasized femininity best reflects the dominant version of femininity that intersects with health and medicine. This form of femininity is culturally valued and emphasizes empathy and nurturance in light of women's subordination. The larger shift from medicalization to biomedicalization illustrates that women and femininity continue to be inextricably connected to medical technologies and discourses (Kempner 2006; Mamo and Fosket 2009; Mamo et al. 2010). For example, Kempner (2006) illustrates how the marketing of migraine products has created migraines as a "woman's health issue." Her analysis suggests that the pharmaceutical migraine market is gendered; DTC advertisements and websites for migraines portray women more so than men and portray women in stereotypical capacities, such as caretaker or mother. These depictions utilize and reproduce traditional notions of femininity. By focusing specifically on women, these gendered messages construct migraines as a "woman's disease."

Masculinity and Health. The dominant form of masculinity is hegemonic masculinity, meaning "the configuration of gender practice which embodies the currently accepted answer the problem of the legitimacy of patriarchy, which guarantees (or is

\footnotetext{
${ }^{8}$ Conrad (2007) illustrates that men too have been subjected to medicalization and examples of such will be discussed in the following section.
} 
taken to guarantee) the dominant position of men and the subordination of women" (Connell 1995:77). This concept embodies the power that resides in dominant forms of masculinity. Hegemonic masculinity refers to traditionally valued aspects of masculinity, such as strength, power, and courage. Connell asserts that "true masculinity is almost always thought to proceed from men's bodies" (1995:45). Pharmaceutical innovations are directly linked to masculinity and the male body as their primary purpose is to maintain or improve the body's functioning. Because health is directly linked to the body, it is useful to explore masculinity within the context of pharmaceutical innovations. The following examples illustrate how masculinity has been utilized in constructing and marketing pharmaceutical drugs.

Research indicates that men and the male body are subject to similar elements of control, a reversal to the historical status quo (Riska 2003). Conrad (2007) elucidates examples of the medicalization of men, such as baldness and erectile dysfunction, which are now within medical domain and thus treated as medical problems. Furthermore, research indicates new intersections between masculinity, medicine, and health (Fishman 2010; Loe 2001, 2004; Mamo and Fishman 2001). For example, Loe (2001) illustrates that the success of Viagra is largely due to constructing and selling masculinity. Similarly, advertisements for Levitra and Cialis, other erectile dysfunction drugs, link the pill to hegemonic masculinity and uphold masculinity as an attainable achievement (Wienke 2006). Advertisements emphasize normative gender and sexuality for men, including physical strength and sexual vitality (Wienke 2006). These findings illustrate how pharmaceutical companies utilize gender to sell their product. Additionally, it 
demonstrates that gender is uniquely tied to the social meaning of these pharmaceutical innovations. Overall, it underscores the importance of examining masculinity within the context of health and medicine.

While the examples of migraine medication and erectile dysfunction drugs clearly illustrate that gender is uniquely tied to the social meaning of pharmaceutical products, this discourse also conveys subtle messages about sexuality. For instance, Loe (2001) demonstrates how sexuality is intertwined with masculinity in the context of Viagra. She argues that Viagra as a technology reproduces gender (specifically hegemonic masculinity) and sexuality (specifically heterosexuality). Because of the intricate connection between Gardasil and gender and sexuality, it is important to study these concepts as interconnected.

This particular research explores how the production and distribution of knowledges, through DTC advertising and news media, envelop gender and sexuality. Through this, I analyze how Gardasil, like other biomedical technologies, utilize gender and sexuality to market a product and concomitantly reproduce gender. In summary, placing Gardasil within the biomedical framework best explains why the media is important to examine the portrayal of health innovations, like Gardasil. The following section explores research pertaining to the media and its coverage of health. In order to do so, I utilize framing theory to analyze how Gardasil was constructed in the media. 


\section{The Mass Media}

This section explains the relevant literature on framing and the media. I utilize framing to uncover how Gardasil was constructed in the media. In this context, framing offers a nuanced approach to studying the presentation of medical technologies in the media. Therefore, I first outline the literature on framing within a communications and sociological context. Additionally, I describe the power that exists within the production of news, and in turn, frames. Next, I detail the relevant literature on news media specifically addressing newspaper and magazines followed by discussing DTC advertising, a major source of health information. This section highlights the intersection of health, medicine, and media.

\section{The Power of Frames: Shaping Discourse}

In his seminal piece, Bateson (1955) argues that meaning is not intrinsic but rather constructed and derived from frames. Following Bateson, Goffman (1974) advances the concept of frames by describing them as structuring experiences, organizing information, and giving meaning to those experiences. These "social frameworks" continually construct meaning for our everyday experiences (Goffman 1974). While framing theory applies to various areas of research (e.g. social movements), this particular study adopts framing as a communications concept as frames "offer a way to describe the power of a communicating text" (Entman 1993:51).

Frames are organizing principles that convey and construct meaning. The concept of framing is particularly useful to examine the construction of frames in news stories. While there are many relevant definitions of framing that attempt to narrow this broad 
concept, Entman defines frames as "to select some aspects of a perceived reality and make them more salient in a communicating text, in such a way as to promote a particular problem definition, causal interpretation, moral evaluation, and/or treatment recommendation" (1993:52). Therefore, media frames convey aspects of social reality by accentuating or deemphasizing information. For this research, I utilize framing to understand how Gardasil was constructed, or framed, in the media.

Frames involve four primary elements - the communicators, the text of the frame, the receivers, and culture (Entman 1993). These pieces affect the organization of information and how the audience understands it. Frames convey and reproduce culture. The current study seeks to uncover the messages within the frame and identify the communicators. Moreover, frames consist of numerous devices including a core position, metaphor, catch phrase, imagery, source of the problem, predicted outcome, and appeal to principle (Entman 1993; Gamson and Modigliani 1989; Pan and Kosicki 1993; Tankard 2001). A frame unifies these diverse, interconnected elements into one central concept (Gamson and Lasch 1983; Gamson and Modigliani 1989). To emphasize a particular feature, a frame can repeat information, highlight particular features, or make cultural connections (Entman 1993). In contrast, a frame can also divert attention by omitting information. In fact, what is absent from a frame can be of equal importance to what is included. In short, frames are purposive and powerful (Gamson 1992).

The development of news stories is based upon the relationship between journalists, sources, and the organizations to which they belong (Gans 1979). Sources, or key actors in a story, provide journalists information to produce a story through 
interviews, observations, or statements. Therefore, sources play a key role in developing media frames. Journalists typically rely on professional or official sources, such as doctors, politicians, scientists and corporate spokespeople (Gans 1979; Gitlin 1980; Shoemaker and Reese 1996; Tuchman 1978). Research indicates that the political and social elite are considered more credible sources and in turn are allocated more influence in the framing process (Carragee and Roefs 2004; Gitlin 1980; Ryan 1991). In fact, their power allows them to enter the news discourse and sustain coverage, often at the expense of opposing sources (Carragee and Roefs 2004). Since elites are given more voice within the framing process, frames can be considered a reflection of elite ideals.

Gramsci's (1971) concept of hegemony best accounts for the power relations that exist within framing (Carragee 1993; Carragee and Roefs 2004). Hegemony, a term originally developed by Gramsci, speaks to how power-holders maintain their status through diffusing meaning and value to subordinate groups. This concept highlights how elite sources maintain power in the media by imposing meaning and knowledge to the general public, namely those without power. Carragee and Roefs explain this intersection stating, "the media hegemony thesis directly connects the framing process to considerations of power and to examinations of the relationship between the news media and political change" (2004:222). The hierarchies and power imbalances that exist within the production of news largely reflects and reinforces the unequal power distribution in the United States (Tuchman 1978). In sum, frames are not just text; frames encompass power relationships, culture, and dominant values. 
In large part, framing research narrowly focuses on the content of frames and framing effects instead of the power relations that exist within the production of media frames (Carragee and Roefs 2004; Vliegenthart and van Zoonen 2011). In response, the current study identifies which groups maintained power in influencing how the media constructed Gardasil. I seek to identify these power holders and illustrate how they framed Gardasil. This speaks to the power relations that exist within the production of news and in turn, the construction of frames.

Next, I turn to research examining the power of the mass media. Shaw and McCombs (1977) argue that the media is an influential tool that shapes our social reality and reflects dominant ideology. They call this the "agenda setting function of mass communication" (Shaw and McCombs 1977). I utilize the news media as a site to examine dominant frames of Gardasil and identify the groups that produced these frames. Therefore, I first discuss media and health more broadly, followed by a detailed discussion of newspapers, magazines (news media) and DTC advertising.

\section{Media as Health Production}

The media is both a source of health information and a marketing tool for health products. The intersection between health, medicine, and the mass media facilitates the proliferation of health knowledge and information (Seale 2003). Research indicates that the media's portrayal of vaccines has not been balanced or provided accurate, comprehensive information (Danovaro-Holliday, Wood, and Lebaron, 2002; GoodyearSmith et al., 2007). In this way, the media provides an interesting site for research, as it has been the largest source of information about the HPV vaccine (Hughes et al. 2009). 
The media conveys health information in two dominant ways. First, the news media regularly covers issues related to health and medicine (Brodie et al. 2003). Second, pharmaceutical companies use the media to market products though DTC advertising. Therefore, medical information regularly bombards the public. This research examines both the news media (newspapers and magazines) and DTC advertisements which I address in the following.

\section{Media Outlets}

Newspapers. Despite declining circulation, newspapers continue to set the agenda and consistently break news coverage. Even as the production of news expands to a variety of outlets (e.g. blogs, Twitter), most stories continue to originate from newspapers (Pew Research Center 2010). Despite the popularity of online news, research indicates that audiences retain information from print newspapers better (Althaus \& Tewksbury 2002, 2002; Eveland and Dunwoody 2001, 2002; d'Haenens, Jankowski, \& Heuvelman, 2004), making print newspapers an influential and important part of the media.

Newspapers regularly report on health and medical issues and people look to newspapers as a source of health information (Brodie et al. 2003). In fact, Brodie et al. (2003) finds that almost half of their respondents follow health news stories regularly. However, in her study on the content and representation of cancers related to women's reproduction (cervical, ovarian, and uterine cancers), Kilgore (1996) states that newspaper coverage is often vague and incomprehensible. Therefore, newspapers provide an interesting site to study the portrayal of medical topics, specifically vaccines. 
Magazines. Magazines are widely circulated, highly visible, and cover a variety of topics. They are a unique form of media that combines entertainment and news (Parrott and Condit 1996). Magazines are a source of health information, particularly for women (Kahn 2001; O’Malley, Kerner, and Johnson 1999). Magazines often discuss issues related to cancer (Freimuth et al. 1984), thus making new developments in cervical cancer prevention a likely topic. Additionally, magazines are a site for pharmaceutical companies to advertise medical treatments or prescription drugs. In fact, pharmaceutical companies are one of the largest sources of revenue for magazines (Pinto et al. 1998).

Women's magazines serve a unique role in the lives of women. In a study about the impact of women's magazines on audiences, girls assert that magazines present "things they need to know about themselves and their social world" (Currie 2001:261). Similarly, magazines reproduce normative femininity as well as inform women of sexual subjectivities (McRobbie 1996). Furthermore, a study examining the portrayal of sexual health in magazines for teenage girls and middle-aged women finds that magazines allocate responsibility of sex and its consequences to women (Clarke 2009). The findings suggest that magazines reinforce women as primarily responsible for sexual expression and maintaining good sexual health. Overall, women's magazines entrench normative femininity and convey cultural messages about gender and sexuality. In effect, magazines are a unique site to study cultural messages about health, gender, and sexuality.

There is a growing body of research on the portrayal of men and masculinities in magazines (Alexander 2003; Attwood 2005; Benwell 2003; Ricciardelli, Clow, and White 2010; Taylor 2005; White and Gillett 1994; Vigorito and Curry 1998).These 
studies suggest that men's magazines reinforce heterosexuality and traditional gender stereotypes. For example, Ticknell et al. (2003) demonstrates that men's magazines emphasize heterosexual values and portray masculinity as highly sexualized and free from commitment. Similarly, Vigorito and Curry (1998) and White and Gillett (1994) find that men's magazines associate men with dominance and control, reflecting a larger trend of perpetuating hegemonic masculinity. Alexander's (2003) study on Men's Health echoes this sentiment while connecting the achievement of masculinity to consumerism. Overall, these studies illustrate that men's magazines regularly reproduce hegemonic masculinity.

Direct-to-Consumer Advertising. DTC advertising is "any promotional effort by a pharmaceutical company to present prescription drug information to the general public through the lay media" (Bradley and Zito 1997:86). This is a unique aspect of American society as the U.S. is one of only two countries that allow pharmaceutical companies to advertise directly to the public. The Food and Drug Administration Modernization Act of 1997 facilitated numerous changes to the nature of DTC advertising, namely, the deregulation of advertising. This legislation loosened advertisement guidelines for pharmaceutical companies, allowing them more time to advertise and less time to discuss side effects (Abramson 2005; Angell 2004; Crister 2005; Terzian 1999). Broadly, it led to a significant increase in advertising (GAO 2002; Kaiser Family Foundation 2003). In fact, expenditures for DTC advertisements have tripled; in 1996, pharmaceutical companies spent $\$ 11.4$ billion on advertisements compared to \$29.9 billion in 2005 (Donohue, Cevasco, and Rosenthal, 2007). In sum, DTC commercial advertising is 
pervasive and one of the largest forms of health information (Brownfield et al. 2004). While pharmaceutical companies often use multiple outlets to advertise, this research examines DTC televised commercial advertisements and print advertisements in magazines.

Recent investigations into DTC advertisements find the content to be insufficient. For instance, DTC commercial advertisements are vague and omit FDA required information such as risk factors and the prevalence of the condition (Frosch et al. 2007). Similarly, DTC print advertisements can be ambiguous by omitting important information (Angell, 2004; Bell et al. 1999; Roth 1996; Wilkes et al. 2000; Woloshin et al. 2001). For example, Roth (1996) employed pharmacists to assess the content of DTC print advertisements using the FDA's official review and approval process. This study finds that while the majority of advertisements present risks and benefits, one-third neglect to detail those risks and explain other relevant health information.

Both DTC commercial and print advertisements highlight the most positive aspects of a drug or treatment while deemphasizing the negative characteristics. For instance, Kaphingst et al. (2004) find that many commercial advertisements allocate more time to discuss the benefits as opposed to risks. Similarly, print advertisements accentuate the benefits through positive headlines and minimize side effects by allocating them to the bottom of the page in small print (Bell et al. 1999; Roth 1996). Many DTC advertisements utilize visual, emotional appeals (Frosch e al. 2007) as well as empowerment discourse, to encourage individual responsibility for health issues (Morgen 2002). For instance, commercial advertisements often depict characters who have lost 
control in their life and regained it through the advertised product, further emphasizing the positivity associated with the product. Therefore, DTC advertisements frequently utilize visual, emotional appeals that encourage individual responsibility for health maintenance (Morgen 2002).

Both print and commercial DTC advertisements tend to specifically target women (Bell et al. 2000; Brownfield et al. 2004; Mastin et al. 2007) and reinforce gender stereotypes (Cline and Young, 2004, Kempner 2006; Mastin et al. 2007). Cline and Young (2004) find that print advertisements often depict women in relation to reproduction. For instance, some advertisements marketing contraception feature a solitary woman, suggesting contraception is a predominately female responsibility (Cline and Young 2004). Additionally, research indicates that DTC advertisements reinforce gender stereotypes as women are more likely to be depicted as caretaker or mother (Mastin et al. 2007). This body of research demonstrates that DTC advertisements frequently portray gender and utilize it to sell a product.

The next section describes the current body of research that examines the portrayal of Gardasil. Most of the literature explores the media's portrayal of Gardasil within a gendered context. I also present research on Gardasil that examines how sexuality is constructed in media representations of the HPV vaccine. This section leads me to the research questions that this thesis seeks to address.

\section{Enter Gardasil}

Research on Gardasil explores the social, cultural, and political nature of the vaccine. Recent investigations turn to the media as it was influential in conveying 
information about Gardasil. There are numerous studies that conduct content and discourse analyses including, but not limited to, media texts (Abdelmutti and HoffmanGoetz 2009, 2010; Braun and Phoun 2010; Carpenter and Casper 2009; Habel et al. 2009; Hilton et al. 2010; Mamo, Nelson, and Clark 2010). Many of these particular studies also elucidate the gendered aspects of the media's portrayal of Gardasil and the subtle messages of sexuality. In this section, I discuss the relevant literature that examines the vaccine in light of gender and sexuality.

\section{Gendering Gardasil}

Habel et al. (2009) and Carpenter and Casper (2009) suggest that the media "feminized" Gardasil through gender-specific rhetoric, narratives, and imagery. The media portrayal constructed Gardasil as a vaccine for women and a symbol of femininity. Therefore, gender is intricately intertwined with the media's portrayal of the vaccine. The following accounts for the multidimensional ways in which the media discourse reproduced gender.

While HPV is associated with numerous forms of cancer, its relationship with cervical cancer has received the most attention. In general, news stories about HPV tend to focus on women, female bodies, and cervical cancer. For instance, the HPV vaccine is regularly referred to as a "cervical cancer vaccine," linguistically linking it to the female body (Habel et al. 2009). Additionally, in a study of online news stories, Habel et al. (2009) finds that stories in their sample relate HPV solely to cervical cancer, ignoring other HPV-related cancers. ${ }^{9}$ It is the pervasive link between cervical cancer and HPV that

\footnotetext{
${ }^{9}$ Other cancers include vaginal, vulva, penile, anal, head, oral, throat, tongue, and neck.
} 
constructs HPV as solely a woman's health problem (Hilton et al. 2010; Habel et al. 2009).

The media reinforced the vaccine's connection to women by listing relevant facts or statistics about HPV, cancer, and the vaccine exclusively to women. For instance, Habel et al. (2009) found that while $75 \%$ of the online articles from 2006 mentioned the availability of the vaccine to women and girls, less than $25 \%$ of the articles mentioned vaccinating men. Similarly, Hilton et al. (2010) found that both the Times and the Daily Mirror reported statistics on the likelihood of women contracting HPV in their life, but failed to discuss statistics regarding men and HPV (Hilton et al. 2010).

News stories about Gardasil often utilize first-hand narratives of women that reinforce the dangers of HPV and cervical cancer. For example, Hilton et al. (2010) find that newspaper articles feature personal accounts of women afflicted with cervical cancer, emphasizing the most grievous accounts. By focusing on the most dangerous aspects, these stories convey messages of risk and fear. The authors state, "The dominant use of women with cancer as main characters anchor the risks posed by cervical cancer and benefits of the new HPV vaccine silence most other discourses" (Hilton et al. 2009:8). The focus on cervical cancer and women narrows the problem of HPV and the cancers that it causes. These emotional messages utilize fear and danger to associate cervical cancer with risk.

Research indicates that risk messages about HPV and cervical cancer were common features of the news media (Abdelmutti and Hoffman-Goetz 2009; 2010). While risk discourse is ubiquitous among health campaigns, risk in the case of Gardasil was 
specifically allocated to women. For example, Abdelmutti and Hoffman-Goetz's (2010) comparative content analysis examines risk messages in Canadian and United States newspaper articles over a two year period starting the year Gardasil was approved for women. This study found that the media regularly associates HPV and cervical cancer with death, illness, or injury (Abdelmutti and Hoffman-Goetz 2010). Consequentially, the media frames HPV as dangerous and inevitable and therefore, an exaggeration of its actual risk. Furthermore, Mamo et al. (2010) find that cervical cancer was constituted a public health problem and a "disease of innocence" that can affect any girl. Braun and Phoun's (2010) research finds that only four percent of articles in major US newspapers accurately describe the rates of cervical cancer. These studies suggest that the media constructed cervical cancer as potentially affecting all girls, therefore making Gardasil an important and obvious solution. However, cervical cancer is an uncommon disease; while 20 million men and women have HPV every year, only 12,000 women develop cervical cancer (CDC 2012).

In light of the risk associated with HPV and cervical cancer, research indicates that the media frames the HPV vaccine positively. This is a common practice as public health campaigns typically construct the solution or treatment to be more positive (Witte and Allen 2000). For example, Habel et al.'s (2009) content analysis of online news stories found that the HPV vaccine was more often framed as positive opposed to negative. One example of a positive headline reads, "A Cancer Vaccine Triumph," (Habel et al. 2009) illustrating the vaccine's importance. This supports Witte and Allen's 
(2000) finding that it is common to find emphasized risk and danger while simultaneously placing the solution in a positive light.

The pronounced risk in media portrayals of Gardasil speaks to one of the major processes of biomedicalization, namely that discourse encourages individuals to take proactive steps to achieve health or maintain health. However, in the case of Gardasil, risk is primarily allocated to women. In a discourse analysis of print and online media between 2005 and 2007, Mamo et al. (2010) find that media coverage of Gardasil constructs girls as universally at risk for cervical cancer. While girls are at risk of cancer and various other ailments, to suggest cervical cancer is inevitable is largely inaccurate and dismisses mechanisms and other risk factors involved. The authors point out that the Gardasil campaign relies on girls to see their "future selves" as part of the necessity to vaccinate. In this case, Gardasil's success is based on risk reduction through consumption (Mamo et al. 2010). In other words, women must invest in Gardasil, which the researchers deem a form of consumption.

This body of research suggests that media messages about Gardasil diligently and exclusively focus on women. In fact, risk was predominately associated with girls and women, therefore allocating the responsibility to vaccinate to women (Mamo et al. 2010). While the focus on women makes sense given its target population at the time, it nonetheless illustrates the salience of gender. Media coverage of Gardasil speaks to how gender was utilized in framing the vaccine and that gender is intricately intertwined within the social meaning of Gardasil. Carpenter and Casper (2009) speak to the introduction of Gardasil in men. They find that when media discussions include men, it is 
based on the assumption of a gender hierarchy, such as men should inoculate themselves to protect women (Carpenter and Casper 2009). Such reasoning reinforces women's frailty while entrenching a chivalrous image of men. Now that Gardasil is also FDA approved for men, this research seeks to address how the media utilized gender in framing the vaccine.

\section{Desexualizing Gardasil}

Issues of sexuality are deeply embedded in the vaccine as Gardasil prevents a STI. Despite efforts on behalf of Merck to avoid the sexualized aspects of the vaccine (Epstein 2010), many groups linked the vaccine to promiscuity which instigated a firestorm over innocence and girlhood. First, I describe how the vaccine was desexualized in the media (Epstein and Huff 2010). Next, I illustrate that despite such efforts, the connections between sexual activity and the vaccine sustained media coverage. Lastly, I discuss how Gardasil is framed within a heteronormative context. While HPV disproportionately affects men who have sex with men (MSM) as well as women who have sex with women (WSW), the promotion of the vaccine has focused almost exclusively on heterosexuals (Epstein 2010).

Research suggests that the media largely avoided the topic of sexuality in representations of Gardasil. In fact, there appears to be an active "desexualization" of Gardasil (Epstein and Huff 2010). Epstein and Huff (2010) argue that the focus on cervical cancer is no accident on behalf of Merck. Indeed, the sexual nature of HPV was deemphasized in the media. Braun and Phoun (2010) echo these findings as they state 
that in-depth information on HPV is largely absent from the media; only 37 percent of articles in their sample explained that HPV is sexually transmitted. Additionally, when the media does mention HPV, the researchers find that more than a quarter of these articles do not explain its link to cervical cancer (Habel et al. 2009). Other than cervical cancer, most HPV-linked cancers go unmentioned. Furthermore, calling Gardasil a “cervical cancer vaccine" avoids HPV, denotes the absence of a sexually transmitted infection, and eliminates acknowledgement of sexual activity and sexual partners (Carpenter and Casper 2009). Therefore, Gardasil is truly framed as a "vaccine against cancer" (Epstein and Huff 2010), and more specifically, a vaccine against cervical cancer. Overall, this desexualization illustrates society's tumultuous relationship with perceptions of sex and sexuality and what is perceived as being taboo.

Despite efforts to contain the sexual connotations associated with Gardasil, concerns about the vaccine's link to sexuality emerged in the media. Some opposed the vaccine on the grounds that it would give girls "the green light to sex" (Carpenter and Casper 2009; Hilton et al. 2010). Research examining these controversial messages finds that these critiques largely stem from institutional organizations (Reich 2010). In fact, it is religious, conservative groups that fuel much of the discussion on girls' potential sexual activity and promiscuity. Reich's (2010) findings speak to the power of organizations in framing Gardasil. Additionally, such a debate illustrates cultural ideologies regarding sexuality, innocence, and appropriate girlhood.

Gardasil, like other medical technologies, operates on the assumption of heteronormativity (Epstein 2010). Heteronormativity upholds heterosexuality as the norm 
and primary sexual orientation. In the case of Gardasil, HPV and HPV-related cancers was primarily discussed within the context of opposite sex partners. For example, early coverage of cervical cancer (prior to the vaccine), omitted discussions about women who have sex with women (Williams 1996), a population uniquely affected by HPV and cervical cancer. Similarly, while there was a brief media discussion about HPV and gay/bisexual men (Epstein 2010), this conversation was not sustained in mainstream media. Today, gay men's health advocates encourage the vaccine, especially with its discovered link with HIV. ${ }^{10}$ Additionally, anal cancer (one of the more common HPVrelated cancers in men) is largely an "invisible disease" due to its association with same sex sexual behavior (Epstein 2010). Despite that sexual minorities are adversely affected by HPV, media coverage predominately focuses on heterosexuals.

\section{Conclusion}

This research presents a nuanced approach to explore the portrayal of medical technologies, specifically Gardasil, in the media. I utilize frame analysis to examine how Gardasil was constructed in the media and to locate the key sources that were influential in framing the vaccine. This will address the power relations that exist in the media and in the marketing of pharmaceutical products. I employ frame analysis to analyze the social and political power behind the portrayal of medical technologies in the media.

There is a body of research that examines the cultural reproduction of the HPV vaccine in the media (Abdelmutti and Hoffman-Goetz 2009, 2010; Carpenter and Casper

\footnotetext{
${ }^{10}$ Continual exposure to HPV has been linked to HIV infection. This is especially prevalent among men who have sex with men who are also at greater risk for developing anal cancer (Palefsky et al. 1990).
} 
2009; Habel et al. 2009; Hilton et al. 2010; and Mamo, Nelson, and Clark 2010; Braun and Phoan 2010). However, this research only examines the construction of Gardasil in the media during the time that it was available to women. Therefore, this study seeks to understand how the media framed the HPV vaccine both before and after it was approved for men. In this way, I can uncover how femininity and masculinity were utilized in media representations of Gardasil and contribute to a more comprehensive understanding of the gendered and sexualized discourse surrounding the HPV vaccine. 


\section{CHAPTER III: METHODOLOGY}

The following outlines my research design. First, I describe the data collection process. I detail each media text individually to best explain the sample and its characteristics. Next, I turn to frame analysis and introduce the frame matrix (Gamson and Lasch 1983), a tool to identify dominant frames. Furthermore, I describe the quantitative code sheet that supplements the frame analysis. The quantitative portion identifies stakeholders, quantifies language, and notes recurring themes. Lastly, I propose that integrating qualitative and quantitative methods is the best approach to understanding how Gardasil was framed in the media.

\section{Data Collection}

Since the media has been the largest source of information about the HPV vaccine to the public (Hughes et al. 2009), I look to the news media as the primary source of data. For this research, news media includes newspaper articles and magazine articles. Newspaper articles frequently cover topics related to health (Brodie et al. 2003) and magazines regularly report on health and medicine (Kahn 2001; O’Malley, Kerner, and Johnson 1999).

This research examines media texts published between 2005 and 2011. Wailoo and colleagues (2010) identify the onset of Merck's DTC advertising in September of 2005 with the "Tell Someone" campaign. This particular campaign introduced the connection between HPV and cervical cancer to the mainstream. Thus, I use September 2005 as the start date for data collection and end in August 2011, at the start of this research. As described in Chapter 1, this six-year period allows for an array of events, 
debates, and topics to be accounted for, such as the approval of Gardasil for women (June 2006), Texas Governor Rick Perry's executive order mandating the vaccine (February 2007), and the FDA approval of Gardasil in men (October 2009). The following describes each of these texts, and more generally, the news media. Please see Appendix A for a full list of the data and their sources.

News Media

Newspaper Articles. I used LexisNexis to identify newspaper articles that discuss the HPV vaccine. LexisNexis is a database that archives various forms of media, including but not limited to, newspaper articles. In order to identify articles on this specific topic, I used two search terms, "gardasil" and "hpv vaccine." Of the articles generated from the search, I narrowed the sample to identify all articles printed in United States newspapers. From that sample, I screened each article to determine if it met requirements for appropriate topic, length, and article type. That is, the main topic was Gardasil and each article was at least 300 words. I eliminated letters to the editor, news bites, duplicate articles, and articles from issue-specific newspapers (e.g. Reproductive Health Matters). Within these parameters, I identified 434 articles in the sample. I then divided all articles by year and randomly selected ten articles from each year. The final sample consists of 60 newspaper articles.

Newspaper articles are predominately from local newspapers (87\%) and only a portion come from national newspapers (13\%). While there was a surge of articles when Gardasil was first approved for women, this coverage did not sustain. Figure \#1 depicts 
the total number of articles over time, illustrating that Gardasil was a common topic when approved for females, but decreased over time.

Figure \#1: Newspaper Articles, by Year

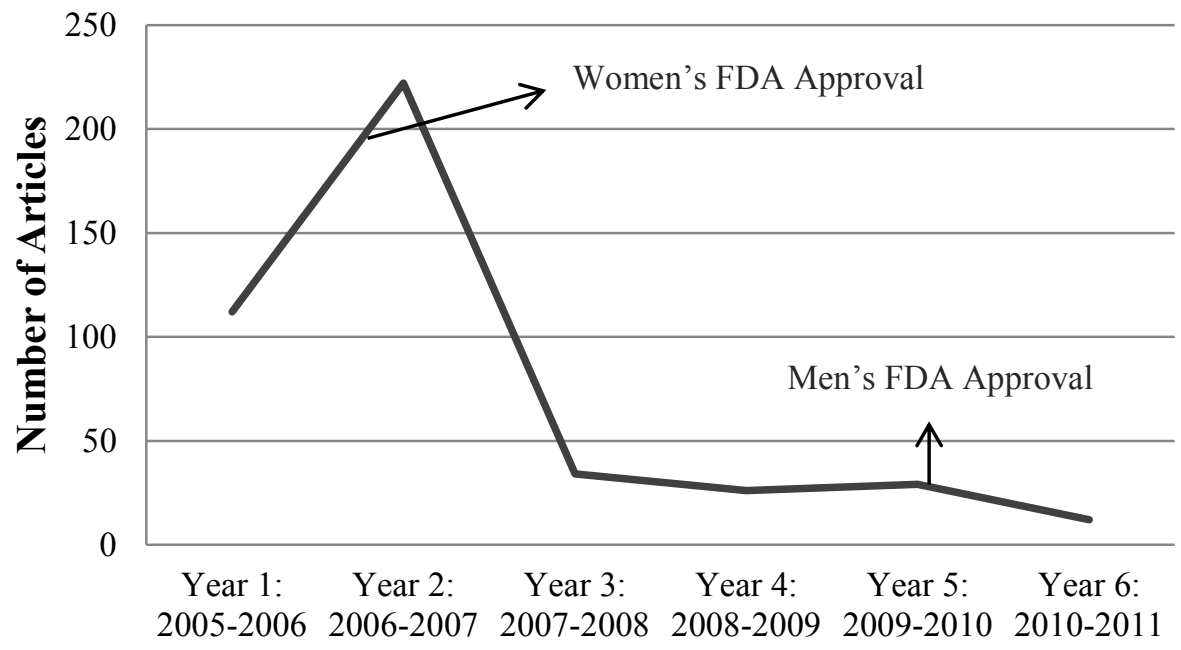

Magazine Articles. In order to locate high-circulation print magazines that report on the HPV vaccine, I used the Reader's Guide to Periodicals. Initially, I sought to identify four female-directed magazines and four male-directed magazines to explore the presence of articles by gender and age. I selected high circulation magazines that include regular sections on health, making the HPV vaccine a likely topic to be discussed. Additionally, I sought to stratify magazines by age to include both an adult readership and a young adult readership. For women, this was easily accomplished due to the abundant and diverse amount of women's magazines. Top adult-women's magazines identified include Good Housekeeping and Woman's Day and young women's magazines, Cosmopolitan and Seventeen. Since Seventeen did not contain any DTC advertisements of Gardasil and a general lack of information regarding the HPV vaccine, I excluded it from analysis. Additionally, I was unable to stratify men's magazines by age 
given the limited selection of men's magazines that discuss health. Therefore, top men's magazines within the parameters include Men's Health, Men's Fitness, and Men's

Journal. These magazines cater to a rather homogenous audience (see Table \#1).

Table \#1: Magazine by Circulation Rate, Gender, and Median Age

\begin{tabular}{lccc} 
Magazine & Circulation Rate & Readership by Gender & Median Age \\
\hline Good Housekeeping & $4,300,000$ & $89 \%$ Female Audience & 51.8 \\
Woman's Day & $3,800,000$ & $96 \%$ Female Audience & 51.7 \\
Cosmopolitan & $3,900,000$ & $85 \%$ Female Audience & 30.3 \\
Men's Health & $1,800,000$ & $83 \%$ Male Audience & 37.7 \\
Men's Fitness & 700,000 & $90 \%$ Male Audience & 36.6 \\
Men's Journal & 700,000 & $84 \%$ Male Audience & 38.3 \\
\hline
\end{tabular}

Note: Hearstintegratemedia.com for information on Good Housekeeping, Cosmopolitan;

http://www.womansdaymediakit.com/r5/showkiosk.asp?listing_id=4176376 for Woman's Day;

http://www.americanmediainc.com/sites/americanmediainc.com/files/mediakits/print/MF_MediaKit.pdffor and for

Men's Fitness; http://www.srds.com/mediakits/mens_journal/demographics.html for Men's Journal;

http://www.menshealth.com/mediakit/online/audience.htm for Men's Health

To identify articles specifically related to HPV or Gardasil, I examined each magazine published between 2005 and 2011. First, I read the table of contents to identify relevant articles by title. If no articles were mentioned, I then went to the regular sections on health (e.g. "GynoNews!" in Cosmopolitan or “Ask Dr. Bob" in Men's Journal). I included question and answer sections (Q\&A), blurbs, and full articles about Gardasil. I excluded any articles that did not mention the vaccine. This strategy yielded 32 magazine articles, of which $81 \%$ were found in women's magazines. Additionally, $56 \%$ of magazine discussions about Gardasil are in blurb form (short sections or paragraphs), $19 \%$ are in question and answer form, and $25 \%$ are full articles. Therefore, the majority of the discussion about HPV and the HVP vaccine are in short paragraphs, typically 
shorter reports in regular sections on health.

Figure \#2: Magazine Articles, by Year and Audience

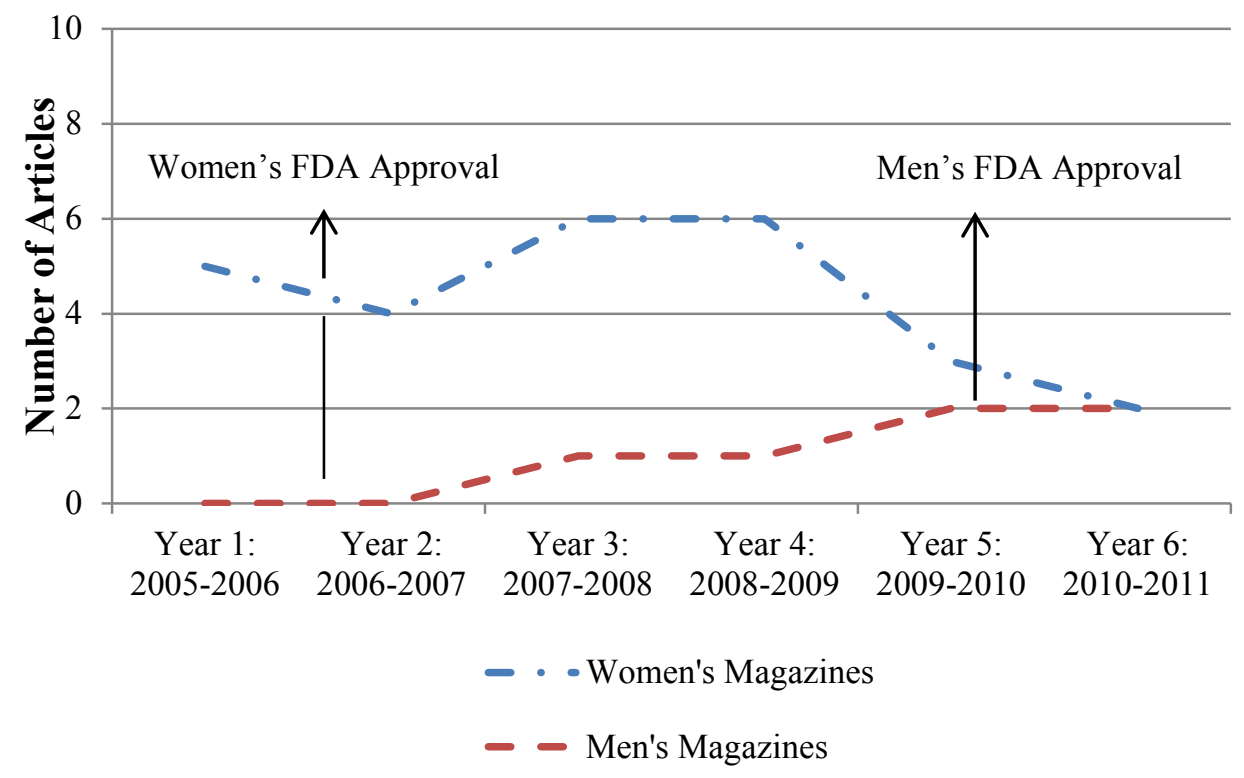

\section{Media Stakeholder Sources}

Identification of Stakeholders. To identify the origin of dominant frames, I located groups or stakeholders used as sources in news media (newspapers and magazines). Stakeholders include individuals, groups, or organizations that made public statements about the HPV vaccine in the news media. This also includes groups that publicly endorsed the vaccine or opposed it. To identify such sources, I utilized a code sheet to quantify groups cited most in the news media (Carragee and Roefs 2004). The method yielded the most influential stakeholders: Merck (12), Planned Parenthood (7), Center for Disease Control and Prevention (6), National Cancer Institute (4), Family Research Council (4), and Focus on the Family (3). Of the stakeholders, Merck is the most cited source and has been a powerful force in framing Gardasil through a popularized DTC advertising campaign, an accessible website, and general presence in the news media. 
Therefore, I look to Merck's DTC advertising and the Gardasil website as primary areas that Merck framed Gardasil. Additionally, I analyze the other stakeholder websites, statements, and fact sheets that directly pertain to the vaccine.

DTC Advertisements. I located DTC print advertisements though the Reader's Guide to Periodicals. Examining the same magazines listed above, I searched for advertisements by inspecting each magazine for official DTC Gardasil advertisements. All advertisements were recorded, copied, and organized chronologically and by magazine. The final sample consists of 44 full-page advertisements, of which, 22 are unique. ${ }^{11}$ Additionally, advertisements were only found in women's magazines, indicating that Merck sought to advertise to a female audience.

Like many other pharmaceutical companies, Merck advertised through numerous DTC commercial advertisements. I identify four commercial advertisements that are publically available via www.youtube.com. I identify two commercials employed the "One Less" campaign, the first official branded DTC advertising campaign for Gardasil. I also identify two advertisements in the "I chose" campaign, which aired two years later.

Stakeholder Statements. To uncover how stakeholders framed the vaccine, I looked to each organization's website. I utilized the search function using the terms "HPV vaccine" and "Gardasil." The search most often generated the groups' official statements in the form of pamphlets or fact sheets. For instance, Focus on the Family produces an information sheet entitled, "The HPV Vaccine: What Parents Need to Know." Identification of these groups answers the question, "Who/what groups

\footnotetext{
${ }^{11}$ Only full-page advertisements were identified in the magazines. Some advertisements included two pages, which were also included.
} 
controlled the dominant discourse about the HPV Vaccine?" and "How do these groups frame the Gardasil vaccine?

The Gardasil website included a substantial amount of information about the vaccine. Given the plethora of data, I did not use search terms. Instead, I examined each page (total of 26 unique pages in 2012) including their primary pages such as "Facts about HPV," "Learn About Gardasil," "Make an Impact," and "More for Parents." Each of these sections included informational material about Gardasil as well as interactive opportunities for audiences. I excluded "Safety and Patient Product Information" and the page for "Health Care Professionals." These pages were unnecessary for the purposes of this research as they deviate from how the vaccine was framed to the general public.

\section{Data Analysis}

This research predominately uses a frame analysis, a concept used to identify dominant frames within texts. Entman (1993) states, "the concept of framing consistently offers a way to describe the power of a communicating text" (1993:51). Since every news story consists of frames (Pan and Kosicki 1993), frame analysis is a useful tool to examine frames, messages, perspectives, or dominant viewpoints of a given topic (Creed, Langstraat, and Scully 2002). First, I describe the frame matrix and the elements of frames. Next, I turn to the quantitative portion of this research, which serves to supplement the frame analysis. I utilized a code sheet for two distinct purposes. First, the code sheet allowed me to quantitatively assesse the dominant sources. Second, I numerated key aspects of news stories, including gendered language, themes, and 
statistics in order to support the frame analysis. The following sections describe the analysis of the texts.

Frame Analysis

I conducted a frame analysis in order to identify purposive frames. Like Gamson and Modigliani (1989), I assume that every news story has a frame that organizes meaning. In order to identify frames, I employed Gamson and Lasch's (1983) frame matrix. The frame matrix is a tool to extract frames and their key components. Many researchers have utilized the frame matrix or a modified version of it (Gamson and Modigliani 1989; Pan and Kosicki 1993; Tankard 2001).This inductive approach locates key devices of frames. The first set of devices includes metaphors, exemplars, catchphrases, depictions, and visual images, or the structure of the frame. The second includes the underlying meaning, or justification behind the frame. These latent features include roots, consequences, and appeals to principle. See Appendix B for an example of a frame matrix.

When conducting a frame analysis, Winett (1997) encourages researchers to read each text at least three times. ${ }^{12}$ The first reading allows the researcher to familiarize himself/herself with the article and its issues. The second reading involves more systematic analysis. During the second reading, I conducted a line-by-line coding within each text. This included examining the features of the text including sources, language, images, catch-phrases, etc. Following that, I noted recurring ideas, language, and images and other salient features. During the third reading, I looked across the texts to identify

\footnotetext{
${ }^{12}$ I use a modified version of Winett's (1997) Guide to Developing Framing Memos as I combine a sociological approach rooted in traditional qualitative methods to uncover frames.
} 
patterns and commonalities. At that point, I conducted axial coding, in which I identified intersections and started to cluster categories (Strauss and Corbin 1998). I then collapsed these categories into themes. Gamson and Modigliani (1989) argue that every news story has a theme that organizes the central idea. I applied the dominant themes to the frame matrix, elucidating how these themes were embodying larger frames. At that time, I extracted frames from key themes with the use of the frame matrix. Therefore, I identified the frame and its key components, pointing out metaphors, exemplars, catchphrases, depictions, and visual images and used the frame matrix to organize them. Once I developed the dominant frames, I examined the frames across the various texts, looking for commonalities and divergences between the various outlets.

The frame matrix is typically applied to news stories, making it a useful tool to identify key frames in newspaper and magazine articles. However, other data included in this analysis such as DTC advertising, websites, and fact sheets present methodological challenges when applying the frame matrix. Therefore, I undertook a nuanced approach to identify frames in such data. For instance, to analyze DTC commercial advertisements, I transcribed the advertisements and used the transcription as the primary data source. From this, I identified key concepts, categories, and themes and applied those themes to the frame matrix. Additionally, I watched the advertisements at least three times in order to capture the visual aspects, which convey cultural messages (Cline and Young 2004; Wilkes et al. 2000). Following Cline and Young (2004), I noted the characteristics of the people portrayed (e.g. healthy, friendly), their gender and race/ethnicity, as well as their activities (e.g. sports). Moreover, I took a similar approach when analyzing DTC print 
advertisements. First, I analyzed the text of the advertisement followed by analyzing its visual elements. Furthermore, when examining the Gardasil website, I analyzed each page as data. Therefore, I read and reread pages, elucidating recurring concepts of the texts that later collapsed into themes and finally frames. Lastly, I accounted for the aesthetics of these various pages, again analyzing the characteristics of those portrayed (gender, race, activities). Furthermore, while I initially thought stakeholder fact sheets would present similar methodological challenges, I actually found the opposite. The frame matrix was easily adaptable to identifying key frames in these stakeholder texts. While official stakeholder documents about the vaccine were primarily text, some included visuals. When fact sheets did include visuals, I included it as data. Therefore, while there were methodological challenges to identifying frames across the variety of media types, I used past research to inform these choices in order to ameliorate such methodological problems.

\section{Quantitative Analysis}

I created a quantitative coding sheet a priori to complement the frame analysis. This instrument was informed by the current body of research that conduct content analyses of Gardasil in the media (Abdelmutti and Hoffman-Goetz 2009, 2010; Habel et al. 2006; Hilton et al. 2010; Carpenter and Casper 2009). The code sheet numerates key elements of every story, including the title, language, statistics, and presence or absence of information. Additionally, it enabled me to systemically account for dominant sources. I utilized this code sheet in magazine and newspaper articles to identify sources that produced frames. After the coding process, I entered the data into the statistical program, 
SPSS. I analyzed the data using univariate and bivariate analyses. These findings serve to further illuminate the key aspects of each frame. Please see Appendix $\mathrm{C}$ for the newspaper code sheet and Appendix D for the magazine code sheet.

\section{Conclusion}

This research takes an inductive and deductive approach. While the frame analysis can be considered inductive, Strauss and Corbin (1998) point out that our conceptualizations of data are to some degree, deduction in nature. My inductive and deductive approach is best explained by integrating qualitative and quantitative methodologies. By integrating methods, I can best account for the frames used and their key elements, a strategy that Koenig (2006) advocates for in frame analysis. While this research analyzes both manifest and latent content, the frame analysis primarily elucidates the latent messages, which guides this research. Therefore, I conceptualize the quantitative portion as complementing the latent data. By integrating methods, I best account for the varied ways in which messages were conveyed through framing, which I will describe in the following chapters. 


\section{CHAPTER IV: KEY STAKEHOLDER FINDINGS}

The findings in this chapter describe how stakeholder groups framed Gardasil. I describe each of these groups and the frames they employed. I identified stakeholders by numerating sources cited in the news media. In other words, I coded articles prior to conducting the frame analysis, identifying the most commonly cited sources. It is important to note that stakeholders used various outlets to either advertise the vaccine or state their official stance. For Merck, this included DTC advertisements and their website, whereas Focus on the Family utilized fact sheets accessible on their website. This chapter accounts for the various types of sources and their frames. Please see Appendix E for a conceptual map of the stakeholders.

I identify Merck, Planned Parenthood, National Cancer Institute, Center for Disease Control and Prevention, Family Research Council, and Focus on the Family as the primary stakeholders in the media. The most prominent source is Merck, the pharmaceutical company that produced Gardasil. Their highly visible DTC advertising campaign and easily accessible website are key sources of information and unique sites of framing. I describe their three most recent DTC advertising campaigns and their official website. Thereafter, I discuss the remaining key stakeholder groups and how they framed the vaccine. I describe each organization, their ideologies, and how they framed Gardasil. Overall, this section elucidates the organizations that maintained power in the media and ways in which they framed the vaccine. In the following chapter, I describe the degree to which the news media adopted these frames and how they contributed to the dominant frames. 


\section{Merck and Co.}

Merck Pharmaceuticals is a leading pharmaceutical company in the United States. This private company produces drugs, vaccines, and other treatments which are often publicized through highly visible DTC advertising. Given their prominence both in the U.S. and abroad, this company has had considerable influence over our medical and health experiences. I first describe Merck's DTC advertising of Gardasil, evidence to their strong presence in the media. I discuss six primary DTC campaigns. The first three, "Make the Connection," "Tell Someone," and "Make the Commitment" were publicized prior to FDA approval. While I did not include these three campaigns in data analysis, I describe them in the findings as they provide a comprehensive examination as to how the vaccine was presented to the public prior to FDA approval. ${ }^{13} \mathrm{Next}$, I detail the past three DTC Gardasil advertisement campaigns and their frames. Such campaigns include "One Less," "I Chose," and "Protect Your Child." I then turn to the Gardasil website, the center of information on Gardasil and another site of marketing. In short, this discussion details Merck's primary frames and their overall influence in the framing the vaccine to the public.

\section{Merck's DTC Advertisements}

Merck employed various branded and nonbranded advertising campaigns before and after the FDA approved Gardasil. A branded campaign includes the product name, which by FDA guidelines can only occur after FDA approval. In turn, unbranded

\footnotetext{
${ }^{13}$ I attempted to account for these campaigns during data analysis by collecting data one year prior to FDA approval. However, I only identified one advertisement in Cosmopolitan from the "Tell Someone" campaign. Due to the lack of articles, I excluded it from data analysis. Nevertheless, it is important to describe these campaigns as it gives background to the more recent advertising campaigns.
} 
advertisements are permitted as long as a product name remains unstated. Prior to approval, three nonbranded marketing campaigns emerged: "Make the Connection," "Tell Someone," and "Make the Commitment."14 I briefly discuss these campaigns to better situate the findings. The "Make the Connection" campaign appeared mid-2005 and underscored the link between HPV and cervical cancer. This campaign featured celebrities and other non-profit organizations (Vanderbilt-Ingram Cancer Center 2006). Similarly, the "Tell Someone" campaign further strengthened the link between HPV and cervical cancer. This campaign implicitly implicated women as social actors to inform their friends, family, and coworkers about the link between HPV and cancer. These campaigns positioned HPV and cervical cancer as a major health concern and paved the way for public acceptance of the new "cancer vaccine."

Following FDA approval of Gardasil, Merck launched a branded DTC advertising campaign with the slogan, "one less." This particular campaign included televised commercial advertisements and print advertisements. Two years later, the "I Chose" campaign emerged. These DTC advertisements presented young women and mothersdaughter dyads affirming that they chose to vaccinate because "it's the right thing to do." The "One Less" and the "I Chose" campaigns focused exclusively on women. It wasn't until 2010 that the "Protect your Child" DTC advertisements emerged and reformulated its message to be inclusive of males. Advertisements in this campaign resided solely in adult women's magazines, arguably catering to mothers. In sum, no commercial DTC advertisements included men. In the following, I discuss the frames found in the "One

\footnotetext{
${ }^{14}$ Data about these campaigns are from Mamo, Nelson, and Clark (2010).
} 
Less," "I Chose," and "Protect your Child" campaigns. I present both commercial and print advertisements in each of the three campaigns and their overall frames. ${ }^{15}$

\section{"One Less" Campaign}

The "One Less" DTC advertisements exclusively focused on women and cervical cancer. These advertisements featured only women and print advertisements were only found in women's magazines. The "One Less" campaign advertised to two primary audiences-young women and mothers. While advertisements varied, they conveyed an analogous message against a simple backdrop with the slogan, "one less." This campaign utilized one primary frame in both commercial and print DTC advertisements: proactive cervical cancer prevention. I identify ten unique advertisements in this campaign.

Proactive Cervical Cancer Prevention. The frame proactive cervical cancer prevention, constructs Gardasil as protection against cancer. This frame encourages women to expedite vaccinating with Gardasil, constituting it a necessary part of their health care. DTC advertisements in Cosmopolitan magazine call on women to protect themselves. While similar in style, advertisements in Good Housekeeping and Woman's Day utilize the cultural expectations of "good" mothering to frame the vaccine as necessary protection for their daughters. Since this frame speaks to two distinct populations, I discuss advertisements intended for young women first, followed by those for adult women.

Print advertisements aimed at young women impose a responsibility on them to vaccinate. The use of bold writing with a neutral backdrop conveys a strong, clear

\footnotetext{
${ }^{15}$ The "Protect your Child" campaign only includes print advertisements. No commercial advertisements are available for analysis.
} 
message. There is a sense of urgency - that women should act now to prevent cervical cancer. For example, one print advertisement reads, "Roll up your sleeves. It's your turn to help guard against cervical cancer.” (See Figure \#3). The statement, "rolling up your sleeves" metaphorically implies hard work by evoking Rosie the Riveter, a feminist icon for hard work and individual responsibility. Telling women to 'roll up their sleeves' is a way to instigate vaccination through personal responsibility. Another advertisement reads, "Will you be one less life affected by cervical cancer?" and calls on women to consider themselves affected by cervical cancer. By explicitly making this connection, the advertisement plays on the dangers of cervical cancer and in association, one's livelihood. This rhetorical question constructs Gardasil as an obvious and important answer to prevent cervical cancer.

Figure \#3: DTC Print Advertisement: Proactive Cervical Cancer Prevention

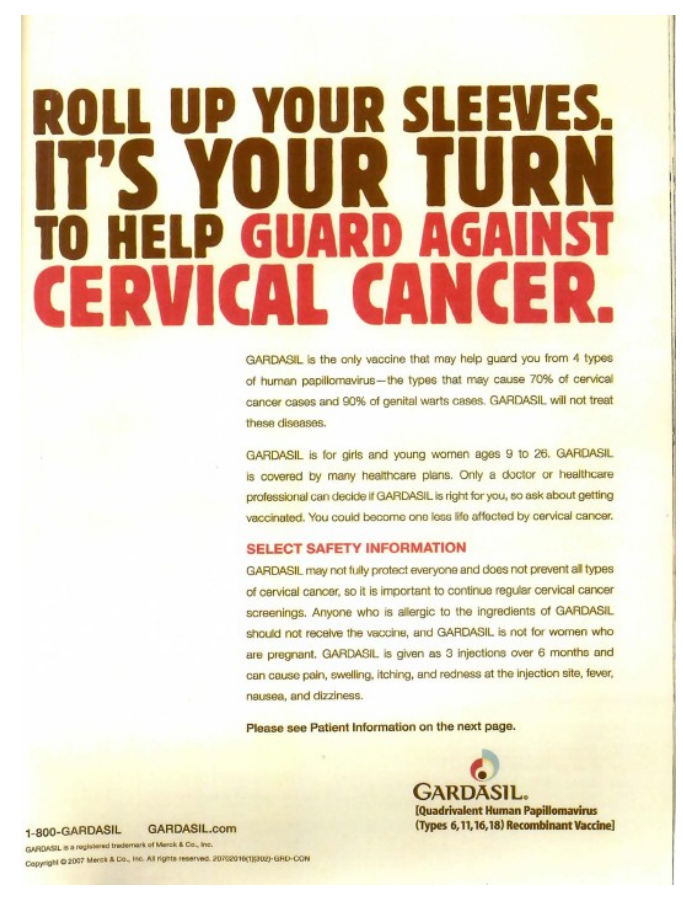


Likewise, commercial advertisements present numerous young girls proclaiming their independence from cervical cancer. Young girls are portrayed engaging in a variety of sports and activities including surfing, skateboarding, and basketball. The diversity of these girls appeals to a wide audience as young women can identify with those portrayed. These advertisements discuss the dangers of cervical cancer by conveying statistics that illustrate the severity of HPV and cervical cancer. Therefore, the "one less" commercials frame cervical cancer as unavoidable. Simultaneously, commercials present Gardasil as a necessary and primary solution. One woman states, "I want to be one less woman who will battle cervical cancer." Broad statements such as this one are easily agreed upon, making Gardasil a natural decision. Like the print DTC advertisements, these commercials convey a sense of urgency by concluding with the text, "get vaccinated."

Furthermore, advertisements in adult women's magazines (Good Housekeeping and Woman's Day) specifically cater to mothers. These advertisements focus on protecting one's daughter, a powerful and emotional message. One advertisement reads, "The power to help prevent cervical cancer is in your hands. And on your daughter's arm." This statement allocates responsibility for vaccinating to mothers. Another advertisement states, "Your daughter can't possibly know the importance of a cervical cancer vaccine. But thankfully, she has her mother." This frame portrays the image of the protective mother who must care for her young, innocent daughter. In this case, one's daughter may not understand cancer or vaccines, but having a mother who does secures her protection. Hays (1996) concept of "intensive mothering" speaks to how Merck positions Gardasil as an important part of health care a mother must provide. Intensive 
mothering is child-centered and all-consuming mothering that typically occurs with middle class mothers (Hays 1996). These advertisements construct vaccinating with Gardasil as a necessary part of mothering by emphasizing protection for one's daughter.

A significant facet of this frame is its reliance on cervical cancer. The focus on cervical cancer constructs Gardasil against cancer, instead of more accurately, HPV. In turn, it omits the association between cervical cancer and HPV and the mechanisms through which cervical cancer develops. One advertisement clearly illustrates this connection stating, "Calling Gardasil a cervical cancer vaccine is only the beginning of the story" (see Figure \#4). The reliance on cervical cancer further brands Gardasil a cervical cancer vaccine and diverts attention away from the sexualized aspects of HPV.

Figure \#4: DTC Print Advertisement: The Focus on Cervical Cancer

CALLING GARDASIL A CERVICAL CANCER VACCINE IS ONL THE BECINNING OF THE STORY.

GARDASIIL is the oniy vaccine that may help guard you trom 4 types at human papillomavirus - the types that may casuse $70 \%$ of oervica cancer cases and $90 \%$ of gential werts cases. GARDASIL will not treed trese diseases

GARDASIL is for gins and yourg women ages 9 to 26. GAPDASL sc covered by mary healthcare plans. Only a doctor of healthoure protessional can decide If GARDASIL. is right for you, so ask abou potting vaccinatod at your next doctor's appointment or check-11.

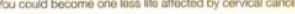

SELECT SAFETY INFORMATION

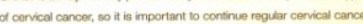

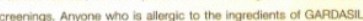

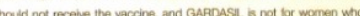
are preonant GAPDASIl is given as 3 iniections orer 6 mosthe

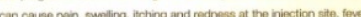
nausea, and dizzness.

Please see the Patient Product Information on the next page 10 discuss it with your doctor.

GARDASIL.

[Quadrivalent Human Papillomavirus

(Types 6,11,16,18) Recombinant Vaccine]

1-800-GARDASIL GARDASILCOM 


\section{“I Chose” Campaign}

In mid-2008, Merck unveiled a new DTC marketing campaign emphasizing choice and empowerment. These advertisements utilized a new slogan, "I chose." Similar to the previous campaign, "I chose" caters to two audiences. First, advertisements in Cosmopolitan magazine display young women discussing their choice to vaccinate. Additionally, advertisements in Good Housekeeping and Woman's Day magazines appeal specifically to mothers by discussing the health and safety of daughters. These advertisements utilize the power of choice to frame Gardasil as an important decision in a woman's health care. The focus on choice frames Gardasil as empowering to women, making the dominant frame women's empowerment. I identify eight unique advertisements that utilize this frame.

Women's Empowerment. DTC print advertisements in the "I Chose" campaign depict young, healthy, and independent women. The text of the advertisements resembles a young girl's writing, personalizing the message. Female adolescents are presented against a backdrop of feminine imagery, such as flowers, shoes, or a purse, further emphasizing Gardasil as a feminine vaccine. These advertisements unanimously state, "I chose to get vaccinated," followed by a litany of reasons including a doctor's recommendation or just securing protection for the future. The phrase "I chose" is illustrative of the rhetoric of choice (Bordo 1993), a powerful type of language that has historically been associated with the women's health movement. In this context, the rhetoric of choice marks a unique way to frame the vaccine as an important decision (or choice) in a woman's life. For example, one advertisement reads, "I chose to get 
vaccinated after my doctor told me the facts. I mean facts are facts. And when it comes to my body and how I can protect it, I'm all ears." (See Figure \#5). Here, the narrator discusses her decision by invoking medical authority to validate her decision. This distinct form of rhetoric relies on autonomy and the powerful ability to make choices about one's own body.

\section{Figure \#5: DTC Print Advertisements: "I Chose" Campaign}
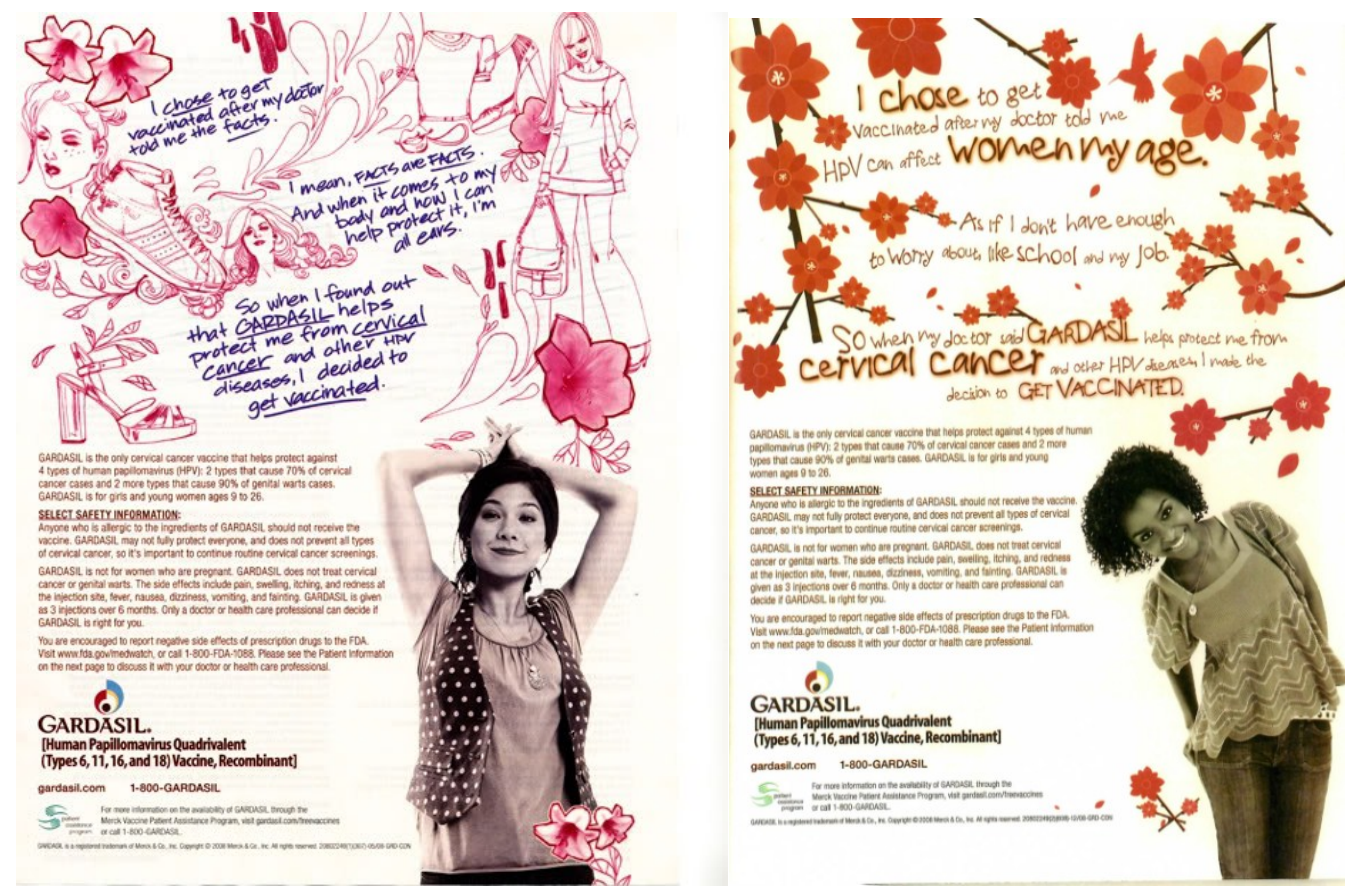

It is the intimate connection between choice and empowerment that constructs

Gardasil as empowering to women. The ability for women to make choices regarding their body has been pivotal to the women's health movement and overall liberation. Therefore, framing Gardasil as a "choice” constitutes Gardasil as important and possibly empowering. One advertisement reads, "I chose to get vaccinated because my dreams don't include cervical cancer." This young woman is accomplished—she has a job, 
school, and life to "worry about." She has taken proactive steps in ensure her future by preventing cervical cancer. The strategic use of choice rhetoric uses women's empowerment as an incentive to vaccinate. Additionally, while the overall message emphasizes women's empowerment, they nonetheless glorify normative femininity through aesthetics of the advertisements.

Similarly, commercial advertisements feature successful, independent young women. Narrators discuss the vaccine in their own homes or in an office, evoking a sense of responsibility and maturity. They repeat the slogan "I chose to get vaccinated." The women portrayed have already been vaccinated and discuss that decision as important and virtuous. Overall, the emphasis on choice and the portrayal of mature and responsible women validate Gardasil as important to women. In fact, vaccinating with Gardasil is presented as a 'coming of age' for women who might be practicing 'choice' for the first time. The frame of choice is further entrenched at the end of the commercial when the screen states, "choose to get vaccinated" (see Figure \#6).

Figure \#6: DTC Commercial Advertisement: Choose to Get Vaccinated

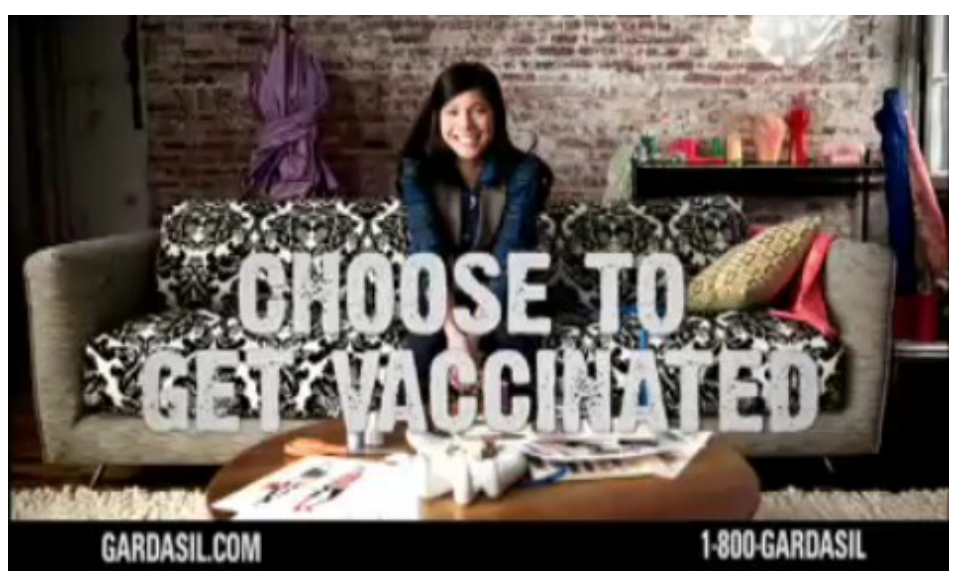


In sum, the focus on "choice," presents the vaccine as a form of self-care linked to empowerment. These advertisements advocate for vaccination, regular doctor checkups, and knowing your body. By exercising choice, vaccination not only provides protection, but a mechanism for empowerment. However, this empowerment is directly linked to consumption; by choosing to vaccinate, one purchases a costly vaccine. ${ }^{16}$ DTC advertisements of Gardasil utilize feminist consumerism. This term speaks to how companies utilize feminist ideals to market products (Johnston and Taylor 2008). In this case, Gardasil is constructed as empowering, important, and central to a woman's health. The tacit appropriation of feminist values allows women to experience feminism through empowerment though avoid the label of feminist all together.

Lippman (1999) offers a critical analysis of discourse that co-opts choice and empowerment. She asserts that reliance on choice ignores various dimensions of inequality that can affect one's ability to choose. Like Mamo et al. (2010), I also found that Merck constructed Gardasil as a vaccine for every woman, regardless of social status, susceptibility, or risk. In turn, it creates unrealistic expectations for those whose agency is limited by various dimensions of inequality. Lippman states that "to frame choice merely as an individual consumer's self-expression is to ignore the intricate webs in which women lives their lives" (1999:284). In addition, relying on choice as a marketing strategy illustrates that women's health needs are privy to market needs. Overall, the cooptation of women's ability to choose illustrates the "marketability of women's health" (Lippman 1999:286). Pharmaceutical companies co-opting feminist ideals to market medical innovations speaks to the corporatization of the pharmaceutical

\footnotetext{
${ }^{16}$ The three shot series costs $\$ 390$. Insurance can offset some of this cost.
} 
industry and the larger shift from patient to consumer. Moreover, while these messages frame Gardasil as empowering to women, a more critical analysis indicates that in the case of Gardasil, choices are limited. In other words, while Gardasil is constructed as an important choice, it is also presented as the only choice. ${ }^{17}$ This narrow appropriation misrepresents other forms of HPV and cervical cancer preventative measures. In sum, this message exploits women's empowerment for economic gain.

Similarly, advertisements for adult women frame the vaccine as an important choice for mothers to make. DTC print advertisements feature a mother and daughter amongst illustrations of a backpack, books, and a lunch bag, exemplifying the intimate aspects of childcare. In these advertisements, the text is from the mother's point of view. One advertisement reads, "Because Gardasil is about prevention. It helps prevent cervical cancer and other HPV disease. She's my little girl and I'll do everything I can to help protect her.” (See Figure \#7). This advertisement focuses on protection and positions Gardasil as the primary mode of protection for one's daughter. The use of choice in these advertisements masks Gardasil as an obligation of a mother.

\footnotetext{
${ }^{17}$ The pap smear is considered the primary form of maintaining good sexual health; it is has led to a drastic decrease in cervical cancer worldwide and especially in the U.S. However, the pap smear was rarely discussed in the media as another form of prevention.
} 


\section{Figure \#7: DTC Print Advertisement: Mother "Chose" to Vaccinate Daughter}

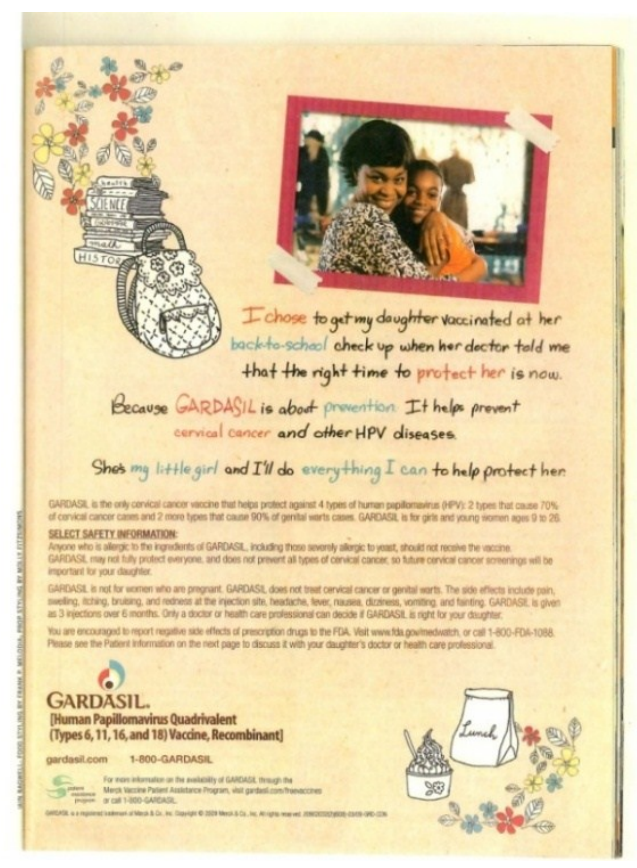

Similarly, DTC commercial advertisements portray mothers and daughters

together. One particular commercial in this campaign features ethnically diverse motherdaughter dyads engaging in various activities like swimming, surfing, sewing, learning how to dance, and shopping (see Figure \#8). Mothers predominately narrate these advertisements, conveying a message of responsibility. The dialogue aligns with various mothers stating, "I chose to get my daughter vaccinated." The choice rhetoric is again employed, focusing on presenting Gardasil as an important choice in women's lives. The following dialogue includes mothers discussing reasons to vaccinate their daughters:

Mother 1: Everyday, about 30 women in the US learn that they have cervical cancer. That's why I chose to get my daughter vaccinated.

Mother 2: I chose to get my daughter vaccinated, when her doctor and I agreed that the right time to protect her is now. Because it's about prevention

Mother 3: I chose to get my daughter vaccinated because the CDC recommends that girls her age get vaccinated. 
Mother 4: I chose to get my daughter vaccinated because I want her to be one less person affected by cervical cancer.

These statements commence with "I chose." In this case, choice is connected to a daughter's health and safety, which is only enacted by a mother. That is, mothers are encouraged to make positive choices on behalf of their daughters. The use of choice in this context presents an interesting appropriation of choice rhetoric and feminist values and connecting it to vaccinating daughters. Like the advertisements aimed at young women, these ads allude to feminist ideas without explicitly naming it. Thus, the powerful use of choice rhetoric links the vaccine to empowerment and specifically the empowerment of mothers through ensuring this form of protection for their daughters. Now, being a "good" mother includes vaccinating one's daughter with Gardasil.

\section{Figure \#8: DTC Commercial Advertisement: Mother-Daughter Dyads}

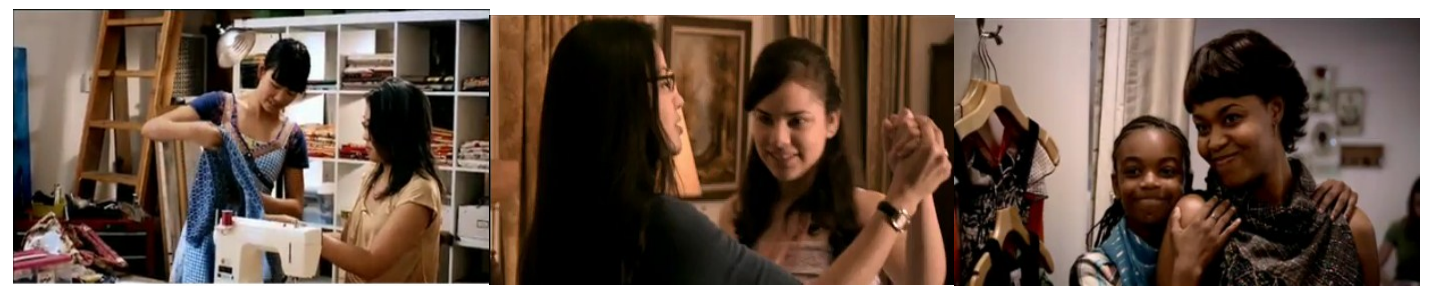

\section{"Protect Your Child” Campaign}

The "protect your child" DTC advertisements were the first to include boys and girls. This campaign emerged one year after Gardasil was officially approved for use in males. This campaign includes print advertisements exclusively located in adult women's magazines, therefore catering to mothers. Overall, these advertisements frame Gardasil as HPV prevention, in contrast to a specific HPV-linked cancer. Additionally, the phrase "your child" implies a male or female child, a clear reversal from the initial feminization 
of the vaccine. The focus on HPV allows Gardasil to be marketable to males and females. Therefore, the predominant frame in this campaign is proactive HPV Prevention.

These advertisements are markedly less feminine and are rather gender-neutral. Advertisements display simple text along an image of a boy and girl. Additionally, the male and female gender symbol is portrayed in the center, illustrating that Gardasil is intended for males and females. There is also a return to the original "one less" slogan, which serves as a focal point in these advertisements. One DTC print advertisement states, "Boys can be affected by HPV disease too. Gardasil helps protect both your son and daughter." (See Figure \#9). The phrase "your child" and "HPV disease" can refer to either a male or female.

\section{Figure \#9: DTC Print Advertisement: "Protect Your Child" Campaign}

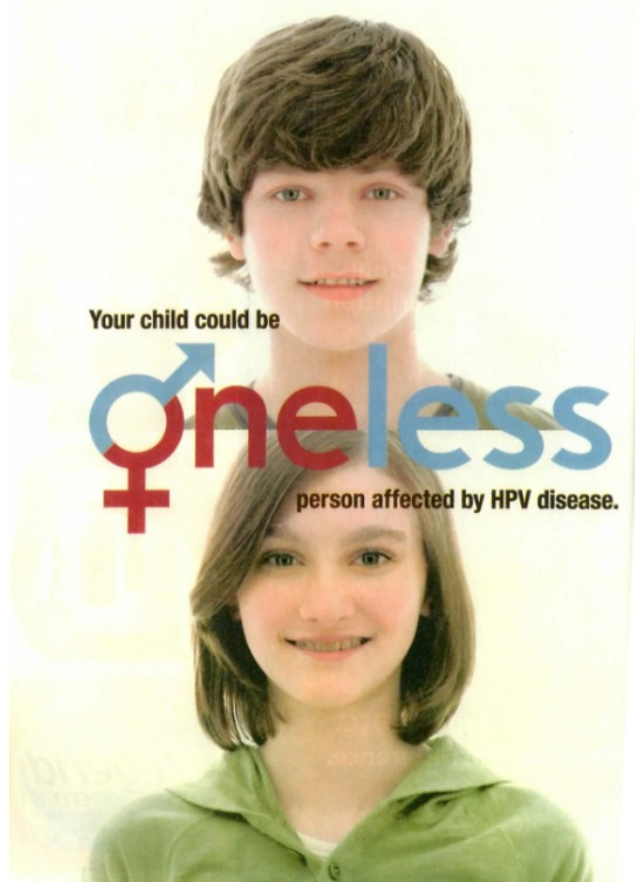

Furthermore, the "protect your child" campaign more accurately represents

Gardasil as an HPV vaccine. In contrast, prior framing of Gardasil focused on cervical 
cancer, rather than HPV. Instead of linguistically linking the vaccine to women by calling it a "cervical cancer vaccine," the use of "HPV vaccine" recognizes that HPV affects both men and women.

The original DTC advertisements specifically called on women to vaccinate. In a clear reversal from that, advertisements that feature males are not advertised to males. While women are faced with the choice to vaccinate, the vaccination of boys is contingent upon the mother. Like the advertisements in the "I chose" campaign, these advertisements implicitly employ mothers to take responsibility for a child's health. In turn, men are not directly called on to participate in vaccinating with Gardasil, as it solely resides in the hands of young women and mothers.

\section{The Gardasil Website}

The official website for Gardasil, www.gardasil.com, may be considered the informational epicenter of the Gardasil vaccine. The website provides substantial information regarding the vaccine in addition to various forms of advertising. Analysis of the Gardasil website in 2012 yields two prevalent frames: proactive HPV prevention and women's empowerment. Since only the current website is publicly available, I discuss the most recent, available information. ${ }^{18}$ First I describe the website followed by a thorough examination of the frames employed.

Overall, the website provides 26 unique pages ranging from informational material, vaccine promotion, and interactive opportunities. Upon visiting the website,

\footnotetext{
${ }^{18}$ Analysis of the website took place in February of 2012. There are likely to be many changes to the Gardasil website between 2005 and 2011 for which I could not account. Since the website largely reflects the themes in the DTC advertisements, it is likely that changes to the website over time parallel the findings from DTC advertisements.
} 
diverse young men and women move across the screen, emblematic of the vaccine's population. The text beside them states, "Gardasil can help protect males and females from HPV disease." Please see Figure \#10 for an example of this introductory page.

\section{Figure \#10: Gardasil Website Homepage}

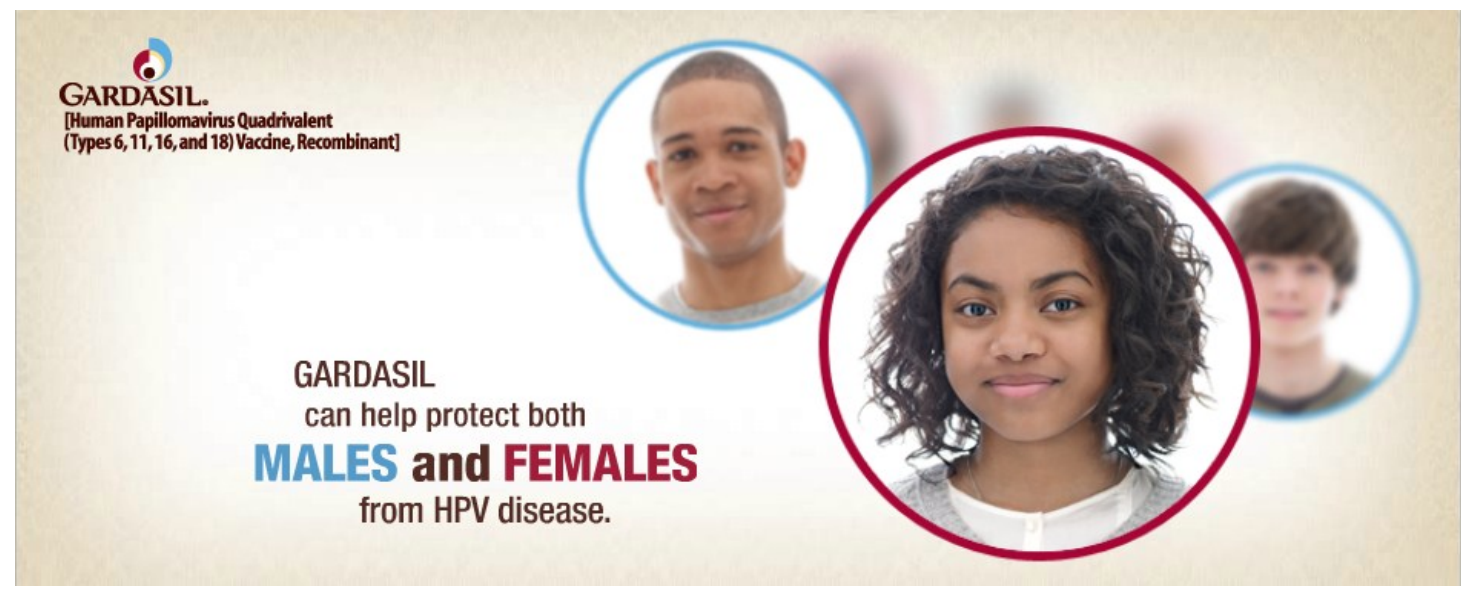

A prominent frame employed on the website is proactive HPV prevention. Like

DTC advertisements in the "protect your child" campaign, the website frames Gardasil as HPV prevention. Headlines on their home page state "HPV" and "HPV disease" instead of a gender specific cancer, like cervical cancer. In fact, a section designed for parents states, "your son or daughter could be one less person affect by HPV disease." The focus on HPV, instead of a gender-specific cancer, enables Gardasil to be more marketable to males.

While the focus on HPV is a notable way to address the infection in men, the website simultaneously obscures HPV-related cancers in men. For instance, the website explicitly describes the infections and vaccine in women, though neglects to discuss beneficial outcomes in men. For example, although Gardasil is FDA approved to prevent 
anal cancer, this cancer, among others that affect men, go unmentioned on the website. However, the website explicitly states that the vaccine prevents cervical cancer, vulva cancer, and vaginal cancer, or the cancers specific to women. The use of "HPV diseases" circumvents the stigma associated with HPV cancers in men, such as anal cancer, a cancer that is linked to sexual minorities. The absence of HPV-related cancers in men makes their sexual health an afterthought compared to the cancers in women which are clearly stated.

Furthermore, the "Watch Real-Life Stories," includes videos of women discussing their experiences with HPV, cervical cancer, and the vaccination process. In keeping with the ideals of do-it-yourself (DIY) self-care and empowerment, women filmed themselves. Videos present emotional stories of women emphasizing the importance of being proactive about one's health. For example, Shannon, a young woman with HPV, discusses coming to terms with her infection. She states, "as women, our bodies are so fragile and we need to take care of them." Her description of women's bodies contributes to traditional notions of women's bodies as fragile and susceptible. As a result, she took action; she talked to her friends, family, and doctors, and now feels better, healthy, and empowered. Shannon encourages other women to take similar preventative measures and be proactive about seeing the doctor and getting vaccinated.

Like DTC advertisements in the "I Chose" campaign, the Gardasil website similarly purports the frame of women's empowerment. Once again, this frame focuses on choice and the empowerment stemming from vaccinating. Another video clearly discusses the empowerment a young woman experienced after vaccinating, an experience 
she was initially afraid of. She states, "I got the shot. After it was done, I had this huge sense of relief. I was so glad that I had done it. Because, I really felt empowered...I wouldn't change it for the world." This first-hand account provides a human-side to the story; depicting the initial fear followed by the empowerment she experienced after vaccinated with Gardasil. Like DTC advertisements, the most positive and empowering aspects were emphasized while the negatives were minimized. Additionally, these stories link feminist values to the vaccine. Such stories, told through the point of view of women, further illustrate how Merck discursively uses "girl-power" as a way to frame the vaccine as empowering to women.

Additional interactive options include a slideshow, information on creating events to "get the word out about HPV, cervical cancer, and genital warts" and options to "have some fun." Additionally, the website presents opportunities to download computer wallpapers, screensavers, icons for messaging with friends, and t-shirts designs. These products display the "I chose" slogan and appear to be directed toward a female audience. Products such as these encourage young women to publicly display their 'choice' to vaccine. While public proclamation of choice and freedom from cervical cancer can be empowering, it nonetheless provides another opportunity for product promotion. In fact, women are encouraged to "help spread the word about HPV disease." Feminist consumerism is again utilized, though it is young women who contribute to the cycle.

Compared to the DTC advertisements, the Gardasil website conveys similar frames via new mechanisms. Videos present nuanced methods of marketing products. The theme of proactive HPV prevention echoes the most recent DTC advertisements 
which focus on HPV rather than a specific cancer. However, the analysis indicates that while these messages are more gender-neutral, there is still an underlying focus on women in relationship to the vaccine. Additionally, the women's empowerment frame caters specifically to women. Like the DTC advertisements in the "I chose" campaign, the interactive features on the website employ a theme of choice, linking the vaccine to empowerment. Utilizing DIY themes and "girl-power," the vaccine is seen as a gateway to maintaining health. In sum, the focus on women's empowerment and the lack of information pertaining to men illustrates that Merck continues to connect the vaccine primarily to women even after it has been approved for men.

Next I turn to the other primary stakeholders that were influential in framing Gardasil. I describe these organizations and the frames that they conveyed. First I discuss Planned Parenthood, followed by the National Cancer Institute, the Center for Disease Control and Prevention, Family Research Council, and Focus on the Family.

\section{Planned Parenthood}

Planned Parenthood is the leading organization in sexual and reproductive health care. This non-profit provides a variety of reproductive health services, ranging from breast exams, contraception, STI treatments, to men's sexual health. Given their extensive work in preventing STIs and promoting sexual health, Planned Parenthood supports the HPV vaccine.

Planned Parenthood provides in-depth information about HPV and the HPV vaccine. A search on their website garners substantial information about the vaccine 
including commonly asked questions and fact sheets. Planned Parenthood details the various outcomes of HPV, including those associated with men. While their website recommends the vaccine for routine vaccination in girls, it stops short of that recommendation for boys. ${ }^{19}$

While there is no one official document about the vaccine, there are various information sheets from regional Planned Parenthoods. For example, the fact sheet Preventing Cervical Cancer in Minnesota, applauds the vaccine as "A revolution in cancer prevention." While different HPV-related cancers are listed, this document primarily focuses on cervical cancer. Planned Parenthood also details their commitment to reducing cervical cancer by routine screening and ensuring access to Gardasil. They expand this prevention to males when they state,

"Planned Parenthood also works to ensure that women, men and teens are aware of HPV and its relationship to cervical cancer; advocates for comprehensive sexual education, and provides ten intensive age-appropriate, culturally-relevant and evidence-based education programs."

Planned Parenthood employs the frame proactive HPV prevention. They openly addresses HPV as a sexually transmitted infection as opposed to Merck. However, while other HPV related diseases were discussed, including HPV cancers in men, the primary focus remains on cervical cancer and women, therefore echoing Merck. In sum, Planned Parenthood has supported the vaccine and Merck's efforts to reduce cervical cancer.

\footnotetext{
${ }^{19}$ The Advisory Committee on Immunization Practices recommends Gardasil for routine vaccination for boys and girls.
} 


\section{National Cancer Institute}

The National Cancer Institute (NCI) is a leading organization for cancer research. It is part of the National Institute of Health, located within the Department of Health and Human Services. This organization supports and conducts cancer research and training

and disseminates information. Additionally, they collaborate with other cancer prevention organizations to provide grants for cancer research. Given their public health stance and goal of reducing cancer, this organization upholds the vaccine as an effective way to prevent HPV and cancer.

Overall, the NCI has been a consistent supporter of the HPV vaccine. Their website provides an in-depth examination of the vaccine, the cancers it prevents, and its overall health and safety. In an official statement regarding the FDA's approval of Gardasil for women, they state that the vaccine "opens a new era in cancer prevention. It has the potential to save women's lives, as well as to reduce health disparities in the United States and around the world." Thus, NCI endorsed the vaccine and its cancerreducing potential.

NCI provides in-depth information about the HPV vaccine. Their website offers numerous pages that describe HPV, HPV-related cancers, the vaccine, and developing research. Given their focus on cancer research, the NCI website surpasses the basic information of HPV that is common elsewhere. In fact, they provide a fact sheet, slideshow, official statements, and other informational pages that offer a comprehensive examination of the vaccine. What is unique about NCI's presentation is their focus on research. They provide various links to relevant research, including clinical trials and 
studies examining vaccine efficacy. NCI summarizes the findings of these studies, making them more accessible to the public. Additionally, they define key terms, easing the reader's learning process. Overall, NCI comprehensively discusses all cancers that result from HPV. And following the Advisory Committee on Immunization Practices ruling, they too recommend the vaccine for males and females between the ages of nine and twenty-six.

Overall, the NCI framed the vaccine as proactive cancer prevention using a public health approach. They view Gardasil as a pivotal opportunity to decrease cancer worldwide and encourage vaccination for both males and females. NCI describes the vaccine as a principal method to prevent HPV and the cancers associated with it.

\section{Center for Disease Control and Prevention}

The Center for Disease Control and Prevention (CDC) is a government agency that works to promote public health and safety in the United States. Like the NCI, the CDC is located within the Department of Health and Human Serves. This organization prevents and responds to public health concerns and provides information to the public about health topics.

Given that HPV is highly contagious and the most common STI, the CDC offers thorough prevention and treatment information. On their website, the CDC provides numerous fact sheets including "Genital HPV Infection- Fact Sheet," "HPV and Men Fact Sheet," and "HPV Vaccine Information for Young Women Fact Sheet" among others. These informational documents provide an in-depth discussion about HPV and the 
vaccine. Additionally, it serves as a unique site for examining gender and sexuality. For example, the primary fact sheet about HPV is "Genital HPV Infection- Fact Sheet." The document depicts general information regarding HPV infection in men and women. An additional fact sheet, "HPV and Men Fact Sheet" is dedicated specifically to HPV infection in males. However, no fact sheet is exclusively for women, and thus implicitly constructs HPV infection in women as the norm and HPV infection in men as unique.

The "HPV and Men Fact Sheet" allocates considerable discussion to HPV in men, a population that has been overlooked in the media. Such information clearly illustrates that men are affected by HPV and the growing concern over HPV in men. Additionally, this page highlights the unequal burden of HPV in men who have sex with men (MSM), a population regularly omitted within the public discourse. However, the CDC fails to discuss the presence of HPV in women who have sex with women (WSW), a population that is also uniquely affected.

The CDC predominately portrays Gardasil as a vaccine for women. The primary fact sheet about the HPV vaccine is entitled, "HPV Vaccine Information for Young Women Fact Sheet." Clearly, this informative piece about vaccinating is specifically dedicated to women. Discussing the vaccine only in regards to women reinforces Gardasil as a vaccine only for women. These documents intricately connect the vaccine to women, reinforcing the original framing of the vaccine as a woman's responsibility.

Overall, the CDC framed the vaccine as proactive HPV prevention. Their website focuses on the HPV and conveys that Gardasil is available to both men and women. 
While the CDC does describe HPV-related diseases, they frame health problems as a result of HPV infection, rather than a gender-specific cancer.

\section{Family Research Council}

The Family Research Council (FRC) places "marriage and family as the foundation of civilization, the seedbed of virtue, and the wellspring of society." This organization conducts policy research, education, and other grassroots projects guided by Judeo-Christian beliefs. FRC interacts with policymakers and maintains a presence in the media and government.

The FRC offers two primary statements about the HPV vaccine on their website, "Gardasil: What Every Parent Should Know about the New HPV Vaccine" and "The HPV Vaccine and School Mandates: Questions and Answers." These documents discuss HPV, its related diseases, the vaccine, and their particular stance. The FRC supports Gardasil and seeks to ensure its accessibility. However, they are critical of an HPV vaccine mandate as they believe such a decision stems from the home. Thus, mandating a vaccine that prevents a sexually transmitted infection is unnecessary as infection can be averted through behavior change, such as abstinence and faithfulness within marriage.

When discussing whether or not Gardasil is causally linked to increased sexual activity, the FRC states, "not necessarily." They assert that if it is "handled properly," the HPV vaccine does not pose a risk to individuals. In fact, the FRC identifies the vaccine as an important learning opportunity, as it "provides a unique opportunity to reinforce a risk 
avoidance or abstinence message as the best form of prevention against HPV infection, as well as many other negative outcomes associated with adolescent sexual activity." In this case, the FRC encourages parents to talk to their children about STIs to mitigate the potential dangers of the vaccine.

Overall, these fact sheets focus predominately on vaccinating women. While cervical cancer is of primary interest, the fact sheet diverges when discussing HPV. For instance, when describing HPV infection it states, "HPV may result from involuntary sexual activity...if a woman marries someone who is carrying HPV." This example illustrates that a woman can be infected with HPV by her spouse, presumably a male. However, they later state, "Genital HPV infections are currently very prevalent in sexually active men, women, and adolescents." Therefore, FRC depicts conflicting information. The first example points out women's susceptibility to HPV, while the latter provides a more accurate portrayal. Overall, while the fact sheets state that both men and women can be infected with HPV, examples, visuals, and other statements focus primarily on women.

Furthermore, one fact sheet directly addresses vaccinating males and offers two primary reasons for such. First, vaccinating boys "indirectly benefits women" as men carry the HPV types that cause cervical cancer. Second, the vaccine can provide protection for men by preventing genital warts. This description, while accurate, does not account for HPV-related diseases in men, some of which the vaccine is approved to prevent. Overall, while the FRC does acknowledge both men and women as affected by $\mathrm{HPV}$, their overall message concerns women. 
In sum, the FRC framed the vaccine as an option. The FRC remains critical of vaccinating girls to prevent a sexually transmitted disease, which they believe can send a dangerous message. However, they applaud its potential to decrease HPV and HPV related cancers. This organization relies on both conservative Christian values and scientific data to support its claim. At the end of "What Every Parent Should Know About the HPV Vaccine," the Family Research Council lists Focus on the Family as a key organization to attain information about the vaccine.

\section{Focus on the Family}

The Christian organization, Focus on the Family (FF) is a "global Christian ministry dedicated to helping families thrive." FF conducts regular radio broadcasts, conferences, and interactive forums while also producing magazines and books. This group is known to be a leading voice in conservative and Christian matters.

The FF website provides three primary documents about the HPV vaccine. These include, "The HPV Vaccine: What Parents Need to Know," “Talking to your Children about the HPV Vaccine," and "Focus on the Family Position Statement: Human Papillomavirus." Based upon these documents, FF supports the protection Gardasil offers and recognizes its potential to "save the lives of millions of women across the globe." In their official position, FF states, "Focus on the Family supports widespread (universal) availability of HPV vaccines but opposes mandatory HPV vaccinations for entry to public school" (original emphasis). Like the FRC, FF believes that decisions to vaccinate should reside in the hands of parents. 
FF provides a critical portrayal of the vaccine, highlighting various aspects about HPV and STIs. The following are some examples of what FF wants parents to consider:

No vaccine is $100 \%$ effective against disease. The types of the virus that these vaccines protect against are the cause of most but not all cases of cervical cancer. The possibility of HPV infection resulting from sexual assault, including date rape. The HPV vaccines do not protect against other STIs or prevent pregnancy. Young people may marry someone who is infected with the virus thus putting themselves as risk for infection. The HPV vaccines do not, in any circumstance, negate or substitute the best health message of sexual abstinence until marriage and sexual faithfulness after marriage. ${ }^{20}$

These considerations for parents provide a critical stance of the vaccine. The latter statement highlights FF's Christian values through conceptualizing sexuality and the vaccine in a religious context. In fact, FF argues that the rampant amount of HPV highlights a need to return to God's plan for sexuality, a belief which upholds abstinence and a faithful marriage as the best methods to prevent HPV. Like the FRC, they state that the HPV vaccine presents an opportunity, or "conversation starter" to begin talking to children about sexuality and relationships.

In sum, FF frames the vaccine as an option. While they commend its potential to reduce HPV and cancer, they remain critical of the vaccine and potential vaccine mandates. As opposed to Merck, FF does not seek to avoid the sexual nature of the vaccine, but rather illustrates their larger concerns over preventing a STI. Also, FF primarily focuses on HPV and cervical cancer, echoing Gardasil as a woman's vaccine. However, these documents appear to be outdated, which may explain the lack of information regarding HPV in men.

\footnotetext{
${ }^{20}$ Focus on the Family is referring to two vaccines: Gardasil and Ceravix, the latter of which is excluded from analysis.
} 


\section{Conclusion}

This chapter has presented the key organizations and their framing of the vaccine in the public discourse. Merck has been the most successful stakeholder given its highly publicized DTC advertising campaigns and interactive, accessible website. Other organizations were successful and present similar and divergent approaches to framing the vaccine. In the next chapter, I turn to the how the vaccine was framed in news media, specifically examining newspaper articles and magazine articles. Many frames in the next chapter echo the frames purported by stakeholder groups described above. The degree to which these frames parallel each other are indicative of their success at dominating the discourse and attaining coverage of their frame(s). 


\section{CHAPTER V: NEWS MEDIA FINDINGS}

This chapter details how Gardasil was framed in the news media, specifically newspapers and magazines. Data analysis indicates that the framing of the vaccine shifted in 2008, three years after Gardasil was approved for women and one year prior to the approval of Gardasil in males. In order to best capture these frames over time, I discuss the findings in two time periods. The first time period, 2005 to 2008, details the initial media coverage of Gardasil. These frames center on cervical cancer, HPV, and women. In 2008, the media expanded its discourse to include males in the on-going discussion about Gardasil and HPV. Given this change, I consider 2008 to be a significant shift in framing. First, I discuss frames in newspapers and magazines between 2005 and 2008 followed by the frames employed between 2008 and 2011. I describe frames that are unique to each media outlet in the two sets of time. Throughout this discussion, I point out how stakeholders influenced these frames. Please see Appendix E for a map of the frames, their sources, and the media outlet in which they were found.

\section{5-2008: Making the Cervical Cancer Connection}

The initial framing of Gardasil focused primarily on women and cervical cancer. While it is unsurprising that women were a primary focus during the time that Gardasil was only approved for them, it nonetheless illustrates how gender was incorporated in media frames. During this time period, Gardasil was heralded a major breakthrough in women's health as newspapers and magazines framed the vaccine as unprecedented in the ongoing fight against cancer. However, these texts diverged when discussing the 
nature of HPV. Newspaper articles focused primarily on cervical cancer, constituting it a major public health concern. In contrast, magazine articles thoroughly described HPV and its link to cervical cancer. These depictions constructed HPV and cervical cancer as ubiquitous and unavoidable. In response, the vaccine was presented as the primary solution to a seemingly inevitable health problem. Overall, both newspapers and magazines entrenched the dangers of HPV and cervical cancer while celebrating the vaccine.

Newspapers

Newspapers heralded Gardasil a major breakthrough in women's health. Doctors, politicians, parents, and other organizations celebrated the vaccine and its potential to decrease cervical cancer. Additionally, Gardasil was framed as proactive cervical cancer prevention. In this frame, women were encouraged to vaccinate in order to avoid cervical cancer. This frame entrenched the risk associated with cervical cancer. The final frame, which was predominately driven by conservative Christian organizations, is promiscuity vaccine which constructed Gardasil as dangerous to young girls. These frames illustrate how Gardasil was first framed in the media via newspapers.

Breakthrough in Women's Health. Prior to and after the FDA's approval of Gardasil, newspaper articles celebrated the vaccine as an unprecedented event in preventing cervical cancer. Gardasil was deemed a "miracle" and "gift" to women's health as it was the "first ever anti-cancer vaccine." Similarly, the National Cancer Institute stated, "the development of [Gardasil] is a product of extraordinary work." In turn, newspaper articles constituted Gardasil an important aspect of women's healthcare. 
A newspaper article published before Gardasil was approved for women stated, "A longsought dream - a vaccine to eradicate most cases of deadly cervical cancer worldwidemoved closer to realization with Merck's announcement that short-term studies have shown its drug to be 100 percent effective in combating the virus that causes the disease." Many articles, like this one, described the great potential Gardasil had to offer. In this case, the media garnered anticipation for the vaccine, framing it as an important form of prevention for women.

Furthermore, this frame sustained considerable coverage after the FDA approved Gardasil for women. In fact, the majority of articles (70\%) during this time reported that the FDA approved Gardasil for women. Simultaneously, Gardasil was constructed as a breakthrough in women's health. The CEO of Merck asserted that Gardasil is a "lifesaving scientific advancement." Similarly, a Planned Parenthood representative stated the importance of Gardasil describing it as "one more vaccine to add to our refrigerator." This frame celebrated the vaccine and created Gardasil as principally important to women and women's health care. For instance, 93 percent of articles discussed vaccinating women specifically. The celebratory language paved the way for its acceptance as an important vaccine for women. Overall, Merck, medical professionals, Planned Parenthood, and the National Cancer Institute were dominant sources that influenced this particular frame.

Proactive Cervical Cancer Prevention. The frame of proactive cervical cancer prevention creates the distinct connection between the vaccine and cervical cancer. Since the onset of media coverage on Gardasil, the vaccine has been framed specifically as 
protection against cervical cancer as opposed to HPV or HPV-related cancers. In fact, more articles during this time referred to Gardasil as a "cervical cancer vaccine" (33\%) instead of "HPV vaccine" (18\%). Calling Gardasil a "cervical cancer vaccine" connects it specifically to women. While there are many numerous HPV-linked cancers in men and women, the connection to cervical cancer has been especially salient. In fact, every article during this time period connected the vaccine to cervical cancer, while other cancers were rarely discussed. In turn, Gardasil becomes principally important to women. In fact, only one article during this time discussed the potential of vaccinating men with Gardasil.

The focus on cervical cancer was ubiquitous in newspaper coverage of Gardasil. In the days following FDA approval of Gardasil, one article stated, "The FDA... approved the first vaccine designed to prevent cancer." Additionally, an OB-GYN applauded the vaccine and stated, "Have we ever had a vaccine to prevent cancer? I don't think we have.” Doctors were frequently used as sources and emphasized the need to prevent cervical cancer. For example, a pediatrician stated, "This is for cancer, regardless of how you catch the virus. It we had a vaccine for leukemia, wouldn't you take that vaccine?" The cervical cancer connection was made in 100 percent of the articles during this time. Interestingly, newspapers transformed cervical cancer from a rare disease to a common and potentially fatal problem that can affect any woman. Furthermore, cervical cancer was constructed as something that happens to girls that is out of their control. Framing the vaccine as cervical cancer prevention concomitantly positions the female body at constant risk of cancer and in need of Gardasil. In turn, Gardasil is offered as a primary and important solution to prevent cervical cancer in women. 
This frame directly parallels the marketing of Gardasil in Merck's "One Less" campaign and points to the pervasiveness of the proactive cervical cancer prevention that stems from Merck. Similar to the DTC advertisements, newspaper coverage omitted discussing HPV and the sexual connotations of it. For instance, 50 percent of the articles during this time did not explain how HPV is spread. Arguably, avoidance of sexuality positions Gardasil as more appealing for parents when vaccinating their daughters. These findings are in line with Epstein and Huff (2010) who illustrate that Merck avoided the sexual connotations of the vaccine suggesting that the focus on cervical cancer is purposive.

Promiscuity Vaccine. Concerns emerged over a possible connection between Gardasil and premature sexual activity. This particular frame-promoted by socially conservative organizations like Focus on the Family and the Family Research Councilconstructed Gardasil as dangerous to girls. These groups argued that preventing a STI could give girls a false sense of protection that could lead to premature, casual sex. One article stated, "conservative groups including the Family Research Council have already raised concerns that giving a sex-related vaccine to young people might encourage them to have early sex." Similar state-level organizations purported analogous frames. For example, a representative from the Oklahoma Family Policy Council stated, "If we're not careful, young women will interpret this wonderful medical news as their own invincible protection against all STDs and as a green light for more sexual activity." Overall, this frame constructed Gardasil as dangerous to young women. This was a common facet of 
media coverage as 40 percent of the articles during this time connected Gardasil to premature sexual activity or promiscuity.

Furthermore, newspaper articles discussed the potential of Gardasil to undermine abstinence and abstinence-only programs. The Family Research Council, an influential organization in constructing this frame, stated in an editorial, "The scientific advance that the HPV vaccine represents should not distract us from the primary truth that abstinence until marriage and fidelity within marriage constitute the single best formula for sexual health." In this case, the FRC advocates for behavior change, such as abstinence, as the best method to maintain good sexual health. This frame was further reinforced as discussions about state-level vaccine mandates emerged. Those in opposition argued that a HPV-vaccine mandate would give tacit approval for sex. One article stated, "social conservatives worried the vaccine law would violate parental rights and encourage promiscuity by lowering inhibitions against sexual activity," a message supported by Focus on the Family. One newspaper stated, "HPV is communicable but hardly contagious... you don't get it simply from breathing infected air." This reinforces the sexual natural of HPV, making Gardasil problematic and dangerous to girls. Findings from the previous chapter illustrate a similar theme; the Family Research Council and Focus on the Family criticized the vaccine and sought to inform parents of similar concerns.

The promiscuity vaccine is a counter frame; it publicly problematized Gardasil and contrasted dominant frames produced by Merck. Focus on the Family, the Family Research Council, and other local conservative organizations were successful in gaining 
coverage of their frame. Furthermore, findings from the previous chapter indicate that the both of these groups were forthright with their criticisms with the vaccine. However, newspapers appear to sensationalize the perceived connection between Gardasil and increased sexual activity. Therefore, the findings in the news media do not completely align with how they portray the vaccine in official statements on their website. However, the messages illustrate the contentious relationship between sexuality, girlhood, and innocence.

Magazines

Women's magazines most often discussed HPV and the vaccine in the form of a blurb or brief synopsis. These blurbs were predominately located in regular sections that report on health, medicine, or the body. Overall, magazine frames entrenched risk associated with HPV and cervical cancer, while emphasizing the urgency for women to vaccinate. The focus on women was salient; women's magazines readily discussed the topic while similar stories were absent from men's magazines. The predominant frame in women's magazines during this time is proactive prevention. This frame constructed HPV and cervical cancer as dangerous. First I discuss how adult women's magazines presented cervical cancer as a major concern while young women's magazines framed HPV and cervical cancer as dangerous. Lastly, I discuss the general lack of coverage in men's magazines.

Proactive Cervical Cancer Prevention. Adult women's magazines emphasized the connection between Gardasil and cervical cancer. In fact, Gardasil was portrayed as the primary way to prevent cervical cancer in young girls and women. A blurb in 2005 
discussed the potential of a "new cervical cancer vaccine." It states, "Can you imagine if we could drastically reduce the incidence of cervical cancer for the next generation of women?" Thus, even prior to FDA approval, the vaccine's connection to cervical cancer was routine.

Articles in adult women's magazines discussed the potential of preventing cervical cancer in young girls. As this magazine speaks to mothers, vaccinating daughters was a common focus. One doctor states, "Like it or not, most girls will engage in sexual activity in their teens. So getting the vaccine at this age will help protect her from developing cervical cancer, which occurs in approximately 10,000 women a year" which recognizes the link to sexual activity yet reinforces the cervical cancer connection. The connection to cervical cancer was common and frequently reinforced. For instance, 75 percent of magazine articles stated the connection between HPV and cervical cancer. Of these articles, cervical cancer was often the only HPV-associated cancer mentioned. For instance, one magazine stated, "Gardasil prevented 100 percent of high-grade cervical precancers and noninvasive cancers caused by two types of human papillomavirus (HPV) linked to cervical cancer.” These articles emphasized that Gardasil protects against cervical cancer which they framed as pervasive and fatal. Magazines also used vignettes featuring adult women inflicted with cervical cancer. One story in particular discussed a woman's experience of learning she had cervical cancer. She explained,

More tests confirmed my worst fear: I had cancer cells on my cervix. Turns out, I had contracted one HPV type that triggers warts and two others linked to cancer. I was terrified. I honestly thought I was going to die, even though the cancer was in an early stage. 
This story underscores the dangers associated with cervical cancer as the young woman described her diagnosis as life-threatening. This personal account creates cervical cancer as a problem that must be prevented though vaccination. Overall, the focus on cervical cancer framed it to be problematic and dangerous. In turn, Gardasil is presented as the primary solution to avoid the cervical cancer.

Proactive HPV Prevention. This frame is similar to the previous frame though it diverges to focus on HPV rather than exclusively focusing on cervical cancer. These articles framed HPV as unavoidable and as affecting most women at some point in their lives. This frame was most common in Cosmopolitan, a young women's magazine that regularly discusses issues related to sexual health. This frame highlights the risk and dangers associated with HPV. One article states that HPV is an "endemic among female college students." Another article engaged its female audience stating, "Think about your group of girl-friends. More than half of you probably now have HPV or have had the virus." This message elicits a sense of fear, conveying that the reader may already be infected with HPV. Similarly, the subheading of another article reads, "HPV can cause warts and may lead to cancer. And are you ready for this? There's a good chance you already have it." Thus, readers are forced to see their bodies as susceptible or infected with HPV. These articles frame HPV as an unavoidable, silent infection that affects most women.

The frame of proactive HPV prevention constructs Gardasil to be an essential part of maintaining good sexual health and preventing HPV. In fact, these articles positioned Gardasil next to the Pap smear, arguably one of the greatest advancements in women's 
sexual health. In turn, Gardasil is framed as principally important to women, their health, and their bodies. Like the moral responsibility that is imposed upon women to get their regular pap smear, Gardasil is presented as important and a primary part of women's health care.

Men's Magazines. During this time, only one article in men's magazines discussed HPV and the vaccine. The article, "Defend Your Manhood" discussed HPV as one of many problems that can affect men's reproductive health. This article focuses primarily on HPV, though it did reference the potential of the vaccine in men. However, Gardasil was not yet approved for men at the time of this article. The lack of coverage in men's magazines and the frequent exposure in women's magazines implies that HPV primarily affects women and that Gardasil is for women.

\section{8-2011: Choice, Empowerment, and a New Vaccine for Men}

In mid-2008, significant changes occurred in the framing of Gardasil. As the FDA approached approving Gardasil for men, newspapers started to discuss vaccinating this new demographic as a new method to prevent cervical cancer in women and HPV in men. While the topic of vaccinating men garnered significant coverage during this time, it was not to the same extent as women. In fact, women and cervical cancer continued to be a primary topic of discussion in the news media even after Gardasil was approved for men. In this section, I also discuss the portrayal of the vaccine in both women's and men's magazines. Women's magazines frequently reported on the vaccine and its role in preventing cervical cancer and HPV. Additionally, I detail a limited discussion of HPV in 
men's magazines during this time. The following outlines the frames in both newspapers and magazines and illustrates how Gardasil was constructed during this later time period. Newspapers

The topic of vaccinating men gained media coverage in newspapers starting in mid-2008. Arguments about vaccinating men were mixed. The most common argument asserted that vaccinating men could provide a necessary form of protection for women, an argument that is encompassed in the frame protecting women. Others advocated for the use of the HPV vaccine in men to prevent HPV and other HPV-related diseases in this population. Overall, women remained a key facet of these frames and were regularly encouraged to vaccinate as part of the frame proactive prevention.

Protecting Women. Newspapers discussed vaccinating men as a new avenue to decrease cervical cancer in women. Implicit in this frame is herd immunization, or vaccinating the majority of the population to provide universal protection. Vaccinating men could slow the spread of HPV and in turn, HPV-related cancers. However, vaccinating men was presented in the media as a new method of protecting women. For instance, when articles did discuss vaccinating men, 70 percent emphasized the protection it could grant women. While some articles described this method as a "favored new strategy in preventing the spread of the virus to girls," the majority of articles framed men as granting protection to women. For example, a mother who vaccinated her 11 year-old son stated, "I think [Gardasil] will protect him and protect his wife in the future. I don't want to see him when he's 35 or 40 have a wife die of cancer." In this case, vaccinating provides protection for her son and his son's future wife. This example 
illustrates how the media utilized emotion to describe the importance of vaccinating boys as a way to protect women. Additionally, a professor of pediatrics described expanding the vaccine to a new population saying, "For boys, you have to make several arguments. Part of it is an altruistic argument. I think it's persuasive, but it's more complex." Vaccinating boys became a new strategy in the fight against HPV and cervical cancer. This frame implicates boys as protectors of women, illustrating how traditional gender norms are intricately tied to this argument.

Additionally, this frame depicts a broader story of how HPV is transmitted between partners. Men are seen as both the infector of HPV while simultaneously part of the solution. While they are framed as carrying and spreading HPV, they appear to be unaffected by it. The construction of masculinity supports Connell's (1995) concept of hegemonic masculinity that emphasizes men's strength and able-bodies. A director of immunizations in El Paso illustrates the connection to hegemonic masculinity when he stated "guys need to realize that women can't get it without us. We are the ones who transfer it to women." In this case, men's bodies carry HPV, though appear to be unaffected by it which in turn ignores men's sexual health. Concurrently, women are framed as susceptible and passive recipients, experiencing the most negative health outcomes. A gynecologist explained this relationship,

Boys are should get the shot because they are the ones spreading the virus to girls...they are like silent carriers of the virus. The virus can stay in their systems and not necessarily affect them, but as soon as they have sex, it gets transmitted into the girl and spreads to many other people.

This statement upholds men as carriers of HPV while simultaneously reaffirming that HPV affects women. Furthermore, Planned Parenthood upheld a similar framework 
stating, "In order for us to stem the tide of HPV infection, the most hopeful remedy of course is to have both young girls and young boys vaccinated, because girls and boys give and get HPV from one another.” Here, transmission of HPV is between boys and girls, a heteronormative approach that ignores HPV transmission between same-sex partners. In fact, most articles during this time discussed HPV transmission between heterosexual partners. Moreover, while these articles recognize that HPV does affect men, one-third of the articles do not indicate that both men and women can be affected by $\mathrm{HPV}$, underscoring HPV as primarily affecting women.

Proactive HPV Prevention. Another dominant frame during this time is proactive $H P V$ prevention. In a rhetorical reversal from the first time period, Gardasil is framed as a vaccine to prevent HPV as opposed to cervical cancer. This frame includes preventing HPV in both men and women. The use of "HPV" is more gender-neutral. Although vaccinating men was perceived as a solution to prevent cervical cancer, many articles discussed the potential of protecting men from HPV. One newspaper stated, "Gardasil's manufacturer Merck plans to ask for federal permission to start offering the shots to boys, too, to protect them from genital warts and penile and anal cancer." Similarly, a Merck representative and lead researcher stated, "This is really, really exciting, promising news in terms of what the future means for preventing these types of cancers in men." Gardasil presents a new potential for improving men's health and preventing HPV-related cancers in men. In fact, more articles in this time period discussed HPV-related cancers in men. For instance, 51 percent of these articles stated at least one HPV-caused cancer in men compared to only 14 percent while Gardasil was only available to women. While this is a 
substantial increase, it is important to note that half of the articles still do not mention HPV-related cancers in men.

While this frame prioritized men's health, not all messages upheld the vaccine as important to men. For instance, many articles constructed vaccinating men as optional or necessitating a cost-benefit analysis. The Family Research Council stated, "The boys of America are not facing an epidemic of genital warts." Another article described the indirect and direct benefits of vaccinating men though questioned its cost-effectiveness. Similarly, another article stated, "Merck may find it difficult to persuade boys to have shots for an uncomfortable but nonlife threatening problem that often resolves itself without medical intervention." This focus on genital warts obscures the seriousness of HPV-related cancers in men. Discussions about vaccinating men often encouraged readers to make a cost-benefit analysis as one article stated, "some experts said they are concerned that there is insufficient evidence about how long Gardasil's protection will last, whether serious side effects will emerge and whether the relatively modest benefit for boys are wroth even the small risks associated with any vaccine." While articles questioned the vaccine's use in men, the media encouraged women to vaccinate. In sum, every article in both time periods discussed at least one HPV-related cancer in females (as opposed to males), reaffirming the vaccine's connection to women.

Overall, women remained part of the dominant coverage even after the vaccine was approved for men. Women were encouraged to protect themselves and messages reinforced the need for parents to provide protection for their daughters. For instance, a state representative reinforced the need for parents to vaccinate young girls by saying, 
"This is a life-saving intervention for your daughters." Moreover, similar messages were conveyed by and for young women. A high school senior stated, "Even if you are scared of getting shots, having a needle put into you for two seconds is a much better idea than having HPV for the rest of your life or dying from cervical cancer." This example illustrates the importance of maintaining health, a key facet of biomedicalization (Clarke et al. 2003). In this case, health is advocated as part of avoiding cervical cancer or other HPV-related cancers. This first-account message presents a compelling and relatable argument for other young girls to follow suit. Furthermore, the connection between Gardasil and women was regularly reinforced. Dr. Gregory D. Zimet told the Washington Post that, "This vaccine principally benefits women's health," reinforcing that Gardasil is primarily for women. One newspaper article quoted The Lancet in the statement, "the vaccine's greatest potential clearly lies in the benefits it could confer on girls [with higher risk] of cervical cancer." Therefore, while Gardasil was approved for both women and men, women remain of primary interest in these frames.

\section{Magazines}

The Gardasil vaccine continued to be a common feature in women's magazines between 2008 and 2011. A dominant theme during this time is proactive HPV prevention which encouraged women to vaccinate to prevent HPV. Additionally, men's magazines started to discuss the vaccine, HPV, and HPV-related cancers. However, when men's magazines discussed Gardasil, they framed it as women's vaccine for men. The following discusses each of these frames found in women's and men's magazines. 


\section{Women's Magazines}

Proactive HPV Prevention. Similar to the initial framing of Gardasil in women's magazines, magazines encouraged women to vaccinate. In fact, magazines continued to construct Gardasil to be of great importance to women. Messages directed at young women applauded the vaccine and encouraged immediate vaccination. In the regular section on health, the author states "Absolutely" to the question of, "Should I definitely get the HPV vaccine?" Immediately after this positive response, the blurb details the protection that Gardasil guarantees. Another article states, "If you haven't gotten the shot yet...call your [gynecologist] and schedule it." Lastly, one full-page article was entitled, “This shot can save your life. Too many women aren't getting a cancer-preventing vaccine. Read on for four reasons to stop stalling now." This particular article lists various reasons for women to vaccinate which is meant to inform women about the potential benefits of the vaccine.

Likewise, adult women's magazines also encouraged vaccination by encouraging mothers to vaccinate their daughters. Blurbs in health sections frequently encouraged mothers to seek out information about the vaccine. One states, "ask your doctor about the HPV vaccine.” Similarly, messages encouraged women to vaccinate their daughters as early as possible. Thus, they reemphasized the dangers of HPV and cervical cancer and presented Gardasil as the solution, reinforcing the connection between HPV and cervical cancer ( 86 percent of articles). Moreover, this frame was largely driven by medical professionals as magazines most often utilized doctors as sources. 
Men's Magazines

Women's Vaccine for Men. Men's magazines did not discuss Gardasil to the extent of women's magazines. The lack of discourse within this outlet illustrates that it is still not of principal importance to men. The frame, women's vaccine for men, reinforces HPV as primarily a woman's infection that can also affect men. For instance, one article states, "Although the infection has been traditionally seen as a female concern-it is the leading cause of cervical cancer - a surprising new study suggests that men are at high risk of contracting the genital HPV infection during their lifetime." Additionally, in an article on oral cancer in men, the heading of the title states, "Doctors used to think this STD threatened only women. Then the men started dying." These articles reaffirms HPV as predominately affecting women while constructing men's infection as a caveat.

Similarly, Gardasil is framed as a vaccine previously available to women that is now accessible to men. While describing the vaccine in a Men's Health article, the author states that since many parents believe that HPV only affects women, they may not know to vaccinate their sons as well. Additionally, when discussing the vaccine in men, authors note that "a vaccine already exists for females," reinforcing the connection between Gardasil and women. While men's magazines do recognize HPV in men, the particular framing reinforces Gardasil as predominately for women. 


\section{Conclusion}

The frame analysis illustrates how the vaccine was portrayed in the mass media. The dominant frames were similar, indicating that media coverage of Gardasil aligned in many ways. Additionally, the frame analysis has identified how sources contribute to frames in the news media. Merck and medical professionals were most influential in driving these frames in the media. Furthermore, newspapers and magazines illustrate that the connection between Gardasil and women remains a salient aspect of frames throughout Gardasil's tenure in the media. In the next chapter, I revisit the empirical data and theoretical framework that informed this research. 


\section{CHAPTER VI: DISCUSSION AND CONCLUSION}

This study explored the framing of the HPV vaccine, Gardasil, in the media. In this chapter, I expound the findings as I revisit the relevant literature and theoretical base. First I examine the stakeholders who framed Gardasil. Next, I discuss the implications of how Gardasil was presented to the public through the news media. Additionally, I discuss how Gardasil upholds biomedicalization through two distinct processes. Overall, I discuss the ways in which Gardasil was gendered and sexualized in the media. This study echoes previous research on the portrayal of health in the media though offers new insight on the framing of the vaccine after Gardasil was approved for men. Lastly, I discuss the limitations of this particular research and future research avenues to explore.

\section{Stakeholder Influence in Framing}

The power analysis identifies the groups that influenced the media discourse of Gardasil. In the case of Gardasil, the medical elite (i.e. pharmaceutical industry) dominated media coverage of Gardasil. Merck, the pharmaceutical company that produced Gardasil, was most often used as a source in the news media. Additionally, professional medical sources, such as doctors, nurses, and national medical associations were frequently cited as sources. These findings support research that states elites are

allocated more influence in the framing process (Gitlin 1980; Ryan 1991; Carragee and Roefs 2004). In the case of Gardasil, the portrayal is largely driven by its own producers, illustrating how frames can be a reflection of elites and elite ideals. 
The Power of the Pharmaceutical Industry

Overall, Merck Pharmaceuticals was the most common source in news media representations of Gardasil. Official spokespersons, doctors, and researchers regularly spoke in support Gardasil. While other doctors quoted may not be financially compensated by Merck, many belong to medical associations (e.g. American Pediatric Association) that endorse the vaccine. The promotion of new medical products illustrates the interconnectedness and elusive elements of power that exist within the pharmaceutical industry. In this case, Merck's influence extends beyond traditional forms of marketing; pharmaceutical companies can affect the portrayal of their own medical products in mainstream news media. The privatization of pharmaceutical companies within a neoliberal age has facilitated the expansion of the pharmaceutical industry, especially in regards to marketing. The pervasive presence of Merck in the media speaks to the larger influence of the pharmaceutical industry and its power in the media. This analysis indicates that the pharmaceutical company was the primary source of information about HPV and the HPV vaccine. These findings support the incorporation of media hegemony when conducting a frame analysis. In short, frame analysis should not be divorced from recognizing the power-holders that produce frames.

Other stakeholder organizations maintained significant authority in framing Gardasil. Planned Parenthood, National Cancer Institute, and the Center for Disease Control were successful at getting their preferred frames to the forefront of media 
coverage. However, these groups largely echoed the frames promoted by Merck which explains why media frames within diverse outlets converged.

Framing research posits that opposing sources are given less coverage in the media (Gitlin 1980; Ryan 1991; Carragee and Roefs 2004). While most stakeholders echoed Merck's dominant frames, two key organizations gained considerable coverage of their counter frame (a frame in opposition to the dominant frame). The Family Research Council and Focus on the Family opposed Merck's dominant frames by presenting a critical portrayal of Gardasil guided by religion and conservative politics. This frame was largely sensationalized and entrenched with controversy. This illustrates that counter frames did gain coverage within the dominant discourse of Gardasil. However, it was not to the same extent as the coverage Merck received which supports research that opposing sources are given less influence in the framing process compared to dominant sources (Carragee and Roefs 2004; Gitlin 1980; Ryan 1991).

Furthermore, counter frames were deeply entrenched with political, moral, and religious undertones. The concerns over Gardasil illustrate the general fear of girls' sexuality and the intense social and cultural expectations of appropriate femininity. Interestingly, the same concern was not upheld during discussions about vaccinating men. This double standard speaks to our cultural beliefs about appropriate femininity and masculinity and the double standard that exists for men and women (Carpenter and Casper 2009). 


\section{Media Coverage of Gardasil}

The coverage of Gardasil in newspapers and magazines aligns in many ways. For instance, the focus on women was pervasive in both outlets; newspapers and magazines regularly discussed and encouraged women's vaccination as the primary way to avoid cervical cancer. However, these texts diverged when discussing HPV. Newspapers often dismissed the sexual connotations of HPV while magazines depicted the infection and its connection to various forms of cancer. Women's magazines regularly described sexual health and its intersections with gender, making HPV or cervical cancer a likely topic (Clarke 2009). In contrast, newspapers are meant for a general audience, which may explain why it avoided sexualized aspects of HPV and the vaccine. Despite these differences, both newspapers and magazines reinforced the vaccine as primarily for women and an important part of women's health care.

Newspaper coverage of Gardasil significantly changed as discussions about men emerged. Coverage of men's vaccination increased with the FDA's approval of Gardasil for men. However, the frame analysis indicates that newspapers continued to focus primarily on women. In fact, very few articles were dedicated specifically to men's vaccination, as opposed to the exclusive coverage of women. Similarly, magazine coverage of Gardasil remained primarily focused on women. While men's magazines engaged with the topic of HPV in men and the potential of Gardasil in this population, these discussions reinforced the vaccine's connection to women. Next, I explore gender and sexuality more in-depth to illustrate how newspapers and magazines utilized these dimensions in framing Gardasil. 


\section{Branding a Feminine Vaccine}

Overall, news media coverage of Gardasil feminized the vaccine (Habel et al. 2009; Carpenter and Casper 2009). While the focus on women may be appropriate given the population it sought to initally inoculate, my analysis found that coverage of Gardasil continued to focus on women even after Gardasil was approved for men. When discussions about men did emerge, it was not to the same extent as the focus on women. Overall, my findings illustrate that Gardasil was branded a cervical cancer vaccine, and therefore, for women.

This research found that media outlets specifically focus on cervical cancer as the primary disease of concern. Like Habel et al. (2009), I too found that Gardasil was often referred to as a "cervical cancer vaccine." The focus on cervical cancer was ubiquitous during the time Gardasil was only available to women. Even after the FDA approved Gardasil for men, the focus on cervical cancer and women sustained. For instance, arguments for vaccinating men still sought to reduce cervical cancer rates. Like Mamo et al. (2010), I found that cervical cancer was constructed as the public health problem and thus, unavoidable. Framing cervical cancer as affecting any woman during her lifetime exaggerates the risk and danger of cervical cancer.

Framing the vaccine as primarily for women constructed HPV to be a health problem that only affects women, a largely inaccurate view. In turn, the infection of HPV was constructed as predominately affecting women. While later discussions about men did emerge, the feminization of Gardasil remained part of media coverage. Moreover, the focus on women reflects a broader cultural assumption that women are more susceptible 
to disease, but also responsible for managing sexual health. This continued well after the time Gardasil was available to men.

Ultimately, by associating femininity with the vaccine, I argue that the media framed the vaccine as an "accomplishment of gender" (West and Zimmerman 1987). DTC advertisements and the news media framed Gardasil as important and empowering to the lives of women. Branding Gardasil as feminine creates the vaccine to be another way to act out femininity. Thus, the discourse constructed Gardasil as an accomplishment of femininity and another way to "do gender" (West and Zimmerman 1987). While there are many routine accomplishments of gender, framing a vaccine as a form of gender expression manipulates gender in order to promote, and ultimately, sell a product. This highlights the power of the pharmaceutical industry and the importance of examining gender and health as interconnected.

\section{Hegemonic Masculinity}

The data speak to how men and masculinity are constructed in media representations of the HPV vaccine. In media frames, men were not allocated the same media attention or equal responsibility to vaccinate compared to women. This coverage largely upholds cultural ideologies of hegemonic masculinity (Connell 1995); men are seen as protectors, strong, and unaffected by HPV. In this section, I discuss how newspapers and magazines entrenched messages of hegemonic masculinity in framing the HPV vaccine.

In mid-2008, newspapers started to discuss HPV infection in males and the use of Gardasil to prevent it. Reasons for vaccinating men were two-fold. First, men were 
encouraged to vaccinate to prevent cervical cancer in women. This idea implies herd immunization, in which the majority of the population vaccinates in order to decrease the prevalence of HPV in the population, though frames it using traditional gender norms emphasizing men as protectors. This particular type of framing negates the presence of HPV in men and the need for preventative measures in this demographic. Additionally, it constructs the male body as carrying HPV, though unaffected by it. While newspaper coverage recognized the health benefits of vaccinating men, it was not to the same extent as the need to protect women. In fact, media messages reinforced HPV as primarily affecting women. Therefore, media coverage reinforced hegemonic masculinity by upholding men as protectors while emphasizing women's frailty.

In general, men's magazines are found to support hegemonic masculinity (Vigorito and Curry 1998). This form of masculinity upholds traditional masculinity, emphasizing men's strength and able-bodies (Connell 1995). Men's magazines rarely discussed HPV or the vaccine in men. In fact, coverage of HPV and other STI's in men was more often discussed in women's magazines than in men's. The topic of men's sexual health and specifically HPV in women's magazines allots maintenance for men's sexual health to women. This speaks to Clarke's (2009) study of the portrayal of sexual health in magazines. She found that women were allocated the responsibility to manage both men and women's sexual health. Similarly, the discourse conveys that vaccinating men is primarily in the hands of women (most often mothers). This reaffirms hegemonic masculinity by constituting the male body as unaffected by HPV and as unnecessary for medical intervention. 
The feminization of Gardasil further polarizes the vaccine from men. Connell (1995) points out that hegemonic masculinity is regularly reinforced by its opposite, emphasized femininity. Therefore, connecting Gardasil to femininity creates it in opposition to traditional masculinity. In turn, if Gardasil is primarily connected to femininity, then men's magazines that entrench hegemonic masculinity would be unlikely to frame it favorably to men as masculinity is regularly constructed in opposition to femininity. In turn, the vaccine might be perceived as fundamentally opposed to men and masculinity. For women, the vaccine's connection to femininity reaffirms its importance to them and their gender enactment.

The feminization of Gardasil has many implications for men. Overall, the media sidestepped HPV and HPV-related cancers in men. In turn, the majority of risks and negative health outcomes associated with HPV were largely often ignored in men. Media coverage that constructed HPV as primarily affecting women contributes to the ongoing invisibility of HPV and HPV-related cancers in men and the overall silence surrounding men's sexual health. In sum, magazines that predominately negated HPV in men and newspapers that constructed men as protectors of women largely upheld hegemonic masculinity.

\section{An (Un)Sexualized Vaccine}

The dominant framing of Gardasil avoided issues of sexuality that are associated with HPV and sexual activity. The focus on cancer and subsequent absence of HPV enabled Gardasil to be an anti-cancer vaccine. The focus cervical cancer diverts attention from the sexual nature of HPV. Like Braun and Phoun (2010), I found that in-depth 
information about HPV and the vaccine were often absent. By framing the vaccine in this way, Merck could evade potential controversy over preventing a STI. Despite efforts on behalf of Focus on the Family and the Family Research Council to expose the sexual nature of the vaccine, these frames did not sustain coverage. This speaks to the power behind framing; dominant frames produced by Merck were most common throughout media coverage of Gardasil while counter frames were not.

Furthermore, media coverage of Gardasil largely operated on heteronormative assumptions. Like Williams (1996), the discourse around Gardasil ignored HPV and HPV-related cancers in women who have sex with women (WSW), a population adversely affected by HPV. However, WSW were ignored in the media's portrayal of Gardasil. Framing Gardasil in this way unfortunately begs the question: are WSW even affected by HPV? Similar heteronormative assumptions are upheld when examining if and how the media covered men who have sex with men (MSM). Like Epstein and Huff (2010), I too saw a very brief discussion in the mass media regarding HPV in gay/bisexual men. In fact, only one newspaper article addressed the potential of Gardasil in this population. In short, I found a lack of coverage regarding HPV among same-sex partners. Ignoring a population that is adversely affected by HPV contributes to the ongoing invisibility of sexual minorities and their health. Epstein (2010) points out, "in order for the promise of medicine to reach this constituency, a largely invisible disease [anal cancer] must be brought into the open, and medical technologies that have been associated with women's bodies must be recoded as usable in men" (2010:61). In sum, 
media portrayal of the HPV vaccine "others" sexual minorities. In turn, more coverage and information about HPV in the mainstream would benefit this population.

\section{Gardasil as a Biomedical Vaccine}

This section reexamines the theoretical framework which has guided my research. In light of the data, biomedicalization helps explain the discourse and content of media frames of Gardasil. In turn, the findings present a nuanced look at how vaccines can be accounted for in the biomedicalization framework. In Chapter III, I outlined biomedicalization and explained two key processes that this research explored: (1) the focus on health, risk, and surveillance and (2) the transformations of information knowledge production, and distribution (Clarke et al. 2003). The following addresses Gardasil in these particular processes of biomedicalization.

Focus on Health, Risk, and Surveillance. Clarke and colleagues (2003) argue that health has become a moral responsibility reinforced through risk and self-surveillance. Media coverage of Gardasil illustrates a similar reality. For instance, the dangers of cervical cancer were especially salient within the "One Less" campaign which specifically constructed Gardasil as a vaccine against cervical cancer. In fact, cervical cancer was presented as a public health concern (Mamo et al. 2010) and as inevitable (Hilton et al. 2010; Abdelmutti and Hoffman-Goetz 2009, 2010). While cervical cancer is a rare disease, it was framed as potentially affecting any women who is not vaccinated. These messages of danger enforced the risks and exaggerated the potentiality of cervical cancer. 
The risk and moral responsibility placed on women encourages them to engage in self-surveillance. This speaks to Foucault's (1988) concept of "technologies of the self." In the case of Gardasil, the media illustrates the necessity of vaccinating with Gardasil and its important role in women's health. For instance, DTC advertisements showcase women making positive choices about their body. Similarly, magazines encouraged women to vaccinate by reminding them to immediately call their doctor. These examples illustrate the ubiquity of health discourse that calls on women to maintain their health through vaccinating. The presence of risk in the media illustrates how the moral obligation of health extends beyond the doctor's office and into our daily discourse. In the case of Gardasil, messages present a compelling argument because of the vaccine's connection to femininity. In turn, women must engage in self-surveillance in order to meet cultural requirements of health and femininity. The Gardasil vaccine illustrates the nuanced ways that surveillance extends into our daily lives as media discourse encouraged women to engage in self-governance through the veil of women's empowerment.

Overall, the Gardasil discourse presents health as a moral responsibility. In general, vaccines rely on people inoculating themselves in order to maintain health and avoid a disease or infection that could potentially affect them. Rose illustrates this when he states, "health, understood as an imperative, for the self and for others...has become a key element in contemporary ethical regimes" (Rose 2007: 23). Indeed, Gardasil is seen as a moral choice for women in meet health and feminine standards. Overall, Gardasil encourages women to make healthy choices, illustrating that one must "choose" health. In 
this case, discourse encouraged women to remain healthy to avoid painful experiences, such as cervical cancer. Women can actively and successful pursue health and normative gender by vaccinating with Gardasil.

Transformation of Information, Knowledge Production, and Distribution. The ubiquity of medical marketing and health information is best captured in biomedicalization (Clarke et al. 2003). Health and medical information is easily accessible and at times, unavoidable. The prevalence of information about Gardasil in DTC advertisements, magazines, newspapers, and on various organizations' websites illustrates this reality. My data speak to both the traditional forms of marketing (DTC advertisements) as well as the nuanced methods (interactive features on the Gardasil website). First, I discuss how my findings from DTC advertisements parallel other research and then describe the new ways companies promote their products.

Overall, the anatomy, message, and presentation of DTC advertisements of Gardasil echoes previous research (Woloshin et al. 2001; Bell et al. 2000; Roth 1996). Like other ads, the content of DTC advertisements of Gardasil was rather ambiguous. Advertisements for Gardasil focused primarily on cervical cancer and neglecting to discuss HPV. Indeed, research indicates that DTC advertisements often omit information or downplay particular aspects (Angell, 2004; Bell et al. 1999; Roth 1996; Wilkes et al. 2000; Woloshin et al. 2001). In the case of Gardasil, advertisements deemphasize HPV, arguably due to its connection to sexual activity. The visual anatomy of DTC advertisements of Gardasil parallels findings within the literature. For instance, advertisements allocate the majority of space to discuss the most positive aspects, such as 
girls proclaiming their decision to vaccinate. Likewise, the side effects were minimized by placing them in small font at the bottom of the advertisement. This is a common practice in DTC advertisements; benefits are broadcasted with large writing at the top and side effects are minimized by relegating them to the bottom of the page (Bell et al. 1999; Roth 1996). In this way, pharmaceutical companies allocate the majority of space to marketing.

Research indicates that DTC advertisements tend to reinforce gender stereotypes (Cline and Young 2004). While traditional gender norms were entrenched in Gardasil advertisements, these particular advertisements offer a nuanced gender enactment. For instance, advertisements displayed girl-power and subversive feminist ideals. However, these advertisements simultaneously constructed the female body as fragile and highly susceptible to disease. For instance, the pervasive focus on cervical cancer constructs any and every female body as susceptible to cancer which reinforces the female body fragile. This supports existing research that DTC advertisements often gender their discourse and reinforce stereotypes (Cline and Young, 2004; Kempner 2006; Mastin et al. 2007). In this case of Gardasil, messages utilized cultural notions of gender to market Gardasil as important to women.

Morgen (2002) notes that DTC advertisements often associate empowerment with an advertised medical product. In the case of Gardasil, DTC advertisements portray the vaccine as a gateway to empowerment. The use of feminist consumerism illustrates a strategy of marketing products specifically to women by employing feminist discourse. As Johnston and Taylor (2008) state, feminist consumerism is an effective marketing 
strategy for companies within an age of consumerism. While this marketing technique seeks to address girls as universal, it nonetheless ignores barriers to choice. Therefore, while feminist consumerism seeks to appeal to wide female audience base, messages of empowerment do not necessarily resonate with all women, especially when examining social barriers such as race and class which can inhibit choice.

Gardasil is a costly vaccine that requires financial resources and regular visits to the doctor. While minorities and low income individuals are adversely affected by HPV and cervical cancer (Kahn, Lan, and Kahn 2007), the structural elements of the vaccinesuch as costs and doctor visits - appear to exacerbate this reality. Indeed, the discourse ignores access to health care, sexual health information, and other barriers to vaccination (Epstein and Huff 2010). In turn, those who are more likely to be affected will be least likely to access preventative measures. Clarke et al. (2010) indicate that biomedical advancements can reproduce health inequities due to the exclusion that exists based upon race, class, gender, sexuality, and other dimensions of inequality. The researchers use "stratified biomedicalization" to capture the effects that biomedicine has on health and social inequality. In this case, the high cost of the vaccine contributes to the ongoing cycle of HPV and the cancers that it causes by making it accessible to those with resources. Additionally, Merck's marketing strategy constructed all girls in need of Gardasil. However, HPV adversely affects racial, ethnic, class, and sexual minorities. Overall, the discourse and structural elements of Gardasil contribute to health differentials by making those most in need less likely to access the vaccine. 
While DTC advertisements were a major source of information about the vaccine, the Gardasil website offers a unique analysis of conveying health information. For instance, the website presents information about the vaccine and is also a key site of marketing. This form of advertising is unique as it subtly encourages women, more so than men, to vaccinate and promote the vaccine. For instance, "get the word out" about HPV and cervical cancer encourages women to host events or offer informative presentations. The "Add a Banner to Your Blog" option allows vaccinated women to download a colorful blog background that publicly proclaims one's decision to vaccinate. The website also offers blogs and t-shirts that state, "I Chose." These examples encourage girls to publicly announce their vaccination which is framed as empowering. Ultimately though, the encouragement for girls to publicly proclaim their decision to vaccinate is an implicit form of advertising and product promotion. This illustrates innovative ways of marketing medical products in the twenty-first century. Additionally, it speaks to how marketing Gardasil extends beyond just a website and DTC advertising; promoting medical products has entered into the daily lives and conversations of women. In an age of biomedicalization, different forms of marketing and advertising medical products continue to reach new bounds.

The Gardasil vaccine illustrates that medical technologies are not neutral sites. The gendered marketing of the vaccine speaks to the intricate intersection between health, medicine, and gender. In this case, the use of empowerment and choice rhetoric tacitly encourages women to publicly support Gardasil. In turn, marketing extends into various forms of multi-media as well as the intimate conversations between women. 
Therefore, the Gardasil vaccine elucidates how medical technologies can extend beyond just medical domain and utilize cultural ideologies about gender, sexuality, health and bodies.

\section{Methodological and Theoretical Considerations}

While framing offers a nuanced examination of media coverage of medical technologies, it nonetheless presents methodological and theoretical limitations. Both Entman (1993) and Scheufele (1999) point out that framing is a broad and even vague conceptualization. Additionally, there appears to be confusion between the meanings of "frame" and "framing" (Scheufele and Tewksbury 2007). Thus, the framing literature is diverse and at times inconsistent, particularly to the lack of a systematic methodology for frame analysis. In turn, this research is privy to such conceptual and theoretical challenges. Therefore, I took steps to ameliorate these problems, such as complementing the frame analysis with quantitative analysis and using other research to guide my analysis. Additionally, this project lacks inter-coder reliability and thus I recognize this research is not immune to my own biases.

While this research does account for multi-media, it does not examine every outlet that covered Gardasil, such as television news. Additionally, while I examined all articles and advertisements in the chosen magazines, I did not examine all magazines or all newspapers that might have discussed the HPV vaccine. Clarke et al. (2003) state that biomedicalization is imbricated with diverse forms of health information. This research only speaks to how Gardasil was framed in the outlets under consideration. 
I identified the most common sources within the Gardasil discourse. This research conceptualized stakeholders as institutional organizations that were cited in support or in opposition to the vaccine. Other stakeholders, both at the local and national level, influenced the framing of Gardasil. However, I could not account for every organization or group. Therefore, I choose the most common sources. While other groups, such as mothers or politicians were used as sources in the news media coverage of the vaccine, I did not conceptualize them as a stakeholder for this research. While they did influence the framing, their frames echoed frames promoted by Merck and the other institutional organizations. Therefore, while I did not account for every stakeholder, I did account for the most influential that other less dominant groups supported.

This research does not claim to describe every frame in news media coverage of Gardasil. I depicted the most dominant frames in the media coverage. Therefore, other topics were present in news media coverage of Gardasil, including but not limited to, safety concerns, legislation, insurance, etc. However, these topics were not covered to the extent as the frames mentioned in this research. In sum, this study does not claim to offer an exhaustive account of media framing of Gardasil but a picture of the dominant framing of Gardasil in the media.

Lastly, this research only sought to examine how the media framed the Gardasil vaccine. Thus, these results only speak to two processes of biomedicalization and it is beyond the scope of this research to discuss the other processes. 


\section{Future Areas of Research}

The iterative nature of research continually engenders new questions to explore. The research specifically sought to examine how knowledge and information about the HPV vaccine was presented to the public. A key aspect that remains unknown is how this information was perceived and internalized among the public. Thus, an in-depth analysis of the construction of health knowledge and its effects would further our understanding

of frame effects. Furthermore, it would be useful to account for other media outlets which discuss health information such as televised news. Lastly, it would be beneficial to explore how men and women conceptualize their own gender enactment in relation to Gardasil, an endeavor which would best be captured through interviews.

Lastly, the future of the HPV vaccine is largely uncertain. Currently, the vaccine is approved and recommended for men and women. Whether a DTC advertising campaign ensues in the future is unknown. How Merck proceeds to market the vaccine for women and men will provide interesting research opportunities to further explore.

\section{Conclusion}

In summary, this thesis has uncovered how Gardasil—a unique vaccine in a biomedical age — was framed in the mass media. Merck, like other pharmaceutical companies, utilized dominant ideologies about gender and sexuality to market this vaccine. The representation of Gardasil in the media constructed all women at risk and in need of Gardasil. In turn, the pharmaceutical industry created HPV as predominately a woman's health issue. In turn, this discourse constructed a false image of women and 
their health and contributed to the invisibility of men and sexual minorities. The findings speak to the salient intersection of health, medicine, gender and sexuality. While this research only addressed two dimensions (gender and sexuality), other cultural statuses (e.g. race) are equally co-opted by the pharmaceutical industry. ${ }^{21}$ This research speaks to the larger influence and expansion of the pharmaceutical industry and the ways that it utilizes, reproduces, and potentially affects non-medical dimensions of our culture and everyday life.

${ }^{21}$ The drug, BiDil, treats heart failure specifically in African American adults, illustrating how race/ethnicity can also by appropriated in the production and marketing of drugs. 


\section{REFERENCES}

Abdelmutti, Nazek, and Laurie Hoffman-Goetz. 2009. "Risk Messages About HPV, Cervical Cancer, and the HPV Vaccine Gardasil: A Content Analysis of Canadian and U.S. National Newspaper Articles." Women and Health 49:422-440

-----. 2010. "Risk Messages about HPV, Cervical Cancer, and the HPV Vaccine Gardasil in North American News Magazines.” Journal of Cancer Education 25:451-456

Abramson, John. 2005. Overdo\$ed America. New York: HarperCollins

Alexander, Susan M. 2003. "Stylish Hard Bodies : Branded Masculinity in Men's Health Magazine." Men's Health 46:535-554

Althaus, Scott L., and David Tewksbury. 2002. “Agenda Setting and the 'New' News: Patterns of Issue Importance Among Readers of the Paper and Online Versions of the New York Times." Communication Research 29:180-207

Angell, Marcia. 2004. The Truth About Drug Companies: How They Deceive Us and What to do About It. New York: Random House

Attwood, Feona. 2005. “'Tits and Ass and Porn and Fighting': Male Heterosexuality in Magazines for Men.” International Journal of Cultural Studies 8:83-100

Balsamo, Anne. 1996. Technologies of the Gendered Body: Reading Cyborg Women. Durham: Duke University Press

Bateson, Gregory. 1955. "A Theory of Play and Fantasy.” Psychiatric Research Reports 2:39-51 
Bell, Robert, Richard Kravitz, and Michael S. Wilkes, M. 1999. "Direct-to-consumer Prescription Drug Advertising and the Public." Journal of General Internal Medicine 14: 651-657

Bell, Robert A., Richard Kravitz, and Michael S. Wilkes. 2000. "Direct-to-Consumer Prescription Drug Advertising, 1989-1998: A Content Analysis of Conditions, Targets, Inducements, and Appeals.” The Journal of Family Practice 49:329-335 Benwell, Bethen. 2003. Masculinity and Men's Lifestyle Magazines. Malden, MA: Wiley Blackwell

Bordo, Susan. 1993. “'Material Girls': The Effacements of Postmodern Culture'” Pp. 245 275 in Unbearable Weight: Feminism, Western Culture, and the Body. Berkeley: University of California Press

Bradley, Lynette R. and Julie Magno Zito. 1997. "Direct-to-Consumer Prescription Drug Advertising." Medical Care 35:86-92

Braun, Lundy and Ling Phoun. 2010. "HPV Vaccination Campaigns: Masking Uncertainty, Erasing Complexity." Pp. 39-60 in Three Shots at Prevention: The HPV Vaccine and the Politics of Medicine's Simple Solutions, edited by K. Wailoo, J. Livingston, S. Epstein, and R. Aronowitz. Baltimore, Maryland: John Hopkins University Press

Brodie, Mollyann, Elizabeth C. Hamel, Drew E. Altman, Robert J. Blendon, and John M. Benson. 2003. "Health News and the American Public, 1996-2002." Journal of Health Politics, Policy and Law 28:927-950. 
Brownfield, Erica D., Jay M. Bernhardt, Jennifer L. Phan, Mark V. Williams and Ruth M. Parker. 2004. "Direct to Consumer Drug Advertisements on Network Television: An Exploration of Quantity, Frequency, and Placement.” Journal of Health Communication 9:391-497

Carpenter, Laura and Monica Casper. 2009. “A Tale of Two Technologies: HPV Vaccination, Male Circumcision, and Sexual Health.” Gender and Society $23: 790-816$.

Casper, Monica and Laura Carpenter. 2008. "Sex, Drugs, and Politics: The HPV Vaccine for Cervical Cancer." Sociology of Health and Illness 30:886-899

Carragee, Kevin M. 1993. “A Critical Evaluation of Debates Examining the Media Hegemony Thesis.” Western Journal of Communication 57:330-348.

Carragee, Kevin M. and Wim Roefs. 2004. “The Neglect of Power in Recent Framing Research.” Journal of Communications 54:214-233

Center for Disease Control and Prevention (CDC). 2011. "HPV and Men- Fact Sheet." Atlanta, GA: Center for Disease Control and Prevention. Retrieved February 17, 2012 (http://www.cdc.gov/std/hpv/STDFact-HPV-and-men.htm)

CDC. 2012. “Genital HPV Infection- Fact Sheet.” Atlanta, GA: Center for Disease Control and Prevention. Retrieved February 17, 2010. (http://www.cdc.gov/std/HPV/STDFact=HPV.htm)

Clarke, Adele. 2010. "From the Rise of Medicine to Biomedicalization: U.S. Healthscapes and Iconography, Circa 1890-Present.” Pp. 104-146 in Biomedicalization: Technoscience, Health, and Illness in the U.S. edited by 
Adele E. Clarke, Laura Mamo, Jennifer Ruth Fosket, Jennifer R. Fishman, and Janet K. Shim.

Clarke, Adele E., Janet K. Shim, Laura Mamo, Jennifer Ruth Fosket, Jennifer R. Fishman. 2003. "Biomedicalization: Technoscientific Transformations of Health, Illness, and U.S. Biomedicine.” American Sociological Review 68:161-194

Clarke, Juanne. 2009. “Women’s Work, Worry and Fear: The Portrayal of Sexuality and Sexual Health in U.S. Magazines for Teenage and Middle-Aged Women, 20002007." Culture, Health, and Sexuality 11:415-429

Cline, Rebecca J. Welch and Henry N. Young. 2004. "Marketing Drugs, Marketing Health Care Relationships: a Content Analysis of Visual Cues in Direct-to Consumer Prescription Drug Advertising." Health Communication 16: 131-157

Colgrove, James. 2006. State of Immunity: The Politics of Vaccination in Twentieth Century America. Berkeley: University of California Press

------. 2010. "The Coercive Hand, the Beneficent Hand: What the History of Compulsory Vaccination Can Tell Us about HPV Vaccine Mandates.” Pp. 3-20 in Three Shots at Prevention: The HPV Vaccine and the Politics of Medicine's Simple Solutions edited by K. Wailoo, J. Livingston, S. Epstein, and R. Aronowitz. Baltimore, Maryland: John Hopkins University Press

Connell, R. W. 1987. Gender and Power. Stanford: Polity Press

---------. 1995. Masculinities. Berkeley: University of California Press

Conrad, Peter. 1992. "Medicalization and Social Control.” Annual Review of Sociology 19:209-232 
------. 2007. The Medicalization of Society: On the Transformation of Human Conditions into Treatable Disorder Baltimore: John Hopkins University Press

Conrad, Peter and Joseph W. Schneider. 1980. Deviance and Medicalization: From Badness to Sickness. Philadelphia: Temple University Press

Crawford, Robert. 1985. “A Cultural Account of 'Health': Control, Release, and the Social Body.” Pp. 60-106 in Issues in the Political Economy of Health edited by J.B. McKinlay. New York: Methuen-Tavistock

Creed, Douglas W.E., Jeffrey A. Langstraat, and Maureen A. Scully. 2002. "A Picture of the Frame: Frame Analysis as Technique and as Politics." Organizational Research Methods 5:34-55

Crister, Greg. 2005. Generation Rx: How Prescription Drugs Are Altering American Lives, Minds, and Bodies. New York: Houghton Mifflin Company

Currie, Dawn. 2001. "Dear Abby: Advice Pages as a Site for the Operation of Power." Feminist Theory 2:259-281

d'Haenens, Leen, Nicholas Jankowski, and Ard Heuvelman. 2004. "News in Online and Print Newspapers: Differences in Reader Consumption and Recall." New Media and Society 6:363-382

Danovaro-Holliday, M. Carolina, Allison L. Wood, and Charles W. LeBaron. "Rotavirus Vaccine and the New Media, 1987-2001." Journal of American Medical Association 287:1455-1462

de Lauretis, Teresa. 1987. Technologies of Gender: Essays on Theory, Film, and Fiction. Bloomington: Indiana University Press 
Donohue, Julie M., Marisa Cevasco, and Meredith B. Rosenthal. 2007. “A Decade of Direct-to-Consumer Advertising of Prescription Drugs." The New England Journal of Medicine 357:673-681

Entman, Robert M. 1993. "Framing: Toward Clarification of a Fractured Paradigm." Journal of Communication 43:51-58

Epstein, Steven. 2010. “The Great Undiscussable: Anal Cancer, HPV, and Gay Men's Health.” Pp. 61-90 in Three Shots at Prevention: The HPV Vaccine and the Politics of Medicine's Simple Solutions, edited by K. Wailoo, J. Livingston, S. Epstein, and R. Aronowitz. Baltimore, Maryland: John Hopkins University Press

Epstein, Steven and April N. Huff. "Sex, Science, and the Politics of Biomedicine: Gardasil in Comparative Perspective.” Pgs. 213-228 in Three Shots at Prevention: The HPV Vaccine and the Politics of Medicine's Simple Solutions, edited by K. Wailoo, J. Livingston, S. Epstein, and R. Aronowitz. Baltimore, Maryland: John Hopkins University Press

Eveland, William P., Jr., and Sharon Dunwoody. 2001. "User Control and Structural Isomorphism or Disorientation and Cognitive Load? Learning From the Web Versus Print." Communication Research 28: 48-78.

--------. 2002. “An Investigation of Elaboration and Selective Scanning as Mediators of Learning from the Web Versus Print.” Journal of Broadcasting \& Electronic Media 46:34-5

Gamson, William A. 1992. Talking Politics. New York: Cambridge University Press 
Gamson, William A. and Kathryn E. Lasch. 1983. "The Political Culture of Social Welfare Policy", pp. 397-415 in Evaluating the Welfare State: Social and Political Perspectives.Edited by S.E. Spiro and E. Yuchtman-Yaar. New York: Academic Press

Gamson, William A. and Andre Modigliani. 1989. "Media Discourse and Public Opinion on Nuclear Power: A Constructionist Approach.” American Journal of Sociology 95:1-37

Gans, Herbert J. 1979. Deciding What's News: A Study of CBS Evening News, NBC NightlyNews, Newsweek and Time. New York: Random House

Gardner, Amanda. 2011. "Slightly More Than Half of Americans Say Vaccines Don’t Cause Autism: Poll.” US News and World Report, January 20. Retrieved April 19, 2012 (snews.com/health-news/familyhealth/brainandbehavior/ articles/2011/ 01/20/slightly-more-than-half-of-americans-say-vaccines-dont-cause-autism poll?page $=2$ )

General Accounting Office (GAO). 2002. "Prescription Drugs: FDA Oversight of Direct-to Consumer Advertising Has Limits.” Washington, DC: United States General Accounting Office

Gillison, Maura, Tatevik Broutian, Robert K.L. Pickard, Zhen-you Tong, Weihong Ziao, Lisa Kahle, Barry I. Graubard, and Anil K. Chaturvedi. 2012 "Prevalence of Oral HPV Infection in the United States, 2009-1010.” The Journal of the America Medical Association 307:693-703 
Gitlin, Todd. 1980. The Whole World is Watching: Mass Media in the Making and Unmaking of the New Left. Berkeley: University of California Press

Giuliano, Anna R., Joel M. Palefsky, Stephen Goldstone, Edson D. Moreira, Jr., Mary E. Penny, Carlos Aranda, Eftyhia Vardas, Harald Moi, Heiko Jessen, Richard Hillman, Yen-Hwa Chang, Daron Ferris, Danielle Rouleasu, Janine Bryan, Brooke Marshall, Scott Vuocolo, Eliav Barr, David Radley, Richard M. Haupt, and Dalya Guris. 2011. "Efficacy of Quadrivalent HPV Vaccine Against HPV Infection and Disease in Males" The New England Journal of Medicine 364:401-411

Goffman, Erving. 1974. Frame Analysis: An Essay on the Organization of Experience. New York: Harper and Row

Goodyear-Smith, Felicity, Helen Petusis-Harris, Colleen Vanlaar, Nikki Tuner, and Stephen Ram. 2007. "Immunization in the Print Media-Perspectives Presented by the Press." Journal of Health Communications 12:759-770

Gramsci, Antonio. 1971. Selections from the Prison Notebooks. New York: International Publishers

Habel, Melissa, Nicole Liddon, and Jo E. Stryker. 2009. "The HPV Vaccine: A Content Analysis of Online News Stories" Journal of Women's Health 18:401-407

Hays, Sharon. 1996. The Cultural Contradictions of Motherhood. New Haven: Yale University Press

Hilton, Shona, Kate Hunt, Mairi Langan, Helen Bedford, and Mark Petticrew. 2010. "Newsprint Media Representations of the Introduction of the HPV Vaccination 
Programme for Cervical Cancer Prevention in the UK (2005-2008)." Social Sciences and Medicine 70:942-950

Hildesheim, Allan, Rolando Herrero, Sholom Wacholder, Ana C. Rodriguez, Diane Solomon, M. Concepcion Bratti, John T. Schiller, Paula Gonzalez, Gary Dubin, Carolina Porras, Silvia E. Jimenez, and Douglas R. Lowy. 2007. “Effect of Human Papillomavirus 16/18 L1 Virus-like Particle Vaccine Among Young Women with Preexisting Infection.” The Journal of American Medical Association 298:743-753

Hughes, Jessica, Joan R. Cates, Nicole Liddon, Jennifer S. Smith, Sami L. Gottlieb, and Noel T. Brewer. 2009. "Disparities in How Parents are Learning About theHuman Papillomavirus Vaccine.” Cancer Epidemiology, Biomarkers, \& Prevention $18: 363-367$

Fishman, Jennifer R. 2010. “The Making of Viagra: The Biomedicalization of Sexual Dysfunction" Pp. 289-306 in Biomedicalization: Technoscience, Health, and Illness in U.S. edited by Adele Clarke, Laura Mamo, Jennifer Ruth Fosket, Jennifer R. Fishman, and Janet K. Shim. Durham: Duke University Press

Food and Drug Administration (FDA). 2006. Center for Biological Products advisory committee meeting Thursday May 18, 2006 [Transcript]. Retrieved from http://www.fda.gov/ohrms/dockets/ac/06/transcripts/2006-4222t1.pdf

Foucault, Michel, Luther H. Martin, Huck Gutman, Patrick H. Hutton. 1988. Technologies of the Self. Amherst: University of Massachusetts Press 
Freimuth, Vicki S., Rachel H. Greenberg, Jean DeWitt, and Rose May Romano. 1984. “Covering Cancer: Newspapers and the Public Interest." Journal of Communication 34:62-73

Frosh, Dominick L., Patrick M. Krugar, Robert C. Hornik, Peter F. Cronholm, and Frances K. Barg. 2007. “Creating Demand for Prescription Drugs: A Content Analysis of Television Direct-to-Consumer Advertising." Annals of Family Medicine 5:6-13

Jackson, Stevi. 2006. "Gender, Sexuality, and Heterosexuality: The Complexity (and limits) of Heteronormativity." Feminist Theory 7:105-121

Johnston, Josee and Judith Taylor. 2008. "Feminist Consumerism and Fat Activists: A Comparative Study of Grassroots Activism and the Dove Real Beauty Campaign.” Signs 4:941-966.

Kaiser Family Foundation. 2003. "Impact of Direct-to-Consumer Advertising on Prescription Drug Spending." Washington, DC: Henry J. Kaiser Foundation Kahn, Caryl. 2001. "How the Media Influences Women's Perceptions of Health Care." Marketing Health Services 21:1094-1304

Kahn, Jessica, Dongmei Lan, and Robert Kahn. 2007. "Sociodemographic Factors Associated with High-Risk Human Papillomavirus Infection.” Obstetrics and Gynecology 110:87-95

Kaphingst, Kimberly A., William DeJong, Rima E Rudd, and Lawren H. Daltroy. 2004. “A Content Analysis of Direct-to-Consumer Television Prescription Drug Advertisements." Journal of Health Communication 9:515-28 
Kempner, Joanna. 2006. “Gendering the Migraine Market: Do Representations of Illness Matter?" Social Science and Medicine 63:1986-1997

Kilgore, M. 1996. "Magic, Moralism, and Marginalisation: Media Coverage of Cervical, Ovarian, and Uterine Cancer." Pp. in Evaluating Women's Health Messages edited by Roxanne Parrott and Celeste Condit. Thousand Oaks: Sage Publishers

Kitzinger, Celia. 2005. "Heteronormativity in Action: Reproducing the Heterosexual Nuclear Family in Afterhours Medical Calls." Social Problems 52:477-498

Koenig, Thomas. 2006. “Compounding Mixed-Methods Problems in Frame Analysis Through Comparative Research." Qualitative Research 6:61-76

Krishnan, Shobha S. 2008. The HPV Vaccine Controversy: Sex, Cancer, God, and Politics. Westport: Praeger Publishers

Lippman, Abby. 1999. “Choice as a Risk to Women's Health.” Health, Risk, and Society $1: 281-291$

Loe, Meika. 2001. "Fixing Broken Masculinity: Viagra as a Technology for the Production of Gender and Sexuality." Sexuality and Culture 5:97-125

--------. 2004. The Rise of Viagra: How The Little Blue Pill Changed Sex In Amercia. New York: New York University Press

Lupton, Deborah. 1999. Risk. London: Routledge

Mamo, Laura and Jennifer Fishman. 2001. "Potency in All the Right Places: Viagra as a Technology of the Gendered Body." Body and Society 7:13-35 
Mamo, Laura and Jennfier Roth Fosket. 2009. "Scripting the Body: Pharmaceuticals and the (Re)Making of Menstruation." Signs: Journal of Women in Culture and Society 34:925949

Mamo, Laura, Amber Nelson, and Aleia Clark. 2010. "Producing and Protecting Risky Girlhoods.” Pgs. 121-145 in Three Shots at Prevention: The HPV Vaccine and thePolitics of Medicine's Simple Solutions, edited by K. Wailoo, J. Livingston, S. Epstein, and R. Aronowitz. Baltimore: John Hopkins University Press

Masters, Coco. 2007. “Oral Sex Can Add to HPV Cancer Risk” Time May 11. Retrieved March 12, 2012. (http://www.time.com/time/health/article/0,8599,1619814,00.html)

Mastin, Teresa, Julie L. Andsager, Jounghwa Choi, and Kyungjin Lee. 2007. "Health Disparities and Direct-to-Consumer Prescription Drug Advertising: A Content Analysis of Targeted Genres, 1992-2002." Health Communication 22:49-58

McRobbie, A. 1996. “More! New Sexualities in Girls’ and Women's Magazines.” Pgs. 172-194 in Cultural Studies and Communication edited by J. Curran, D. Morley and V. Walkerdine. London: Arnold.

Messner, Michael. 2002. Talking the Field: Women, Men, and Sports. Minneapolis: University of Minnesota Press

Morgen, Sandra. 2002. Into Our Own Hands: The Women's Health Movement in the United States, 1969-1990. New Brunswick: Rutgers University Press 
National Cancer Institute. 2011. "Trends in U.S. Vaccination Rates: Ages 13-17 Yrs." Retrieved April 23, 2012 (http://deainfo.nci.nih.gov/advisory/ncab/159_0911/905\%20b\%20Lowy.) O’Malley, Ann S., Jon F. Kerner, and Lenora Johnson. 1999. “Are we Getting the Message out to all?: Health Information Sources and Ethnicity.” American Journal of Preventative Medicine 17:198-202

Omaha World-Herald. 2005. Newspaper Editorial. November 16. P. 06B

Oudshoorn, Nelly. 2003. The Male Pill. Durham: Duke University Press

Palefsky, J.M. and J. Gonzales, R.M. Greenblatt, D.K. Ahn, and H. Hollander, E.A. Holly, M.L. Ralston, and N. Jay, 1990. "Anal Intraepithelial Neoplasia and Anal Papillomavirus Infection Among Heterosexual Males with Group IV HIV Disease." Journal of the American Medical Association 263:2911-2916

Pan, Zhongdang and Gerald M. Kosicki. 1993. "Framing Analysis: An Approach to News Discourse." Political Communications 10:55-75

Parkin, D. Maxwell, and Freddie Bray. 2006. "The Burden of HP-Related Cancers." Vaccine 24:11-25

Parrott, R.L. and Condit, C.M. 1996. "Priorities and Agendas in Communication About Women's Reproductive Health" Pp. 1-11 in Evaluating Women's Health Messages, edited by R.L. Parrott and C.M. Condit. Thousand Oaks: Sage Publishers 
Pew Research Center. 2010. How News Happens: A Study of the News Ecosystem of One American City. Project for Excellence in Journalism. Washington: PEW Research Center

Pinto, Mary Beth, Jeffry K. Pinto, and Joseph C. Barber. 1998. "The Impact of Pharmaceutical Direct Advertising: Opportunities and Obstructions." Health Marketing Quarterly 15:89-101

Reich, Jennifer A. 2010. "Parenting and Prevention: Views of HPV Vaccines Among Parents Challenging Childhood Immunizations.” Pp. 165-182 in Three Shots at Prevention: The HPV Vaccine and the Politics of Medicine's Simple Solutions, edited by K. Wailoo, J. Livingston, S. Epstein, and R. Aronowitz. Baltimore, Maryland: John Hopkins University Press

Ricciardelli, Rosemary, Kimberley A. Clow, and Philip White. 2010. "Investigating Hegemonic Masculinity: Portrayals of Masculinity in Men's Lifestyle Magazines." Sex Roles 63:64-78

Riessman, Catherine Kohler. 1983. "Women and Medicalization: A New Perspective." Social Policy 14:3-18

Riska, Elianne. 2003. "Gendering the Medicalization Thesis." Advances in Gender Research 7:61-89

------. 2010. "Gender and Medicalization and Biomedicalization Theories." Pp. 147 170 in Biomedicalization: Technoscience, Health, and Illness in U.S. edited by Adele Clarke, Laura Mamo, Jennifer Ruth Fosket, Jennifer R. Fishman, and Janet K. Shim. Durham: Duke University Press 
Rosenfeld, Dana and Christopher A. Faircloth, eds. 2006. Medicalized Masculinities. Philadelphia: Temple University Press

Rose, Nikolas. 2007. “The Politics of Life Itself.” Princeton: Princeton University Press

Roth, Martin. 1996. "Patterns in Direct-to-Consumer Prescription Drug Print Advertising and Their Public Policy Implications.” Journal of Public Policy and Marketing $15: 63-75$

Ryan, Charlotte. 1991. Prime Time Activism: Media Strategies for Grassroots Organizing. Boston: South End Press.

Scheufele, Dietram and David Tewksbury. 2007. "Framing, Agenda Setting, and Priming: The Evolution of Three Media Effects Models." Journal of Communication 57:9-20

Seale, Clive. 2003. "Health and Media: An Overview." Sociology of Health and Illness $6: 523-531$

Shaw, Donald Lewis and Maxwell E. McCombs, eds. 1977. The Emergence of American Political Issues: The Agenda Setting Function of the Press. St. Paul: West Shoemaker, Pamela J. and Stephen D. Reese. 1996. Mediating the Message: Theories of Influence on Mass Media Content. White Plains: Longman

Strauss, Anselm and Juliet Corbin. 1998. Basic of Qualitative Research: Techniques and Procedures for Developing Grounded Theory. Thousand Oaks: Sage Publications

Tankard, J.W. Jr. 2001. “The Empirical Approach to the Study of Media Framing” Pp. 95-106 in Framing Public Life: Perspectives on Media and our Understanding of 
the Social World edited by Stephen D. Reese, Oscar H. Gandy Jr., and August E. Grant. Mahwah: Lawrence Erlbaum Associates.

Taylor, Laramie D. 2005. “All For Him: Articles About Sex in American Lad Magazines." Sex Roles 52:153-163

Ticknell, Estella, Deborah Chambers, Joost Van Loon, and Nichola Hudson. 2003.

'Begging for It: 'New Femininities,' Social Agency, and Moral Discourse in Contemporary Teenage and Men's Magazines." Feminist Media Studies 3:47-63

Terzian, Tamar. 1999. "Direct-to-Consumer Prescription Drug Advertising." American Journal of Law \& Medicine 25: 149-68

Tewksbury, D., Weaver, A. J., \& Maddex, B. D. 2001. “Accidentally Informed: Incidental News Exposure on the World Wide Web.” Journalism \& Mass Communication Quarterly 78: 533-554

Tuchman, Gaye. 1978. Making News: A Study in the Construction of Reality. New York: Free Press

Vanderbilt-Ingram Cancer Center. 2006. “'Make the Connection’ Between HPV and Cervical Cancer." Vanderbilt University Medical Center. Retrieved February 13, 2012 (http://www.vicc.org/news/2006/cervical.php)

Vesely, Rebecca. 2006. "FDA gives nod to HPV vaccine to stop cancer." Inside Bay Area, June 9. Retrieved August 18, 2011. LexisNexis

Vigorito, Anthony J. And Timothy J. Curry. 1998. "Marketing Masculinity: Gender Identity and Popular Magazines.” Sex Roles 39:135-152 
Vliegenthart, Rens and Liesbet van Zoonen. 2011. "Power to the Frame: Bringing Sociology Back to Frame Analysis.” European Journal of Communications 26:101-115

Wailoo, Keith, Julie Livingston, Steven Epstein, and Robert Aronowitz, ed. 2010. "Three Shots at Prevention: The HPV Vaccine and the Politics of Medicine's Simple Solutions.” Baltimore: The John Hopkins University Press

Weitz, Rose. 2010. The Politics of Women's Bodies. New York: Oxford University Press

Wertz, Richard and Dorothy Wertz. 1989. Lying In: A History of Childbirth in America. New Haven: Yale University Press

West, Candace and Don H. Zimmerman. 1987. "Doing Gender.” Gender and Society $1: 125-151$

White, Philip G. and James Gillett. 1994. "Reading the Muscular Body: A Critical Decoding of Advertisements in Flex Magazine." Sociology of Sport Journal $11: 18-39$

Wienke, Chris. 2006. "Sex the Natural Way: The Marketing of Cialis and Levitra” Pp. 45-64 in Medicalized Masculinities edited by Dana Rosenfeld and Christopher A. Faircloth. Philadelphia: Temple University Press

Wilkes, Michael, Robert A. Bell, and Richard L. Kravitz. 2000. “Direct-to-Consumer Prescription Drug Advertising: Trends, Impact, and Implications." Health Affairs 19:110-128

Winett, Liana. 1997. “Do the Media Govern?” Pp. 420-433in Do The Media Govern edited by Shanto Iyengar and Richard Reeves. Thousand Oaks: Sage Publications 
Witte, Kim and Mike Allen. 2000. “A Meta-Analysis of Fear Appeals: Implications for Effective Public Health Campaigns.” Health Education and Behavior 27:591-615.

Williams, Melanie Ayn. 1996. "Cervical, Ovarian, and Uterine Cancer: Advancing Awareness, Choices, and Survival.” Pp. 234-248 In Evaluating Women's Health Messages edited by Roxanne Louiselle Parrott and Celeste Michelle Condit. Thousand Oaks: Sage Publishers

Woloshin, Steven, Lisa M. Schwartz, Jennifer Tremmel, and H. Gilbert Welch. 2001. "Directto-Consumer Prescription Drugs: What are Americans Being Sold?" The Lancet 358:1141-1146

Woosley, Leigh. 2006. “Cervical Cancer Vaccine Hailed” Tulsa World, August 21. Retrieved August 18, 2011. LexisNexis

Zola, Irving. 1972. "Medicine as an Institution of Social Control." The Sociological Review. 20:487-504 


\begin{tabular}{|c|c|}
\hline Text & Source \\
\hline \multicolumn{2}{|l|}{ News Media: } \\
\hline Newspaper Articles & LexisNexis Database \\
\hline Magazine Articles & The Reader's Guide to Periodicals \\
\hline \multicolumn{2}{|l|}{ Stakeholder Organizations: } \\
\hline $\begin{array}{l}\text { Merck Pharmaceuticals } \\
\text { DTC Commercial Advertisements } \\
\text { DTC Print Advertisements } \\
\text { Gardasil Website }\end{array}$ & $\begin{array}{l}\text { www.youtube.com } \\
\text { The Reader's Guide to Periodicals } \\
\text { www.gardasil.com }\end{array}$ \\
\hline $\begin{array}{l}\text { Planned Parenthood } \\
\text { "Preventing Cervical Cancer 2010" }\end{array}$ & www.plannedparenthood.com \\
\hline $\begin{array}{l}\text { National Cancer Institute } \\
\text { "Recombinant Human Papillomarvirus } \\
\text { (HPV) Quadrivalent Vaccine } \\
\text { "HPV and Cancer" } \\
\text { "Human Papillomavirus (HPV) Vaccines" }\end{array}$ & www.cancer.gov \\
\hline $\begin{array}{l}\text { Center for Disease Control } \\
\text { "Fact Sheet" } \\
\text { "HPV and Men Fact Sheet" } \\
\text { "HPV Vaccine Information for Young } \\
\text { "Women Fact Sheet" } \\
\text { "Genital HPV- The Facts Brochure" }\end{array}$ & www.cdc.gov \\
\hline $\begin{array}{l}\text { Family Research Council } \\
\text { "The HPV Vaccine and School Mandates" } \\
\text { Questions and Answers" } \\
\text { "Gardasil: What Every Parent Should } \\
\text { Know about the New HPV Vaccine" }\end{array}$ & www.frc.org \\
\hline $\begin{array}{l}\text { Focus on the Family } \\
\text { "HPV Vaccine: What Parents Need to } \\
\text { Know" } \\
\text { "Focus on the Family Position Statement: } \\
\text { Human Papillomavirus Vaccines" } \\
\text { "Talking to Your Children About HPV } \\
\text { Vaccine" }\end{array}$ & www.focusonthefamily.org \\
\hline
\end{tabular}




\section{APPENDIX B: Frame Matrix}

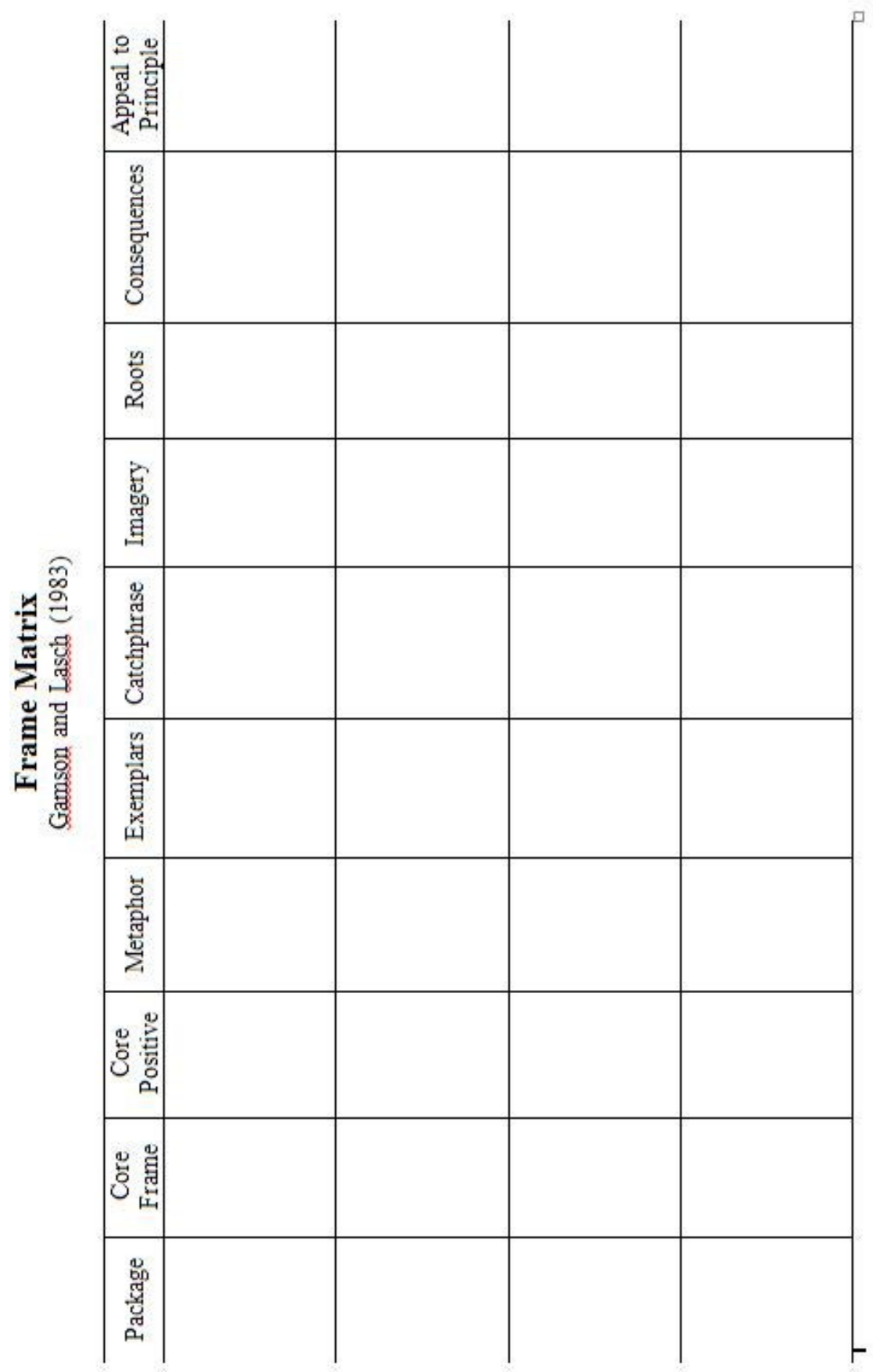




\section{APPENDIX C: Newspaper Code Sheet}

Print Newspaper Articles

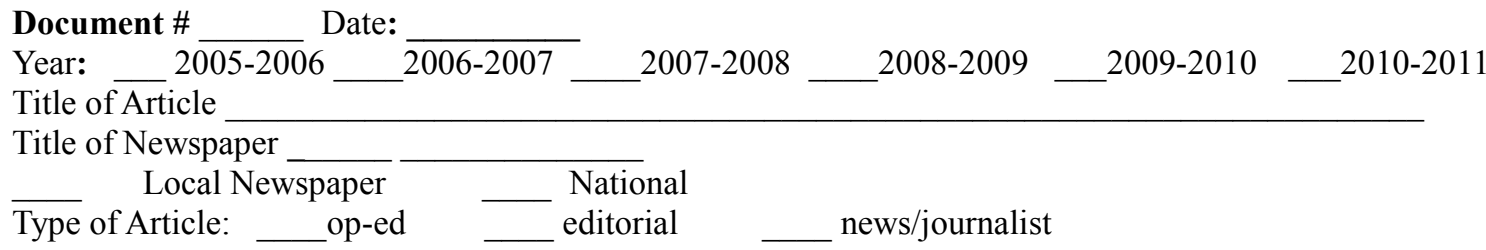

Title Includes

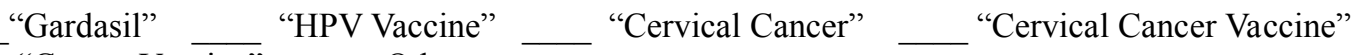
"Cancer Vaccine" Other

Who does the article state can be vaccinated?

Women only___ Men only_ B__ Both___ Does Not specify___ Unclear

What group does the article state can get HPV? Women only Men only

Both Does not specific Unclear

Check all that the article covers:

Gender/Sexuality: FDA Approval of Gardasil (non-gender) Men's FDA Approval Encourage moms to get kids vaccinated Linked to sexuality/promiscuity $\mathrm{HPV} /$ vaccinate Lesbian Women

Women's FDA Approval Both Women's and Men's FDA approval Parents and Moral Responsibility $\mathrm{HPV} /$ vaccinate Gay males Vaccinating boys/men

\section{Medical:}

Explains HPV is an STD/STI States minimal side effects (fainting) States effectiveness

\section{General:}

Examples of Serious Reactions (death) Insurance and Gardasil Access Problems

Legislation regarding Gardasil (i.e. compulsory vaccination, state legislation)

What cancers does the article state are HPV caused?

cervical

oral vaginal throat vulva

penile
Genital warts anal Other

Does the article state the cause of cervical cancer? Yes No Unclear

Does the article explain how HPV is spread (other than just "an STD/STI")? Yes_ No Unclear Is it accurate?

Amount of times article states (zeros if absent):

$$
\text { "women"/ "girls"/ "female" " "men"/ "boys"/ "males" }
$$

"Gardasil"

Male Specific cancers ("penile", "anal")

Female Specific Cancers (“cervical cancer”, "vulvar cancer”)

Non-gender specific cancers ("oral", "throat", or "anal")

"HPV vaccine"

"cervical cancer vaccine"

Does the article discuss sexual partners?

Yes No 
If yes: Heterosexual couples Same Sex couples Unclear NA

Reports Statistics:

Statistics:

Statistics:

Statistics:

Statistics:

Statistics:

Statistics: applied to women applied to women applied to women applied to women applied to women applied to women applied to men applied to men applied to men applied to men applied to men applied to men

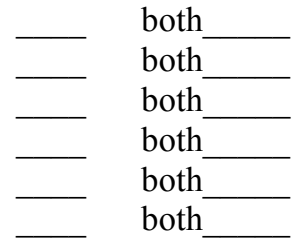

Answer the following questions together:

Does article mention men getting vaccinated? ___ Yes No DK (if "no" then "NA" on next 3) If yes, does it support men's vaccination? _ Yes _ No _ Gives both pro/con argument _ DK _ NA If yes, what is the reason? Protect men's health _ _ Protect women's health _ Gay men's health _ NA DK Other (explain)

If no, what is the reason? Unnecessary Other (explain):

Men's Health Concerns NA

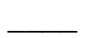

\begin{abstract}
Other (explain):
\end{abstract} - Protect - DK

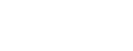

\title{
What Groups/Organizations are stated in support?
}

What Groups/Organizations are stated in opposition?

What Groups/Organizations are stated who are neutral?

\section{Other Notes:}




\section{APPENDIX D: Magazine Code Sheet}

Magazine Articles

\begin{tabular}{|c|c|c|c|c|c|}
\hline Document \# & Date & & & & \\
\hline $\begin{array}{l}\text { Year: } \quad 2005-2006 \\
\text { Title of Article }\end{array}$ & 2006-2007 & $2007-2008$ & 2008-2009 & 2009-2010 & \\
\hline Men's Magazines: & Men's health & $\mathrm{Mer}$ & s Journal & Men's Fitne & \\
\hline Women's Magazines: & Seventeen & Cosmo & Good Hou & $g \quad$ Won & an's Day \\
\hline
\end{tabular}

Title Includes

"Gardasil" "Cancer Vaccine" "HPV Vaccine" "Cervical Cancer" "Cervical Cancer Vaccine"

\section{Target Audience} Adult Men Adolescent Women Adult Women

\section{Who does the article state can be vaccinated?} Women only Men only

Both

Does not specify Unclear

What group does the article state can get HPV? Women only

\section{Check all that the article covers:}

\section{Gender/Sexuality:}

FDA Approval of Gardasil (non-gender) Men's FDA Approval

Encourage moms to get kids vaccinated Linked to sexuality/promiscuity $\mathrm{HPV} / v a c c i n a t e$ Lesbian Women

Women's FDA Approval

Both Women's and Men's FDA approval

Parents and Moral Responsibility HPV/vaccinate Gay males Vaccinating boys/men

\section{Medical:}

Explains HPV is an STD/STI States minimal side effects (fainting) States effectiveness

\section{General:}

Examples of Serious Reactions (death)___ Insurance and Gardasil__ Access Problems Legislation regarding Gardasil (i.e. compulsory vaccination, state legislation)

What cancers does the article state are HPV caused? cervical vaginal vulva oral throat penile
Genital warts anal Other

Does the article state the cause of cervical cancer? Yes No Unclear

Does the article explain how HPV is spread (other than just "an STD/STI")? Yes No_Unclear Is it accurate?

Amount of times article states (zeros if absent): "women"/ "girls"/ "female" "men"/ "boys"/ "males" "Gardasil" Female Specific Cancers ("cervical cancer", "vulvar cancer") Male Specific cancers ("penile", "anal")

Non-gender specific cancers ("oral", "throat", or "anal") "HPV vaccine" "cervical cancer vaccine" "genital warts" 
Does the article discuss sexual partners?

Yes
Same Sex couples $\_$Unclear $\_$NA

If yes:

Heterosexual couples

Reports Statistics:

Statistics:

Statistics:

Statistics:

Statistics:

Statistics:

Statistics:

applied to women applied to women applied to women applied to women applied to women applied to women applied to men applied to men applied to men applied to men applied to men applied to men

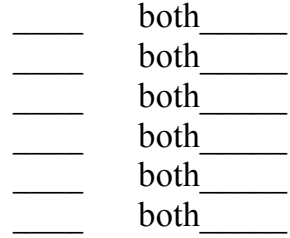

Answer the following questions together:

Does article mention men getting vaccinated? Yes No DK (if "no" then "NA" on next 3) If yes, does it support men's vaccination? _ Yes _ No If yes, what is the reason? _ Protect men's health If $\overline{\mathrm{DK}}$ Other (explain) No Gives both pro/con argument DK NA

If no, what is the reason? - DK Other (explain): Protect women's health Gay men's health

What Groups/Organizations are stated in support?

What Groups/Organizations are stated in opposition?

What Groups/Organizations are stated who are neutral?

\section{Other Notes:}


APPENDIX E: Conceptual Map of Frames and Their Sources

$\underline{\text { Stakeholder }}$
Frames

Media Outlet

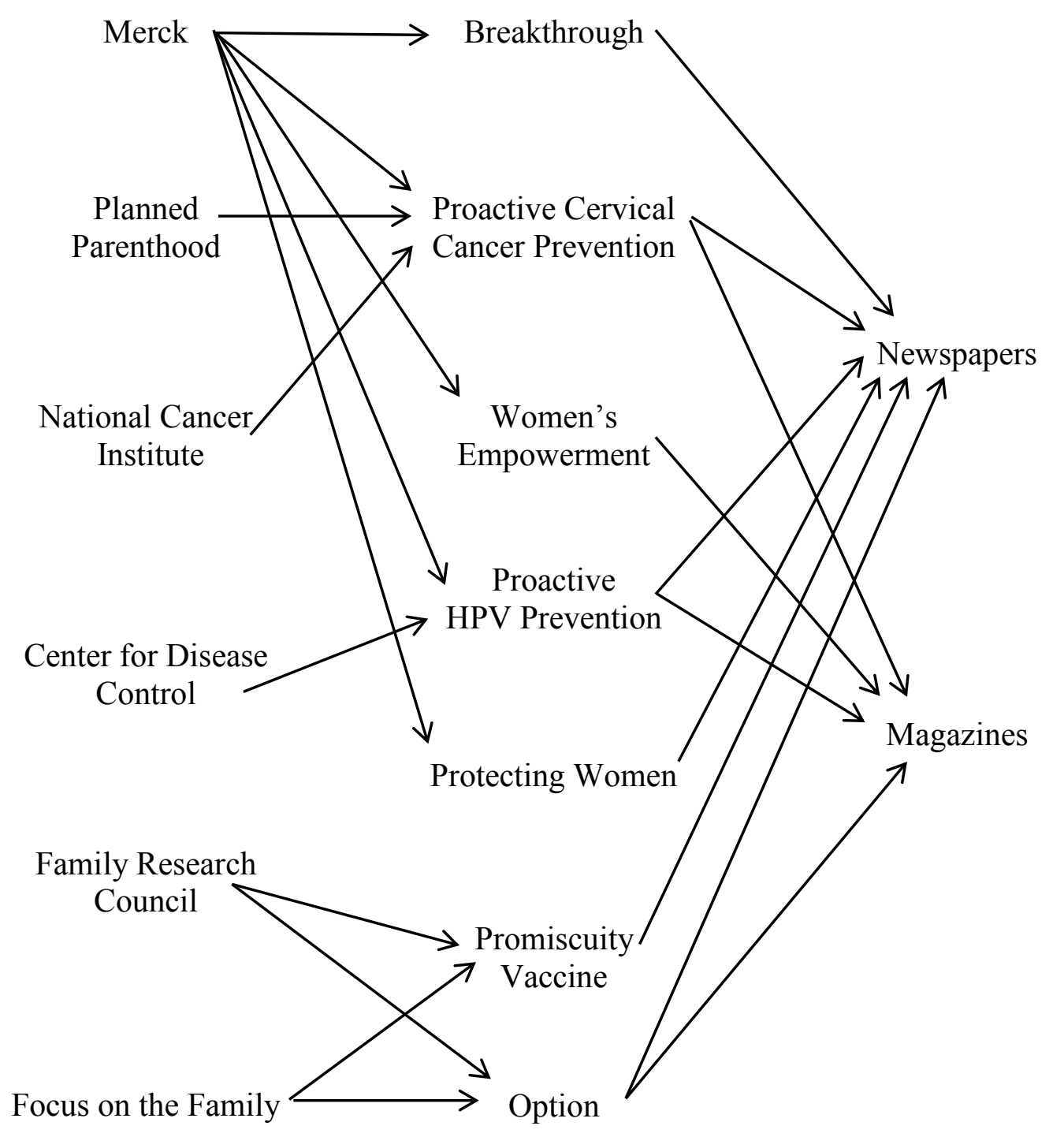

